\title{
CASTING WARPAGE STUDY
}

Published August 1976

Project Leader:

E. P. Patterson

Department 821

Project Team:

J. A. Brunk

H. Carter

M. Colgate

M. L. Garcia

Hemet Casting Company Personnel

PDO 6984517

Final Report
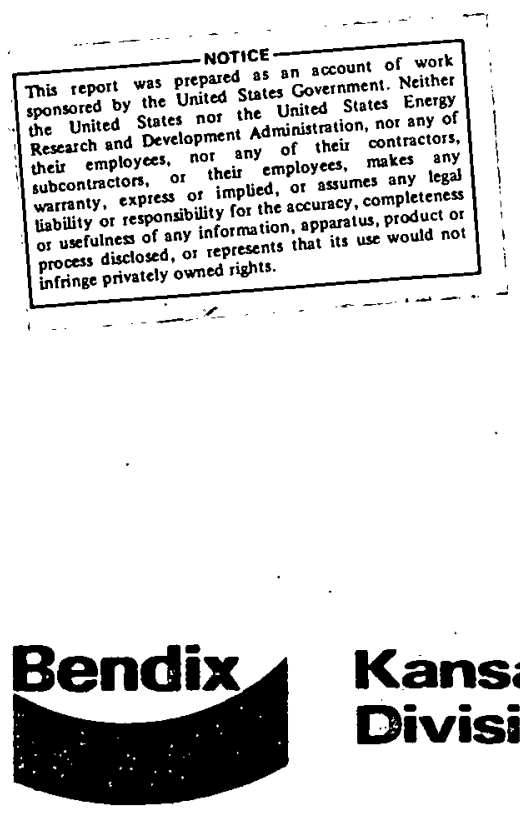

\section{Kansas City Division}




\section{DISCLAIMER}

This report was prepared as an account of work sponsored by an agency of the United States Government. Neither the United States Government nor any agency Thereof, nor any of their employees, makes any warranty, express or implied, or assumes any legal liability or responsibility for the accuracy, completeness, or usefulness of any information, apparatus, product, or process disclosed, or represents that its use would not infringe privately owned rights. Reference herein to any specific commercial product, process, or service by trade name, trademark, manufacturer, or otherwise does not necessarily constitute or imply its endorsement, recommendation, or favoring by the United States Government or any agency thereof. The views and opinions of authors expressed herein do not necessarily state or reflect those of the United States Government or any agency thereof. 


\section{DISCLAIMER}

Portions of this document may be illegible in electronic image products. Images are produced from the best available original document. 


\section{CASTING WARPAGE STUDY}

BDX-613-1368, UNCLASSIFIED Final Report, Published August 1976

Prepared by E. P. Patterson, D/821, under PDO 6984517

Warpage of A356-aluminum-alloy investment castings can be reduced by using aqueous solutions of polyethylene glycol or polyalkylene glycol for quenching. Solutions of 20 and 40 percent, by weight, appeared most effective and did not significantly change the mechanical properties of the parts. Minimum warpage resulted from a quenching solution temperature of $210^{\circ} \mathrm{F}\left(98.9^{\circ} \mathrm{C}\right)$. Quenching at a temperature of $160^{\circ} \mathrm{F}\left(71.1^{\circ} \mathrm{C}\right)$ produced maximum strength with less warpage than was obtained from room-temperature solutions.

This report was prepared as an account of work sponsored by the United States Government. Neither the United States nor the United States Energy Research and Development Administration, nor any of their employees, nor any of their contractors, subcontractors, or their employees, makes any warranty, express or implied, or assumes any legal liability or responsibility for the accuracy, completeness or usefulness of any information, apparatus, product or process disclosed, or represents that its use would not infringe privately owned rights.
THE BENDIX CORPORATION

KANSAS CITY DIVISION

P.O. BOX 1159

KANSAS CITY, MISSOURI 64141

A. prime contractor for the United States Energy Research and Development Administration Contract Number E(29-1)-613. USERDA 
CONTENTS

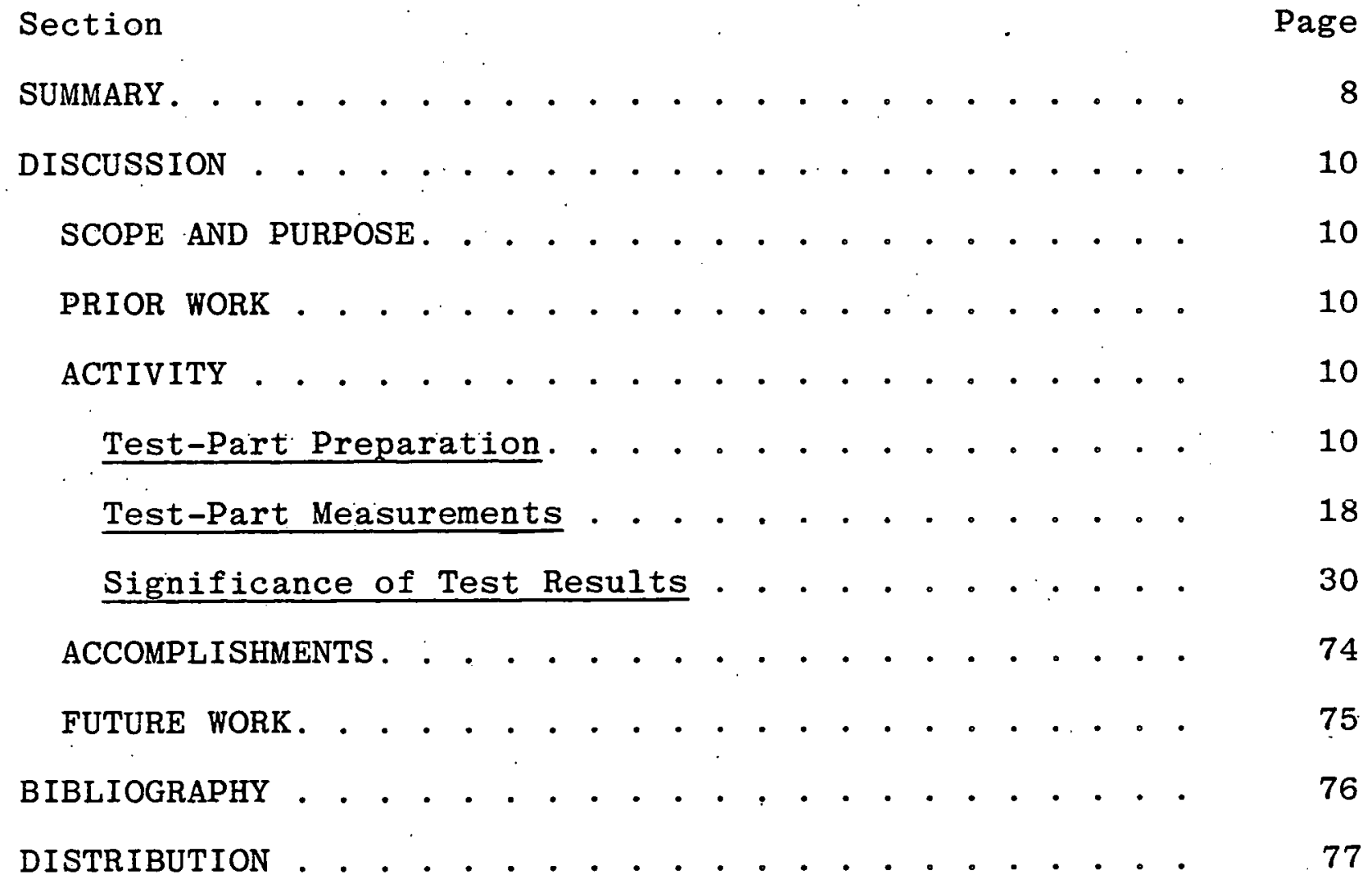




\section{ILLUSTRATIONS}

Figure

Page

Test Part Drawing. . . . . . . . . . . . . .

Test Part Casting Arrangement. . . . . . . .

Investment She11-Casting Techniques. . . . . .

Investment Flask-Casting Techniques. . . . . .

Diagram of Areas for Spectrographic

Chemical Analysis. . . . . . . . . . .

Arrangement of Solid Flasks in Mold Oven . .

Diagram of Holding and Positioning Fixture .

Holding and Positioning Fixture. . . . . . .

Runner- and Gate-To-Part Relationship Measurements . . . . . . . . . . .

11 Gating System Showing Test Parts With Two Curved Runners... . . . . . . . . . . .

Gating System Showing Angular Runners and Test Parts Slightly Misaligned . . . . . .

Quench Positions of Parts in the HeatTreat-Furnace Quenching Basket . . . . . .

Effect of Water Quench on Average Deflection of All Points . . . . . . . . .

Effect of Water Quench on End-Point Deflection . . . . . . . . . . . . . .

Effect of 40-Percent Polyalkylene G1ycol Quench on Average Deflection of A11

Points. 
Effect of 10-Percent Polyalkylene Glycol

Quench on Average Deflection of All

Points . . . . . . . . . . . . . .

Effect of 5-Percent Polyalkylene Glycol

Quench on Average Deflection of All

Points . . . . . . . . . . . . . . .

Effect of 40-Percent Polyalkylene Glycol

Quench on End-Point Deflection . . . . . .

Effect of 20-Percent Polyalkylene Glycol

Quench on End-Point Deflection . . . . . .

Effect of 10-Percent Polyalkylene Glycol

Quench on End-Point Deflection . . . . . .

Effect of 5-Percent Polyalkylene Glycol Quench on End-Point Deflection . . . . . . .

Effect of 90-Percent Polyethylene Glycol Quench on Average Deflection of AII Points... . . . . . . . . . . . . .

Effect of 60-Percent Polyethylene Glycol Quench on Average Deflection of AlI Points . . . . . . . . . . . . . .

Effect of 40-Percent Polyethylene Glycol Quench on Average Deflection of All Points

Effect of 20-Percent Polyethylene Glycol Quench on Average Deflection of AlI

Points

Effect of 90-Percent Polyethylene Glycol Quench on End-Point Deflection . . . . . .

Effect of 60-Percent Polyethylene Glycol Quench on End-Point Deflection . . . . .

Effect of 40-Percent Polyethylene Glycol Quench on End-Point Deflection . . . . . .

Effect of 20-Percent Polyethylene Glycol Quench on End-Point Deflection . . . . . . 
Effect of Methyl Alcohol Quench on End-

Point Deflection . . . . . . . . . . . . .

Effect of Precipitation Hardening (T6) on

General Warpage of All Points of Parts.

Quenched in the Horizontal Attitude.

Effect of Precipitation Hardening (T6) on End-Point Deflection of Parts Quenched in the Horizontal Attitude... . . . . . .

Effect of Precipitation Hardening (T6) on General Warpage of All Points of Parts Quenched in the Vertical Attitude. . . . .

Effect of Precipitation Hardening (T6) on End-Point Deflection of Parts Quenched in the Vertical Attitude . . . . . . . . .

Variations in End-Point Deflection for Parts Quenched in Horizontal and Vertical Attitudes at Various Quench Positions. . . . . . . . . . . . . . .

Warpage After Annealing (Bottom Trace) Compared to Additional Warpage After Quenching (Difference Between Top and Bottom Trace).

Mean Averages of Mechanical Properties Developed in 20-Percent Polyalkylene Glycol (Ucon A) Solution : . . . . . . . .

Mean Averages of Mechanical Properties Developed in 20-Percent Polyethylene Glycol Solution. . . . . . . . . . . .

Mean Averages of Mechanical Properties Developed in 40-Percent Polyethylene Glycol Solution. . . . . . . . . . . . .

Mean Averages of Mechanical Properties Developed Versus Concentration of Polyalkylene Glycol (Ucon A) Solutions at 75 to $84^{\circ} \mathrm{F}\left(23.9\right.$ to $\left.28.8^{\circ} \mathrm{C}\right)$. . .

Mean Averages of Mechanical Properties

Developed Versus Concentration of

Polyalkylene Glycol (Ucon A) Solutions at 160 to $163^{\circ} \mathrm{F}\left(71.1\right.$ to $\left.72.8^{\circ} \mathrm{C}\right)$ : . . 
Mean Averages of Mechanical Properties

-Developed Versus Concentration "of

Polyalkylene Glycol (Ucon A) Solu-

tions at 180 to $181^{\circ} \mathrm{F}\left(82.2\right.$ to $\left.82.8^{\circ} \mathrm{C}\right)$. .

67

47

Mean Averages of Mechanical Properties

Developed Versus Concentration of

Polyalkylene Glycol (Ucon A) Solu-

tions at 209 to $210^{\circ} \mathrm{F}\left(98.3\right.$ to $\left.98.9^{\circ} \mathrm{C}\right)$. . .

68

48

Mean Averages of Mechanical Properties

Developed Versus Concentration of

Polyethylene Glycol Solutions at

72 to $77^{\circ} \mathrm{F}\left(22.2\right.$ to $\left.25.0^{\circ} \mathrm{C}\right)$. . . . . . .

49

Mean Averages of Mechanical Properties

Developed Versus Concentration of

Polyethylene Glycol Solutions at

160 to $161^{\circ} \mathrm{F}\left(71.1\right.$ to $\left.71.7^{\circ} \mathrm{C}\right)$. . . . . . .

50

Mean Averages of Mechanical Properties

Developed Versus Concentration of

Polyethylene Glycol Solutions at

210 to $213^{\circ} \mathrm{F}\left(98.9\right.$ to $\left.101.0^{\circ} \mathrm{C}\right)$. . . . . .

71

51

Mean Averages of Mechanical Properties

Developed in Water Quench. . . . . . . . .

72

TABLE

Number

Page

1

Solution Heat-Treatment Quench Tests . . . . 


\section{SUMMARY}

Because of a need to reduce warpage in investment castings, and because of reported success in the use of aqueous polyalkylene glycol solutions for reducing warpage in heat-treated sheet-metal parts, particularly for aluminum alloys, an experiment was designed to include these solutions along with polyethylene glycol solutions in a study of quenching parameters. At the time of the study, the cost of polyethylene glycol was approximately one-third that of polyalkylene glycol.

A total of 1032 cast parts was produced from 13 cast-furnace heats for study. Conclusions concerning warpage and mechanical properties were based on 2064 tensile specimens and the cast parts.

Warpage was reduced significantly in the two glycol-solution systems. Solutions of 20 and 40 percent, by weight, appeared to be more effective for both polyethylene glycol and polyalkylene glycol. Minimum warpage occurred at a quenching temperature of $210^{\circ} \mathrm{F}\left(98.9^{\circ} \mathrm{C}\right)$. Warpage in the glycol quenching solutions was less than that which occurred in water at all temperatures studied.

The average warpage of the parts was affected by their attitude during quenching. This warpage was caused by differential cooling rates on the forward and rear surfaces of the parts produced by the turbulence created by the downward motion of the basket during the quenching operation. Parts which displayed thin edges upon approach to the quenching solution showed less tendency to warp than did those which displayed broad surfaces.

The amount of warpage also was found to vary with the position of the part in the quenching basket. This condition undoubtedly was due to directional currents in the quenching tanks during immersion of the parts.

Because of the large number of process. variables involved, many either could not be maintained constant for the experimental tests or were not recognized until much of the study had been completed. Even with the large quantity of test parts and test specimens studied, conclusions could not be finalized concerning the effect of a number of interesting factors. Of the 54 quenchlots studied, warpage results and mechanical properties were obtained in the evaluation of 53 .

Among the more important factors involved were the developed stress-patterns of the castings prior to quenching and the initial warpage of parts. Restraint exerted on the parts during solidification proved to be an important consideration. Restraint 
is determined by the gate-runner-part relationships (which include the masses involved), the dimensional orientation of the several components of the total casting, and hence, the total wax-pattern assembly. Another factor was the relative rigidity or flexibility of the investment compound used.

Significant relief of stresses in many parts was observed as a result of annealing followed by a slow cooling of the castings. This effect was discovered late in the study, and therefore it was applied to only a limited number of the cast lots. 


\section{DISCUSSION}

\section{SCOPE AND PURPOSE}

The purpose of this study was to reduce the amount of casting warpage caused by quenching variables without adversely affecting the mechanical properties of the castings. The elimination or reduction of initial quenching warpage and stresses provides the following advantages:

- Mechanical straightening operations after quenching are not required;

Secondary stresses induced during straightening are eliminated; and

Warpage caused by the relieving of stresses during the machining of a cast part is eliminated or reduced.

PRIOR WORK

Prior to this effort, liquid-nitrogen quenching was used on aluminum sheet-metal parts to reduce the stresses and the resulting warpage. Polyalkylene glycol solutions were used at room temperature for quenching sheet-metal parts only; polyethylene glycol solutions had not been used in quenching operations: The use of hot or boiling water as a quenching medium was the principal means of reducing quenching stresses in 356 or A356 aluminum castings.

\section{ACTIVITY}

Test-Part Preparation

Part Design

A part, designed to be sensitive to quenching warpage, was developed in order to measure its susceptibility to induced warpage through variations in the quenching media (Figures 1 and 2 ). This part was L-shaped with a thin blade for the upright portion of the $\mathrm{L}$ and a base approximately eight times the thickness of the blade. The blade and the base formed a.90-degree angle. On either side of the base and parallel with its length, flat tensile specimens were integrally cast and gated to the base at each of their gripping ends. 


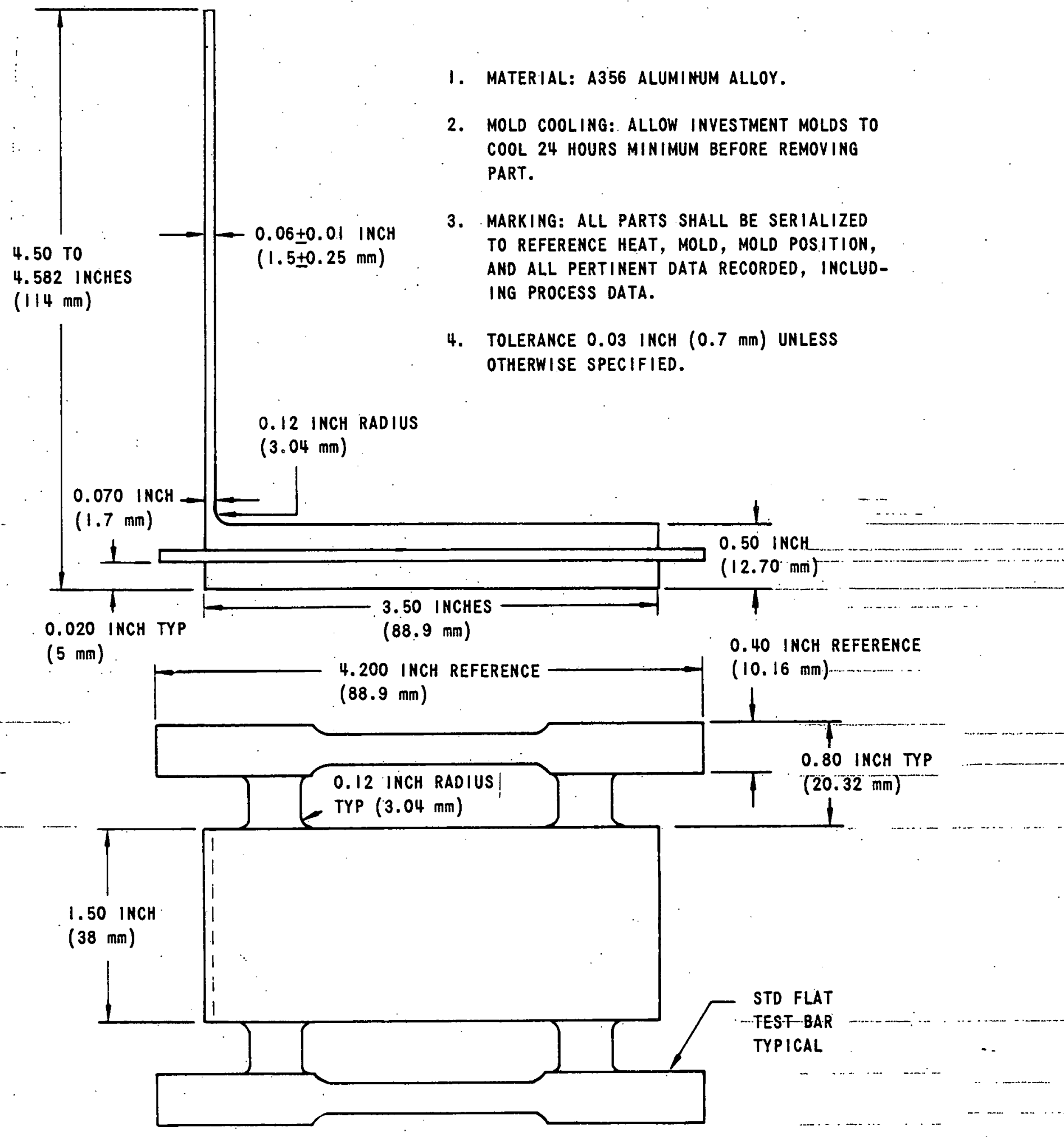

Figure 1. Test Part Drawing 


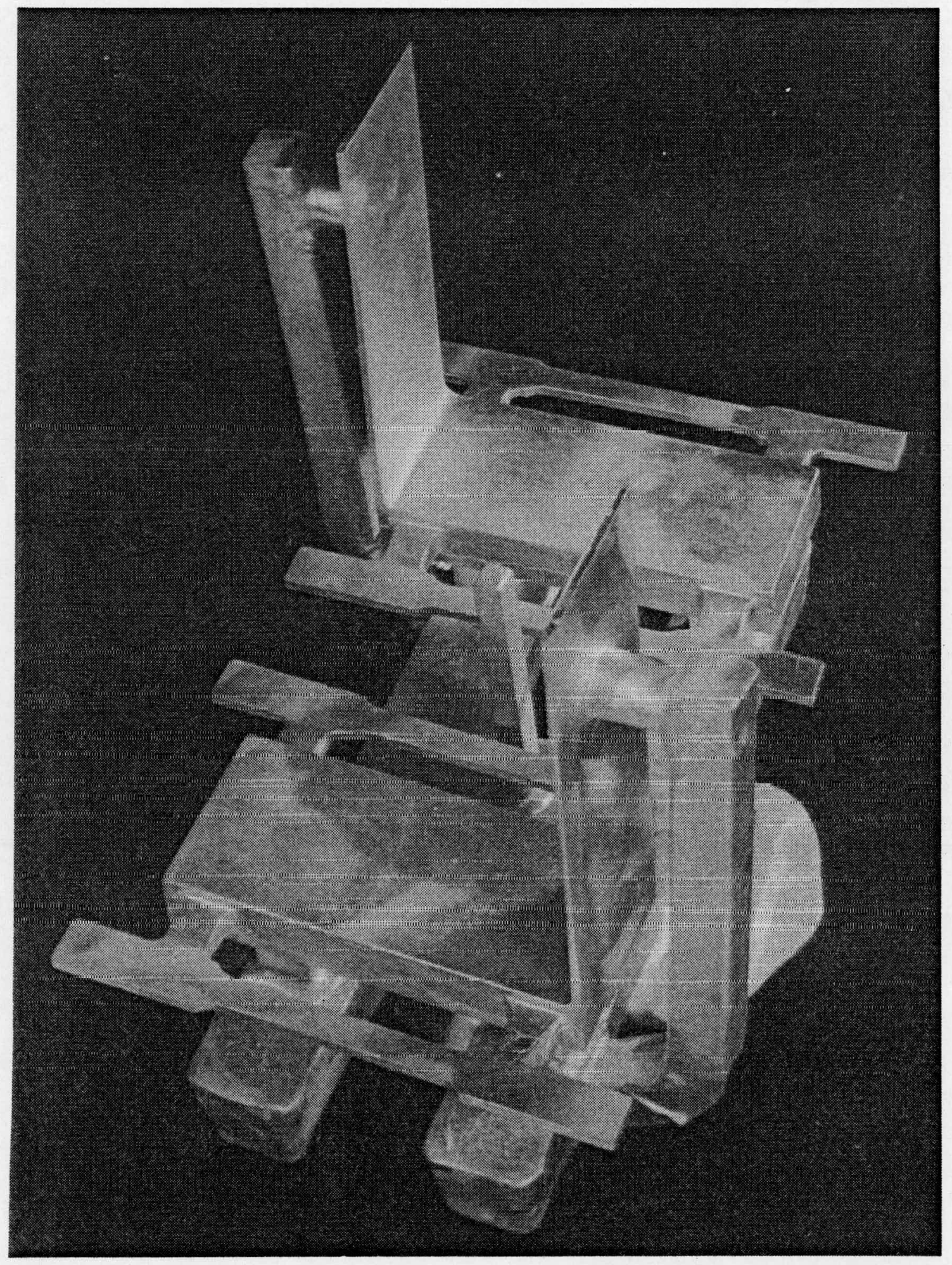

Figure 2. Test Part Casting Arrangement 


\section{Molding and Casting Process}

Approximately 1560 of the L-shaped parts were cast from 13 castfurnace heats of A356 aluminum alloy. Two cast heats were used to pour shell-molded parts (Figure. 3 ), while the other 11 heats were used for flask-molded parts (Figure 4). One-hundred-twenty test parts were cast from each cast heat into 60 molds. After radiographic inspection by the casting supplier, approximately 1100 parts were certified by the supplier as being radiographically Class $A$ at the junction between the upright blade and the base according to Specification 9921013.

The alloy was melted in 300-pound-melt-capacity (136 kg) aluminum gas-fired furnaces. The furnaces were monitored with thermocouples for temperature control. The ladle for transfer of the metal to the molds was hung by the handle along the side of the melting pot with the ladle proper immersed in the melt for preheating and to prevent chilling during transfer. Both the furnace and ladle were of iron construction, coated or lined with an aluminum-oxide ceramic layer to prevent contamination and to avoid possible undesirable chemical reactions. Mold temperatures were monitored periodically during the pour.

After pouring, each mold was identified on the sprue with a mold number (such as 15-16) representing the two parts in the mold. Cast parts were numbered from 1 to 120 , prefixed with the castheat letter identification.

Spectrographic chemical analyses of the cast parts were made at Bendix Kansas City at the part locations indicated in Figure 5. All results were recorded. The specimen identification provided an indication as to which portion of the cast heat was represented by a particular analysis. For example, Part 120 was at the end of the pour, while Part 1 was at the beginning. There were 13 cast-heat identifications comprised of the letters $A$ through $L$ (excluding $J$ ), $L S A$, and $L S B$. The latter two designations were used to identify shell-molded parts. The first cast heat poured was represented by test parts prefixed with $A$, the second with $B$, etc. The last two heats poured were $L S A$ and $L S B$, in that order.

After removal from the investment and the sprue-gate-runner system, all parts were identified by steel stamping on an edge of the base. Through an oversight, Cast Heat $I$ was not represented in the analyses.

Wax Patterns, Mold Oven, and Mold-Investment Removal

Prior to investment-molding, wax patterns were arranged with two parts per flask, or two per shell mold. After dewaxing in a steam autoclave, the dewaxed molds were stored in a drying oven until the moment of casting. Figure 6 shows the mold-oven 


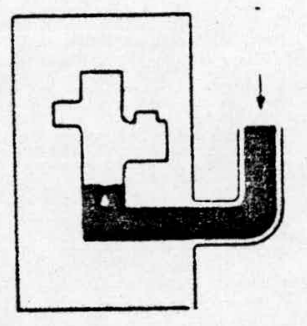

1. WAX OR PLASTIC IS INJECTED INTO DIE TO MAKE A PATTERN.

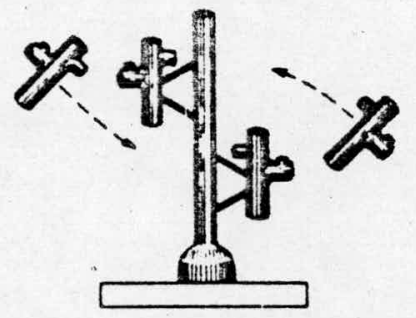

2. PATTERNS ARE GATED TO A CENTRAL SPRUE.

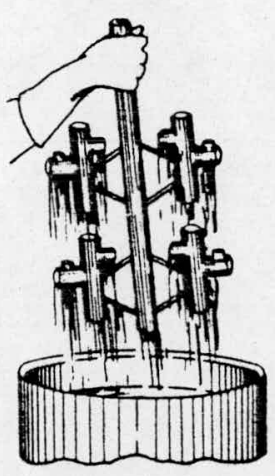

3. PATTERN CLUSTERS ARE DIPPED IN CERAMIC SLURRY.

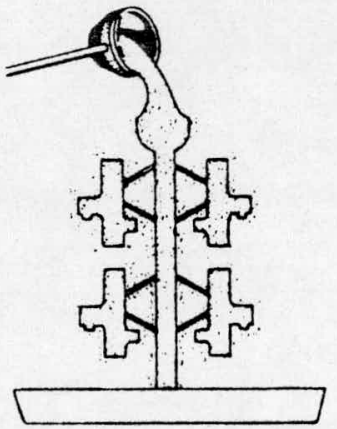

6. HOT MOLDS ARE FILLED WITH METAL BY GRAVITY, PRESSURE, VACUUM, OR CENTRIFUGAL FORCE.

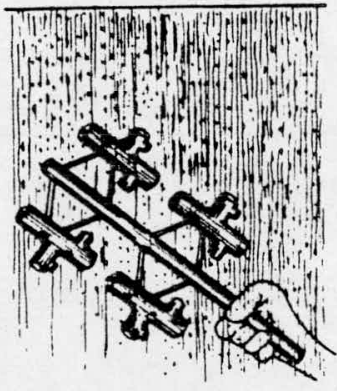

4. REFRACTORY GRAIN IS SIFTED ONTO COATED PATTERNS; STEPS 3 AND 4 ARE REPEATED SEVERAL TIMES TO OBTAIN DESIRED SHELL THICKNESS.

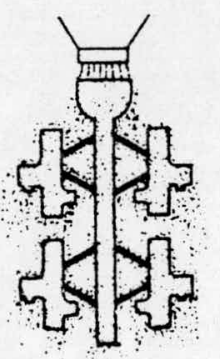

7. MOLD MATERIAL IS BROKEN AWAY FROM CASTINGS.

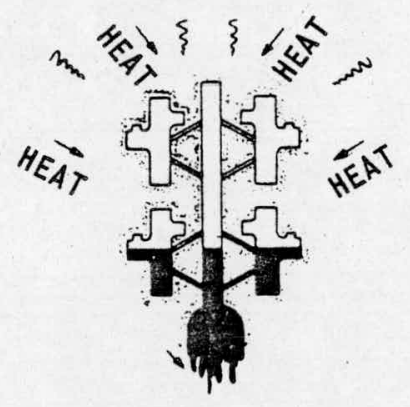

5. AFTER MOLD MATERIAL HAS SET AND DRIED, PATTERNS ARE MELTED OUT OF MOLD.

Figure 3. Investment Shell-Casting Techniques 


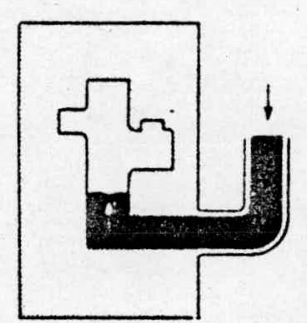

1. WAX OR PLASTIC IS INJECTED INTO DIE TO MAKE A PATTERN.

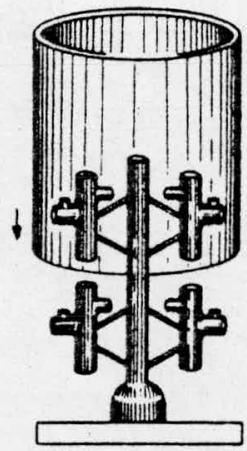

3. A METAL FLASK IS PLACED AROUND THE PATTERN CLUSTER.

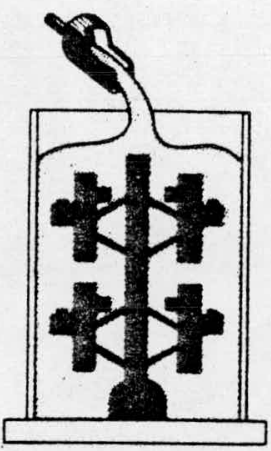

4. THE FLASK IS FILLED WITH INVESTMENT MOLD SLURRY.

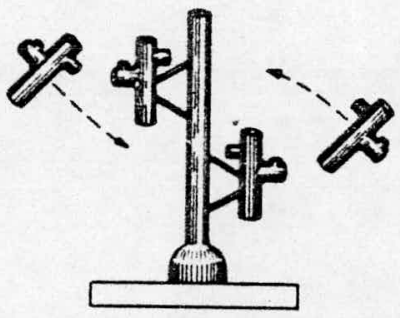

2. PATTERNS ARE GATED TO A CENTRAL SPRUE.

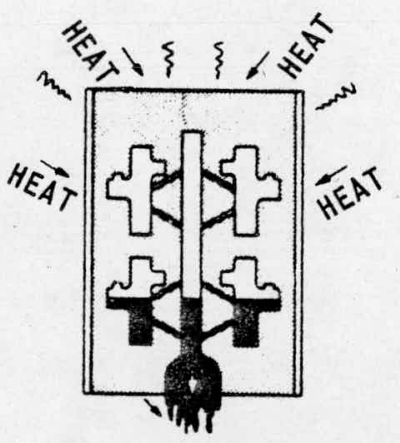

5. AFTER MOLD MATERIAL HAS SET AND DRIED, PATTERNS ARE MELTED OUT OF MOLD.

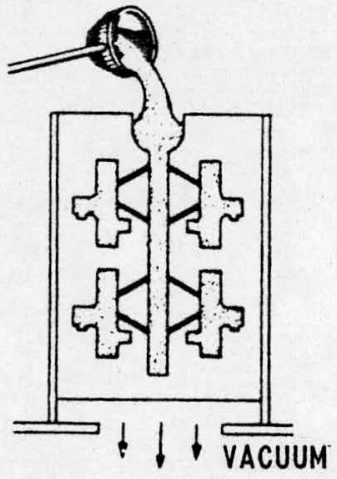

6. HOT MOLDS ARE FILLED WITH METAL BY GRAVITY, PRESSURE, VACUUM, OR CENTRIFUGAL FORCE.

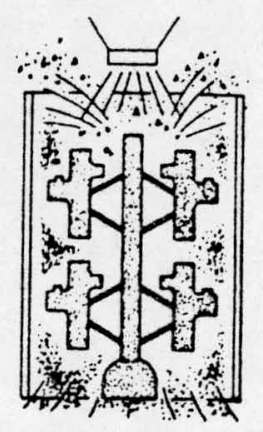

7. MOLD MATERIAL IS BROKEN AWAY FROM CASTINGS.

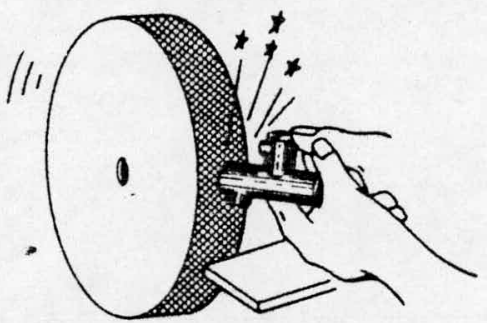

8. CASTINGS ARE REMOVED FROM SPRUE, AND GATE STUBS ARE GROUND OFF.

Figure 4. Investment Flask-Casting Techniques 


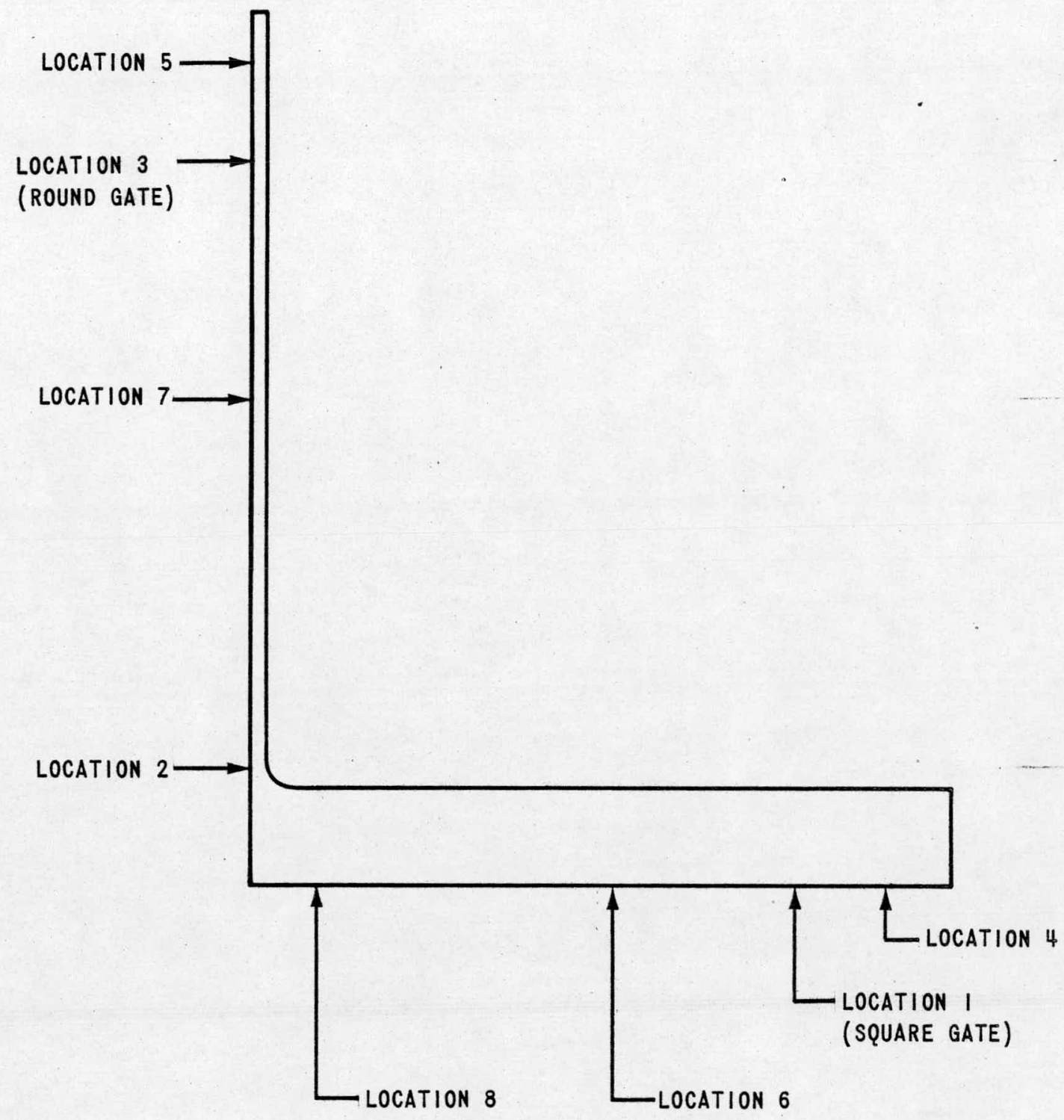

Figure 5. Diagram of Areas for Spectrographic Chemical Analysis

arrangement of the solid flasks. The nominal mold temperature was $400^{\circ} \mathrm{F}\left(205^{\circ} \mathrm{C}\right)$. Flask-molded castings were allowed to cool and stabilize for 24 hours prior to removal of the mold material.

The mold investment was removed from the cast parts inside a large glove box by hydraulic action. The hydraulic jet was carefully directed as the investment assembly was turned by the operator. Although some dissolving of interparticulate 

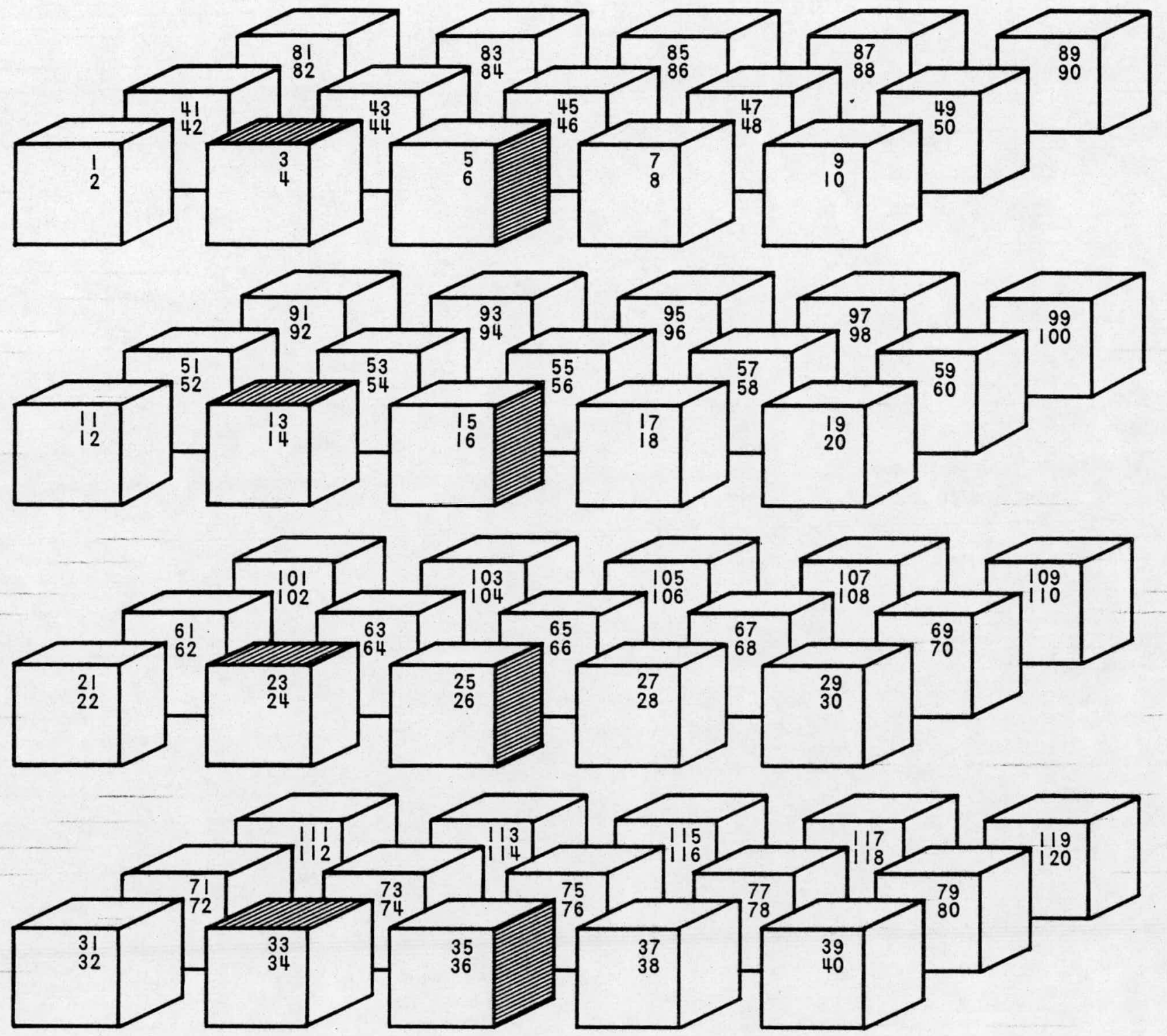

CANS SHOWN WITH TOPS SHADED WERE USED FOR FURNACE-TEMPERATURE CHECKS. CANS SHOWN WITH SIDES SHADED WERE USED FOR TEMPERATURE CHECKS OF PART MOLDS. ALL PARTS WERE NUMBERED REGARDLESS OF SUBSEQUENT ACCEPT/REJECT STATUS. ACCEPTABLE PARTS ONLY WERE USED IN QUENCHING TESTS.

Figure 6. Arrangement of Solid Flasks in Mold Oven

cement occurred, the investment was removed principally by the erosive action of water under pressure (approximately 90 psi or $620.5 \mathrm{kPa}$ ).

The parts were heat-treated in 54 lots in which the quenchsolution variables consisted of composition, temperature, and 
means of agitation. The heat-treat quench lots and the corresponding computer lot numbers which were assigned are shown in Table 1. These computer-lot-identification numbers were assigned to each quench lot for the purpose of handling and interpreting the computer data. A separate computer-lotidentification number was assigned for each heat-treat quench lot.

Heat-Treatment of Test Parts

The parts from Computer Lots 40 through 54 .were annealed at $750 \pm 10^{\circ} \mathrm{F}\left(399 \pm 6^{\circ} \mathrm{C}\right)$ for 2 hours prior to solution heat treatment. All parts were given a solution heat-treatment at $1000 \pm 10^{\circ} \mathrm{F}$ ( $\left.538 \pm 6^{\circ} \mathrm{C}\right)$ for 10 hours, and precipitation-agehardening at $315 \pm 5^{\circ} \mathrm{F}\left(157 \pm 3^{\circ} \mathrm{C}\right)$ for 4 to 5 hours.

Test-Part Measurements

Radiographic Inspection

All castings were X-rayed to Grade A standards according to Specification 9921013 by the Hemet Casting Company of Hemet, California. The parts were reradiographed at Bendix Kansas City to determine the quality of the blade-base intersection, the area in which changes in the soundness of the material would have the greatest effect on blade deflection--particularly the deflection arising from a cantilever-imposed thermal stress.

All of the tensile specimens.were $X$-rayed at Bendix in an attempt to explain results that did not meet the anticipated pattern or that did not correlate under nominally similar processing conditions. All results of the radiographic examinations of both the parts and the tensile specimens were recorded.

Dimensional Inspections

Part-Deflection or Warpage Measurements. Dimensional change or warpage was determined by the deflection in the blade portion of the L-shaped casting. Movement of the blade in a direction to decrease the angle between the blade and the base was arbitrarily designated positive, and movement to increase the angle was designated negative. Data was collected on all test castings before solution heat-treatment, after solution heattreatment, and after aging. Some parts also were measured before gating-system removal, after gating-system removal, and after annealing prior to solution heat-treatment.

Deflection measurements were taken at six locations on the outside surface of each blade portion: two near the tip, two at mid-blade, and two near the blade-base intersection (Figure 7 ). The locations on each blade were established with a marking 
Table 1. Solution Heat-Treatment Quench Tests

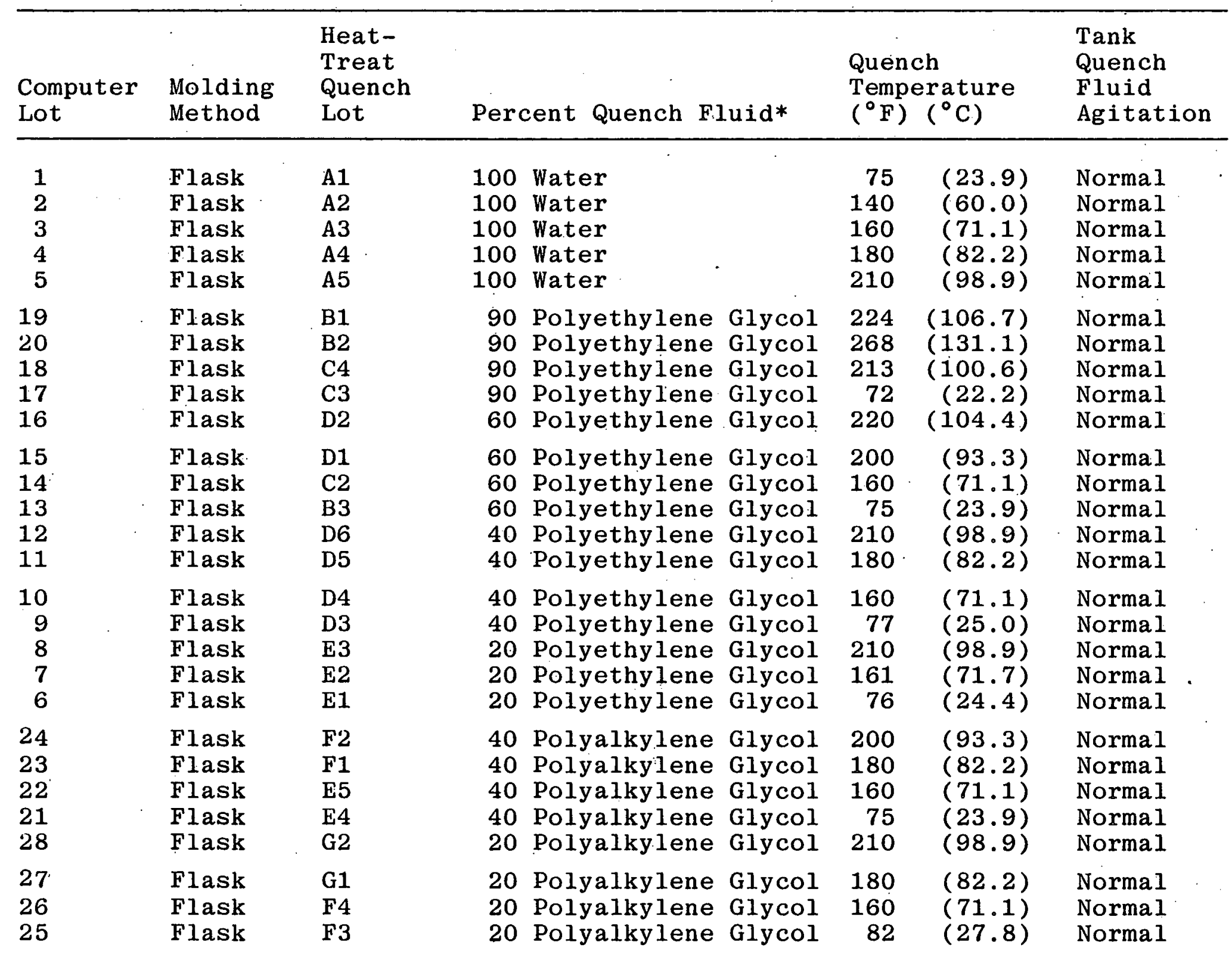


Table 1 Continued. Solution Heat-Treatment Quench Tests

\begin{tabular}{|c|c|c|c|c|c|c|}
\hline $\begin{array}{l}\text { Computer } \\
\text { Lot }\end{array}$ & $\begin{array}{l}\text { Molding } \\
\text { Method }\end{array}$ & $\begin{array}{l}\text { Heat- } \\
\text { Treat } \\
\text { Quench } \\
\text { Lot }\end{array}$ & Percent Quench Fluid* & $\begin{array}{l}\text { Quen } \\
\text { Tempe } \\
\left({ }^{\circ} \mathrm{F}\right)\end{array}$ & $\begin{array}{l}\text { ature } \\
\left.{ }^{\circ} \mathrm{C}\right)\end{array}$ & $\begin{array}{l}\text { Tank } \\
\text { Quench } \\
\text { Fluid } \\
\text { Agitation }\end{array}$ \\
\hline $\begin{array}{l}32 \\
31 \\
30 \\
29 \\
36\end{array}$ & $\begin{array}{l}\text { Flask } \\
\text { Flask } \\
\text { Flask } \\
\text { Flask } \\
\text { Flask }\end{array}$ & $\begin{array}{l}\text { G6 } \\
\text { G5 } \\
\text { G4 } \\
\text { G3 } \\
\text { H3 }\end{array}$ & $\begin{array}{r}10 \text { Polyalkylene Glycol } \\
10 \text { Polyalkylene Glycol } \\
10 \text { Polyalkylene Glycol } \\
10 \text { Polyalkylene Glycol } \\
5 \text { Polyalkylene Glycol }\end{array}$ & $\begin{array}{r}209 \\
181 \\
160 \\
80 \\
209\end{array}$ & $\begin{array}{l}(98.3) \\
(82.8) \\
(71.1) \\
(26.7) \\
(98.3)\end{array}$ & $\begin{array}{l}\text { Normal } \\
\text { Normal } \\
\text { Normal } \\
\text { Normal } \\
\text { Normal }\end{array}$ \\
\hline $\begin{array}{l}34 \\
33 \\
39 \\
38 \\
37\end{array}$ & $\begin{array}{l}\text { Flask } \\
\text { Flask } \\
\text { Flask } \\
\text { Flask } \\
\text { Flask }\end{array}$ & $\begin{array}{r}\mathrm{H} 2 \\
\mathrm{H} 1 \\
\mathrm{H} 4 \\
\mathrm{H} 5 \\
\mathrm{I} 2\end{array}$ & $\begin{array}{l}5 \text { Polyalkylene Glycol } \\
5 \text { Polyalkylene Glycol } \\
40 \text { Methyl Alcohol } \\
20 \text { Methyl Alcohol } \\
10 \text { Methyl Alcohol }\end{array}$ & $\begin{array}{r}163 \\
84 \\
80 \\
80 \\
81\end{array}$ & $\begin{array}{l}(72.8) \\
(28.9) \\
(26.7) \\
(26.7) \\
(27.2)\end{array}$ & $\begin{array}{l}\text { Normal } \\
\text { Normal } \\
\text { Normal } \\
\text { Normal } \\
\text { Normal }\end{array}$ \\
\hline $\begin{array}{l}41 \\
42 \\
54 \\
43 \\
44\end{array}$ & $\begin{array}{l}\text { Flask } \\
\text { Flask } \\
\text { Flask } \\
\text { Flask } \\
\text { Flask }\end{array}$ & $\begin{array}{l}1 \mathrm{~A} \\
1 \mathrm{~B} \\
2 \\
3 \mathrm{~A} \\
3 \mathrm{~B}\end{array}$ & $\begin{array}{l}20 \text { Polyethylene Glycol } \\
20 \text { Polyethylene Glycol } \\
40 \text { Polyethylene Glycol } \\
20 \text { Polyalkylene Glycol } \\
20 \text {. Polyalkylene Glycol }\end{array}$ & $\begin{array}{l}208 \\
207 \\
210 \\
209 \\
210\end{array}$ & $\begin{array}{l}(97.8) \\
(97.2) \\
(98.9) \\
(98.3) \\
(98.9)\end{array}$ & $\begin{array}{l}\text { None } \\
\text { Normal } \\
\text { Normal } \\
\text { None } \\
\text { Normal }\end{array}$ \\
\hline $\begin{array}{l}45 \\
46\end{array}$ & $\begin{array}{l}\text { Flask } \\
\text { Flask }\end{array}$ & $\begin{array}{l}3 C \\
3 D\end{array}$ & $\begin{array}{l}20 \text { Polyalkylene Glycol } \\
20 \text { Polyalkylene Glycol }\end{array}$ & $\begin{array}{l}210 \\
210\end{array}$ & $\begin{array}{l}(98.9) \\
(98.9)\end{array}$ & $\begin{array}{l}\text { Mechanical } \\
\text { Normal }+ \\
\text { Mechanical }\end{array}$ \\
\hline $\begin{array}{l}47 \\
48 \\
49\end{array}$ & $\begin{array}{l}\text { Shel1 } \\
\text { She11 } \\
\text { Shell }\end{array}$ & $\begin{array}{l}4 A \\
4 B \\
5\end{array}$ & $\begin{array}{l}20 \text { Polyethylene Glycol } \\
20 \text { Polyethylene Glycol } \\
40 \text { Polyethylene Glycol }\end{array}$ & $\begin{array}{l}210 \\
209 \\
208\end{array}$ & $\begin{array}{l}(98.9) \\
(98.3) \\
(97.8)\end{array}$ & $\begin{array}{l}\text { None } \\
\text { Normal } \\
\text { Normal }\end{array}$ \\
\hline $\begin{array}{l}50 \\
51 \\
40 \\
52 \\
53\end{array}$ & $\begin{array}{l}\text { She11 } \\
\text { She11 } \\
\text { Flask } \\
\text { Flask } \\
\text { Flask }\end{array}$ & $\begin{array}{l}6 \mathrm{~A} \\
6 \mathrm{~B} \\
7 \\
8 \\
9\end{array}$ & $\begin{array}{l}20 \text { Polyalkylene Glycol } \\
20 \text { Polyalkylene Glycol } \\
100 \text { Liquid Nitrogen } \\
100 \text { Water } \\
100 \text { Water }\end{array}$ & $\begin{array}{l}210 \\
210 \\
-320 \\
151 \\
82\end{array}$ & $\begin{array}{l}(98.9) \\
(98.9) \\
(-195.6) \\
(66.1) \\
(27.8)\end{array}$ & $\begin{array}{l}\text { None } \\
\text { Normal } \\
\text { None } \\
\text { Normal } \\
\text { Normal }\end{array}$ \\
\hline
\end{tabular}

*Solution treat-temperature $1000^{\circ} \mathrm{F}\left(537.8^{\circ} \mathrm{C}\right)$ for 10 hours. 


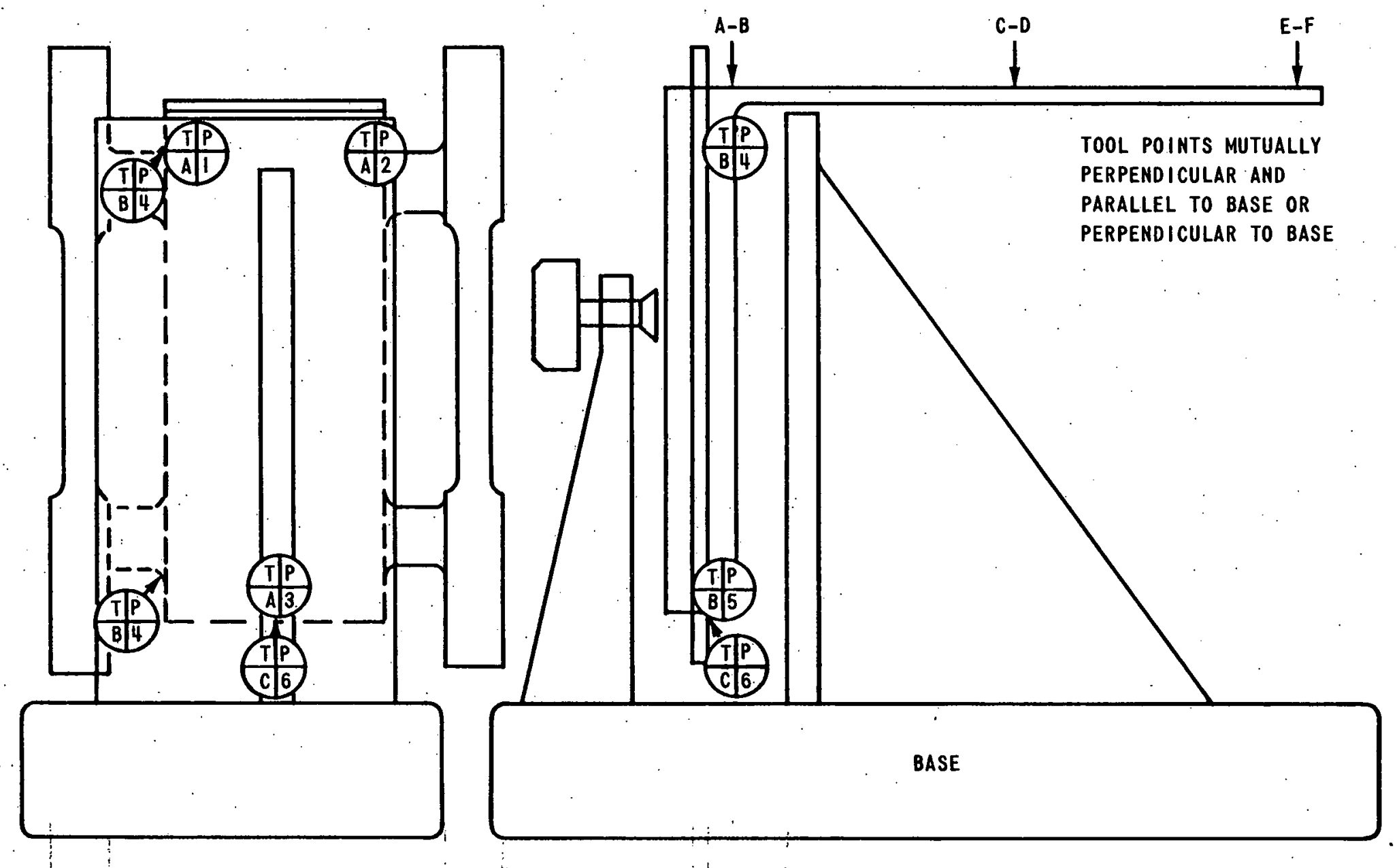

CLAMP TO HAVE TORSION CAP.

TP: TO BE TOOLING BALLS FOR A1,A2,A3, AND C6. USE DOWEL PIN WITH SIDE CONTACT FOR B4 AND B5.

DRAWING MAY BE SCALED FOR LOCATIONS OF TP.

DIAL INDICATOR ON HEIGHT GAGE MEASURES AT A-B, C-D, AND E-F (A. TOTAL OF SIX PLACES).

Figure 7. Diagram of Holding and Positioning Fixture 
template, and the deflections were measured through the use of a holding and positioning fixture (Figures 7 and 8 ), a height gage, and a surface plate. The inspection setup used is shown in Figure 9.

Warpage measurements made at Location $A$ were adjusted to zero. Measurements at Locations $B$ through $F$ then were made with respect to Location $A$ and tabulated for each heat-treat condition studied. The annealed (T2) condition was measured for its effect on warpage deflection for Cast Heats L, K, LSA, LSB, and the corresponding heat-treat Sublots 40 through 54.

Measurements also were made and recorded to determine the correction factors to be applied to the deflection results obtained for warpage following the removal of the gate and runner. The deflection was measured at Locations A through $F$ on the blade under the load-range experienced from pressures exerted by the pin of the dial-indicator.

Variations in Runner, Gate, Sprue, and Part Relationships. The runner-and gate-to-part distances and angles were measured and recorded for a number of test parts. The differences in these distances and angles probably constituted the greatest single variable accounting for the variations in internal stress prior to quenching (and consequently, resultant warpage) in flaskinvested parts: Not only did the distances and angles shown in Figure 10 vary, but often the straight runners of the figure were curved outward or inward by various amounts. (Figures 11 through 13). Although these later observations, as well as data pertaining to the combined pattern of two parts in a single mold, are not reflected in the test results, all of these variations contributed to complex and unpredictable stresses and manifestations of distortion in the parts.

Quench Lots and Quench Positions. A typical heat-treatment quench lot consisted of 20 castings--10 placed at various locations in the quenching basket with the blade upright and the base horizontal, and 10 placed with the edge of the blade and edge (thickness) of the base vertical during furnaceheating and quenching. The identification of the quench positions is shown in Figure 14: Location charts such as this were used with each quench lot as a part of the processing traveler.

Mechanical-Test Specimens. An average quench lot yielded 40 tensile specimens--20 from parts in the vertical attitude (with both the base and blade presenting an edge to the quenching medium), and 20 from parts in the horizontal attitude (with the base presenting its broad side to the quenching medium).

Tensile specimens, attached to and associated with the test parts, were designated -1 and -2 . In vertical-attitude-quenched 


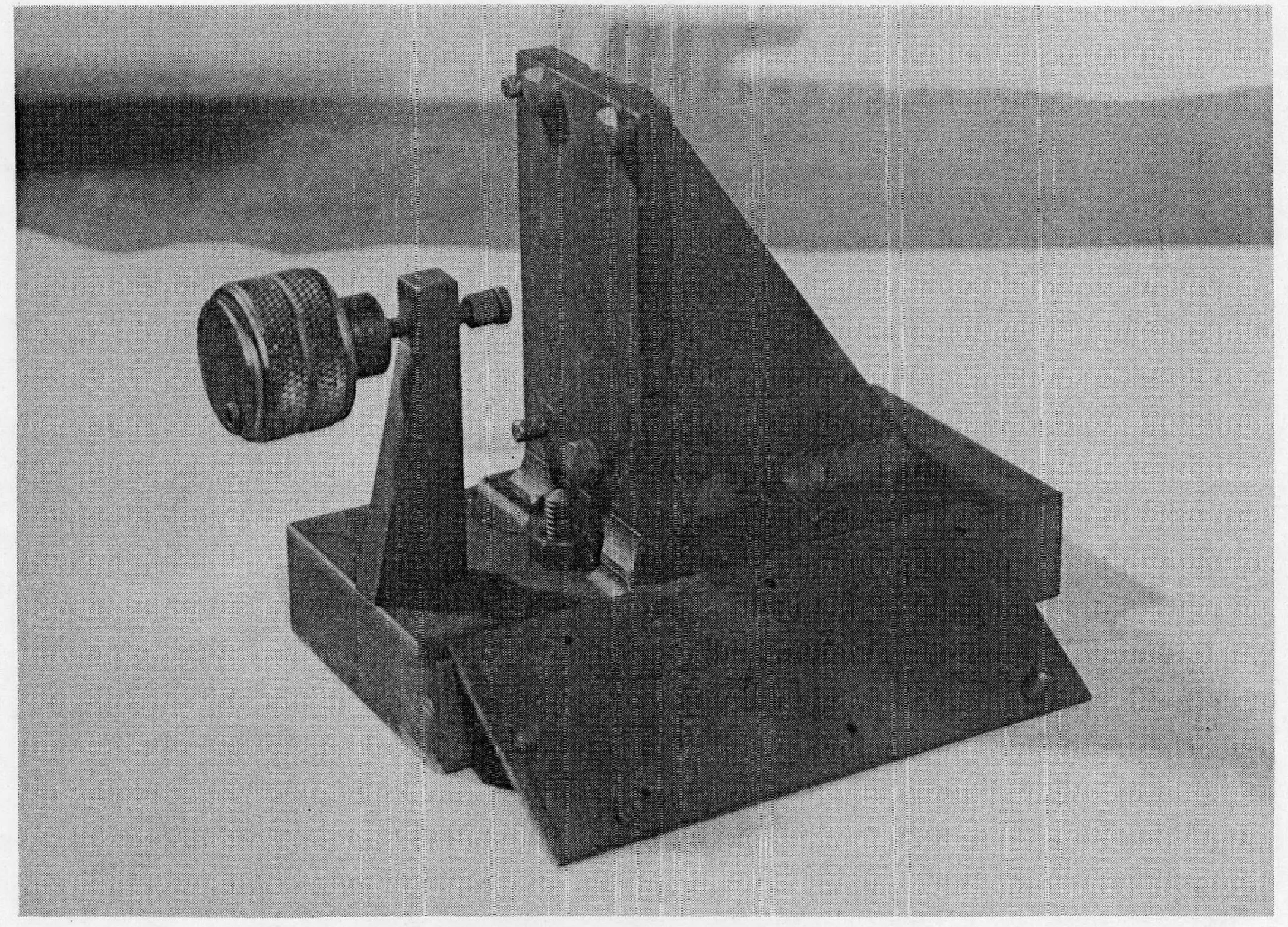

Figure 8. Holding and Position:ng Fixture 


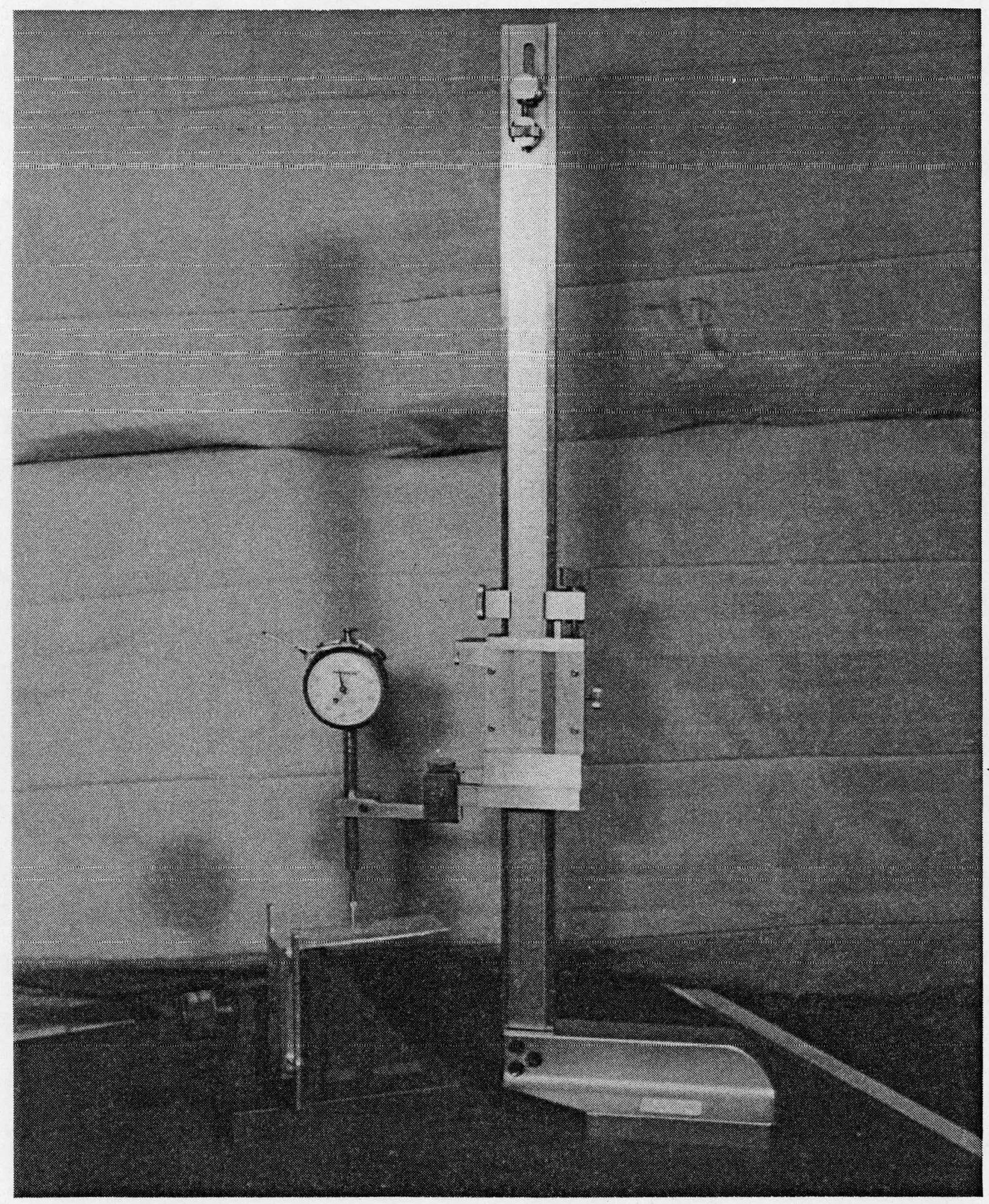

Figure 9. Inspection Setup for Casting Warpage Study 


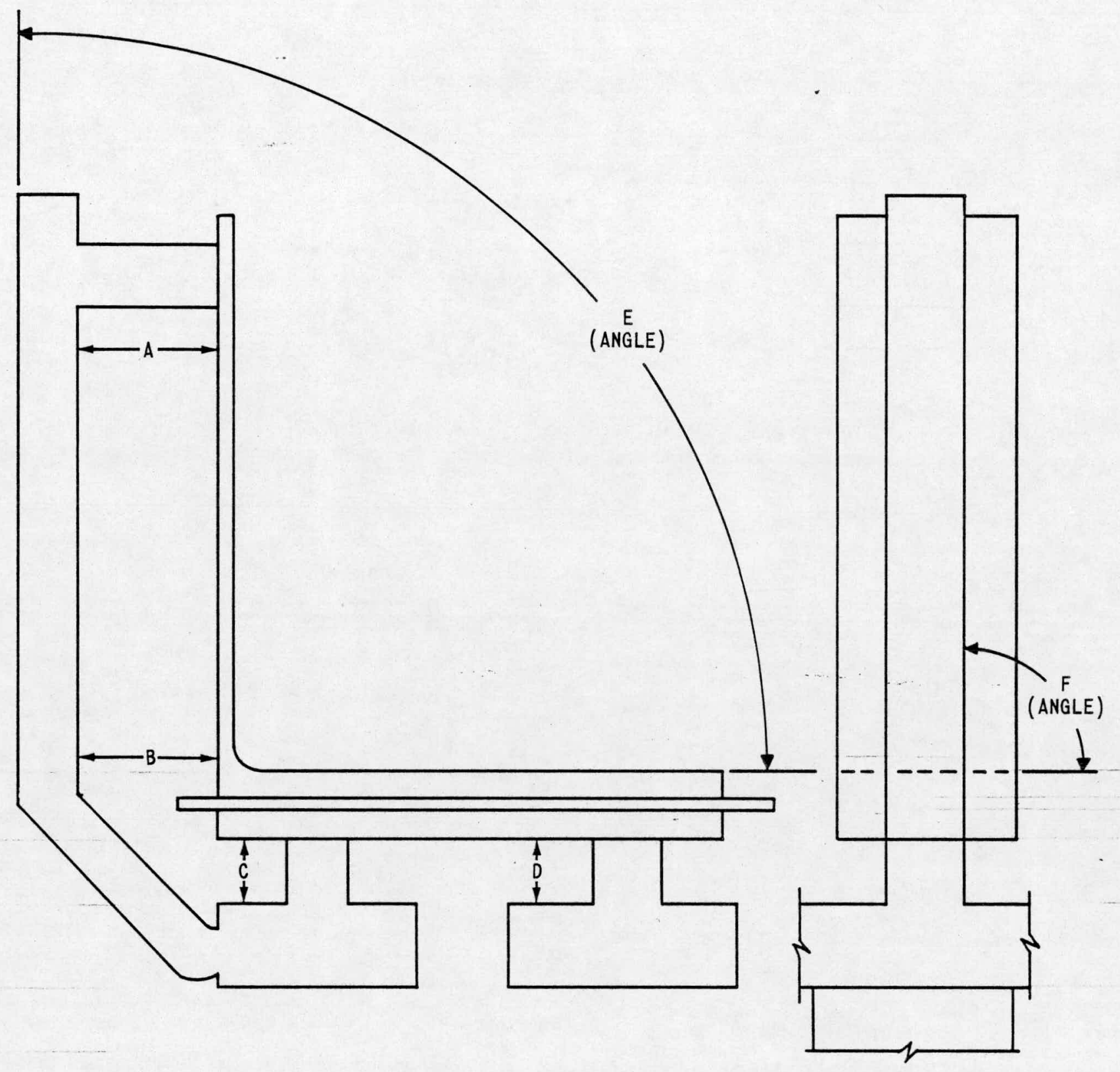

Figure 10. Runner- and Gate-To-Part Relationship Measurements

parts, the -1 specimen entered the quenching bath first. (The -1 specimen was the right-hand specimen when the base projected toward the viewer from the upright member with the right angle in full view.) From the number of specimens involved in the tests, considerable reliability can be placed on the properties reported for the various heat-treat conditions.

Mechanical-Property Tests. The mechanical properties of the test specimens attached to the test parts and of other specimens

Text continued on page 29. 


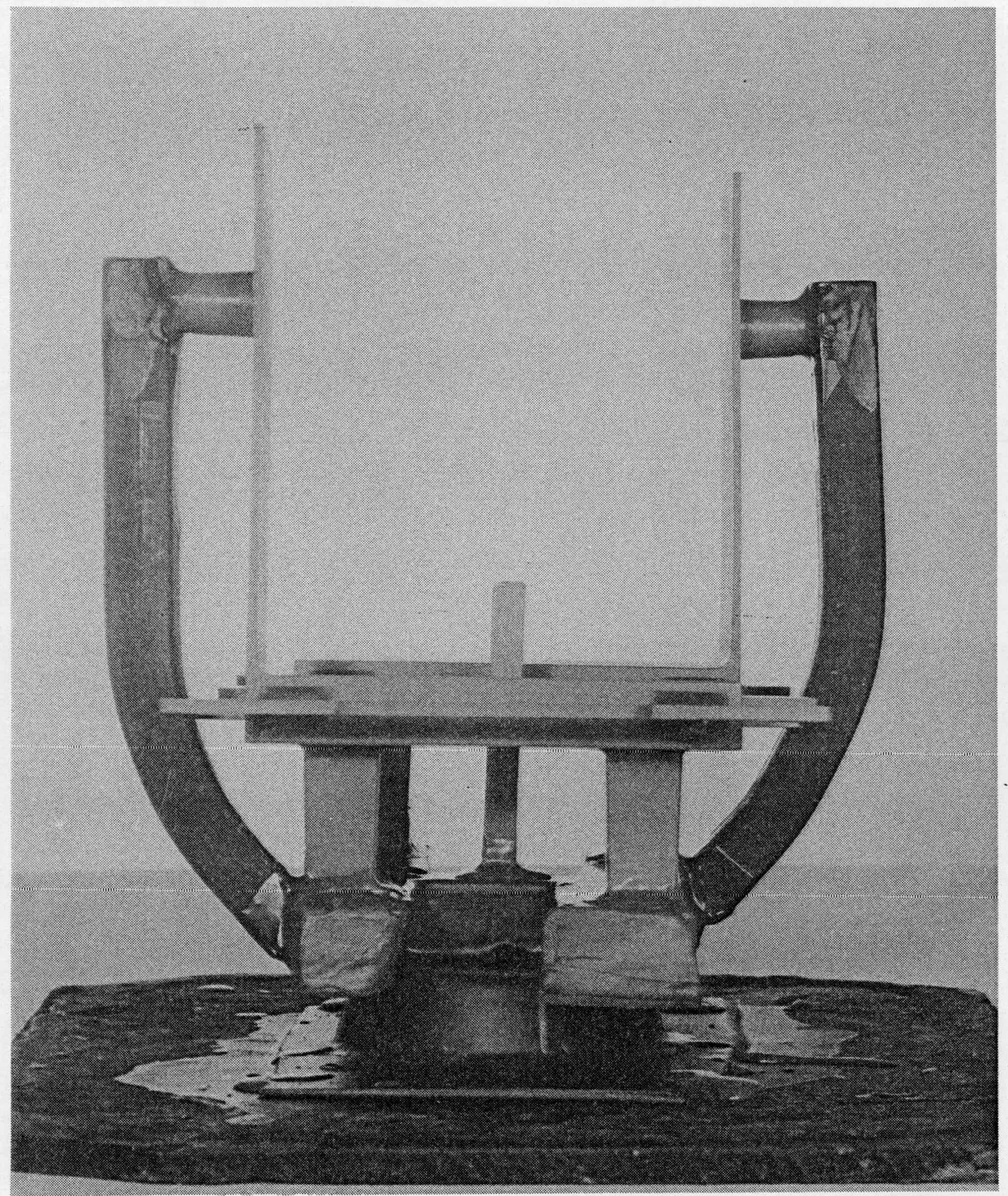

Figure 11. Gating System Showing Test Parts With Two Curved Runners 


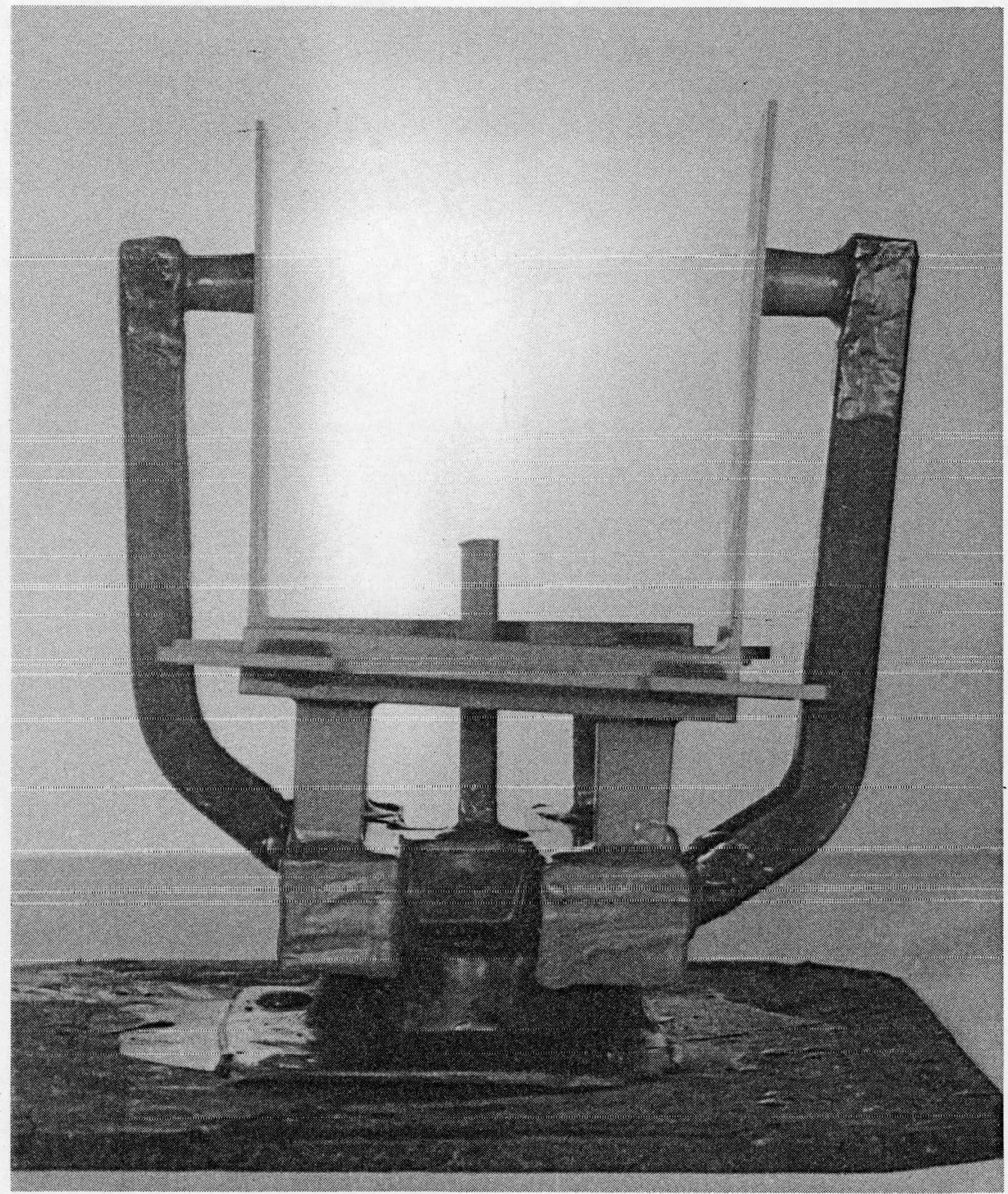

Figure 12. Gating System Showing Angular Runners and Test Parts Slightly Misaligned 


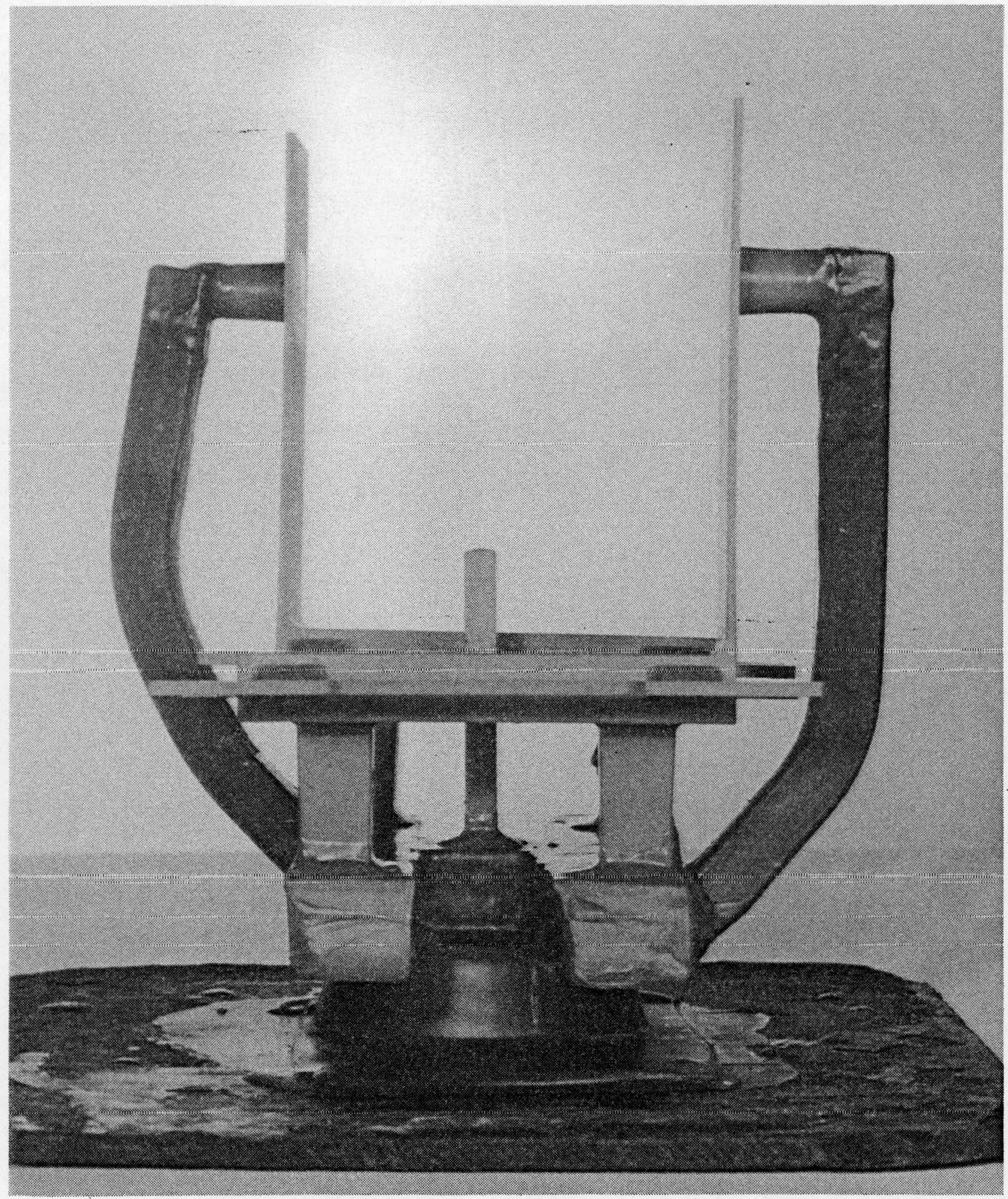

Figure 13. Gating System Showing One Curved and One Angular Runner. 


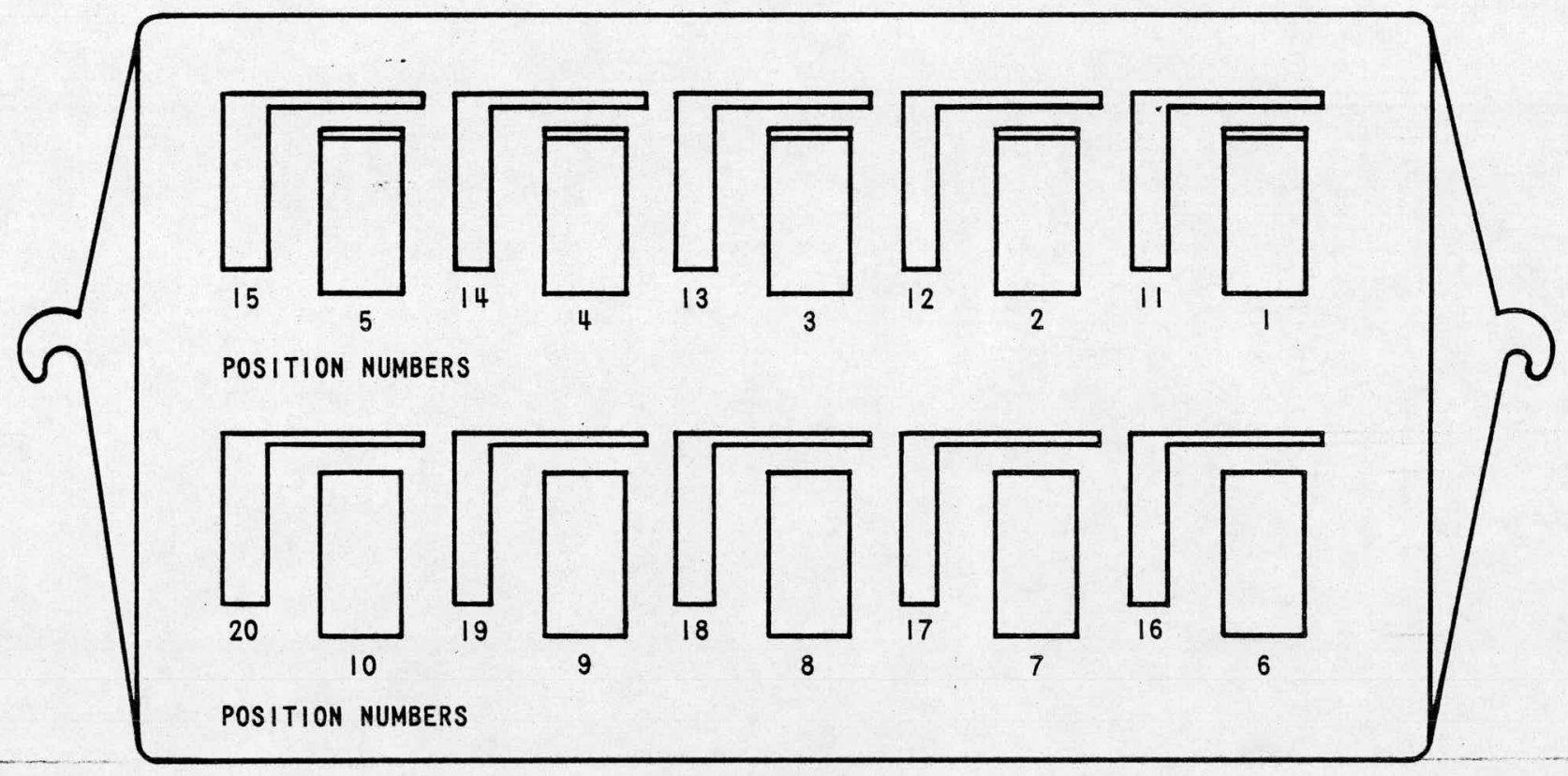

OPERATOR SIDE

Figure 14. Quench Positions of Parts in the Heat-Treat-Furnace Quenching Basket

machined from the massive base of selected test parts were obtained through the use of a 60,000-pound-capacity TiniusOlsen Electro-Mechanical Universal Testing Machine. The strain rate was 0.05 inch/inch per minute $(0.05 \mathrm{~mm} / \mathrm{mm}$ per minute), and the yield strength was determined at 0.2 -percent offset.

Data Analysis

Computer Analysis of Dimensional Data. The accumulated dimensional data were analyzed by computer, and rankings were established according to the rms averages of all data, and also according to the central 60 percent of the measurements. Average warpage tendencies were calculated and recorded for all-point and end deflection values for heat-treat lots, quench positions, part attitudes, flask and shell-molded part comparisons, and complete cast heats.

Mechanical-Property Tests. Tensile tests were conducted on 2064 tensile bars, and the mechanical property results were based largely on the results of those tests. Information obtained from the mechanical tests was used to calculate mean and median results by heat-treat lot, part attitude at quench, shell-versus-flask-molded properties, and quench-position 
effects. Mechanical properties, test-part and specimen identification, quench position, heat-treat lot, and heat-treat sublot number were tabulated for all tensile-test specimens.

Miscellaneous Observations. Although some of the miscellaneous information that was observed, determined, and reported during the study was not used to arrive at specific conclusions, it contributed significantly to the total knowledge obtained during the study and may prove useful in subsequent investigations.

\section{Significance of Test Results}

Dimensional Stability

Water Quench. Although the water control-and-comparison quenches developed good mechanical properties in the specimens, the warpage was severe (Figures 15 and 16).

Polyalkylene Glycol Solutions. Warpage was reduced by using solutions of polyalkylene glycol and polyethylene glycol in water. The best results for polyalkylene glycol were obtained by using a 20-percent (by weight) solution in water at $210^{\circ} \mathrm{F}$. $\left(98.9^{\circ} \mathrm{C}\right)$ with the parts in a vertical attitude to reduce turbulence. Under conditions of turbulence (parts quenched in the horizontal attitude), the 20-percent polyalkylene solutions yielded good results, but not as good as those obtained by using 5 - and 1.0-percent solutions at $210^{\circ} \mathrm{F}\left(98.9^{\circ} \mathrm{C}\right)$. The lowest warpage in 40-percent polyalkylene glycol solutions was found at room temperature for horizontal-attitude parts, and at $160^{\circ} \mathrm{F}\left(7.1 .1^{\circ} \mathrm{C}\right)$ for vertical-attitude parts.

Figures 17 through 20 show the rms average deflection of all test-part points for the different polyalkylene glycol solution concentrations over the range of temperatures investigated. Figures 21 through 24 illustrate the rms end deflection (or blade-tip warpage) for the same solution compositions over the same temperature range. Quench Lots $3 \mathrm{~A}, 4 \mathrm{~A}$, and $6 \mathrm{~A}$ were not plotted because the data appeared to be independent and showed excessive warpage. Lots $3 \mathrm{~A}$ and $4 \mathrm{~A}$ had no normal tank-fluid movement, and the Lots $4 \mathrm{~A}$ and $6 \mathrm{~A}$ were shell-molded and not from the mainstream of material investigated.

At temperatures exceeding $160^{\circ} \mathrm{F}\left(71.7^{\circ} \mathrm{C}\right)$, polyalkylene glycol (Ucon A) solutions separate into two fluids, thus losing solubility. A part undergoing quenching at these temperatures therefore is subjected to two separate cooling rates, one rate for the top layer of the quenching fluid and a different rate for the bottom layer.

Polyethylene Glycol Solutions. The best results for polyethylene glycol were obtained by using 20 - and 40-percent solutions (by weight) at $210^{\circ} \mathrm{F}\left(98.9^{\circ} \mathrm{C}\right)$. Lower concentrations may not be as

Text continued on page 41 . 
QUENCH FLUID TEMPERATURE $\left({ }^{\circ} \mathrm{C}\right)$

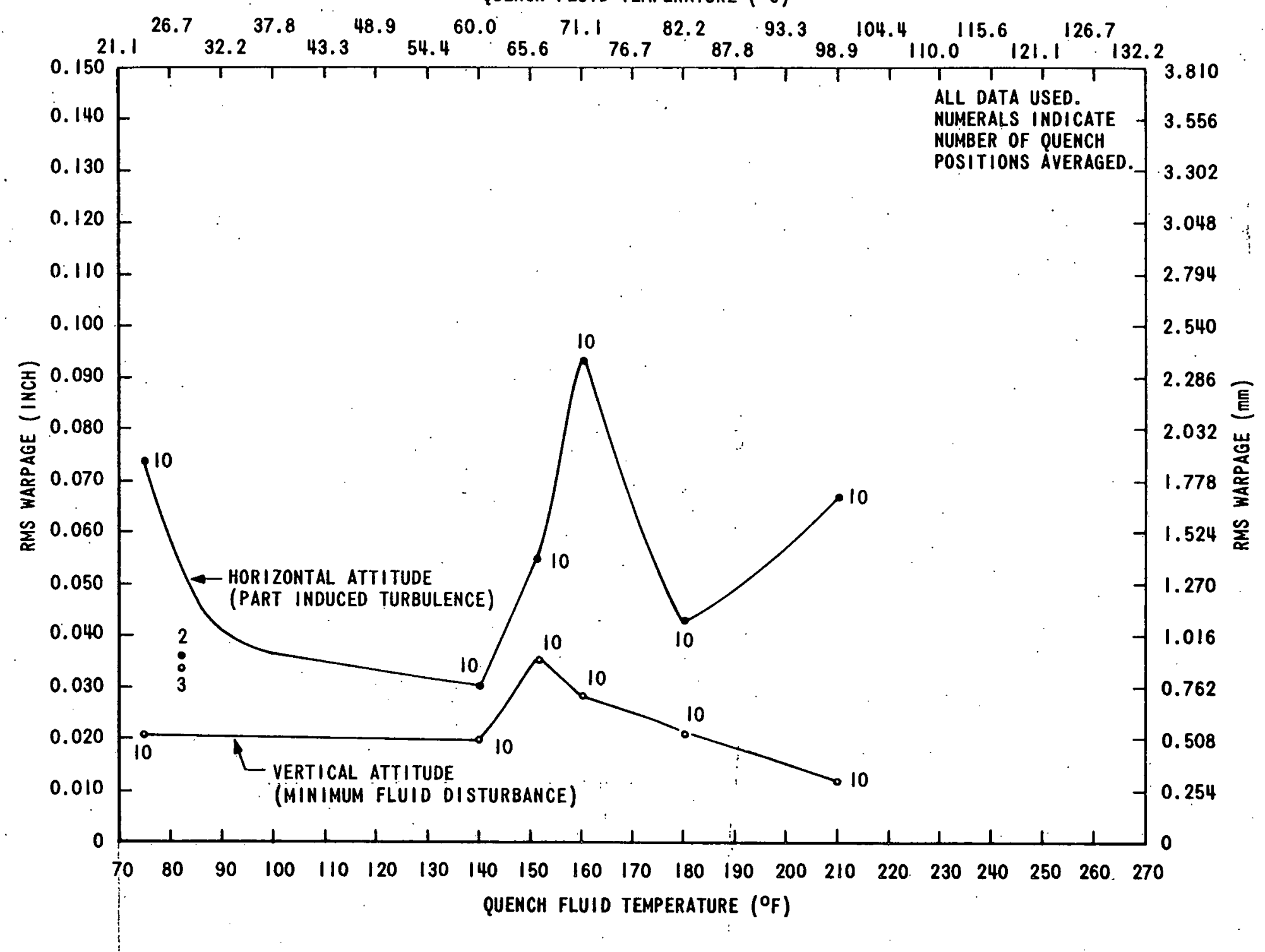

Figure 15. Effect of Water Quench on Average Deflection of All Points 
QUENCH FLUID TEMPERATURE $\left({ }^{\circ} \mathrm{C}\right)$

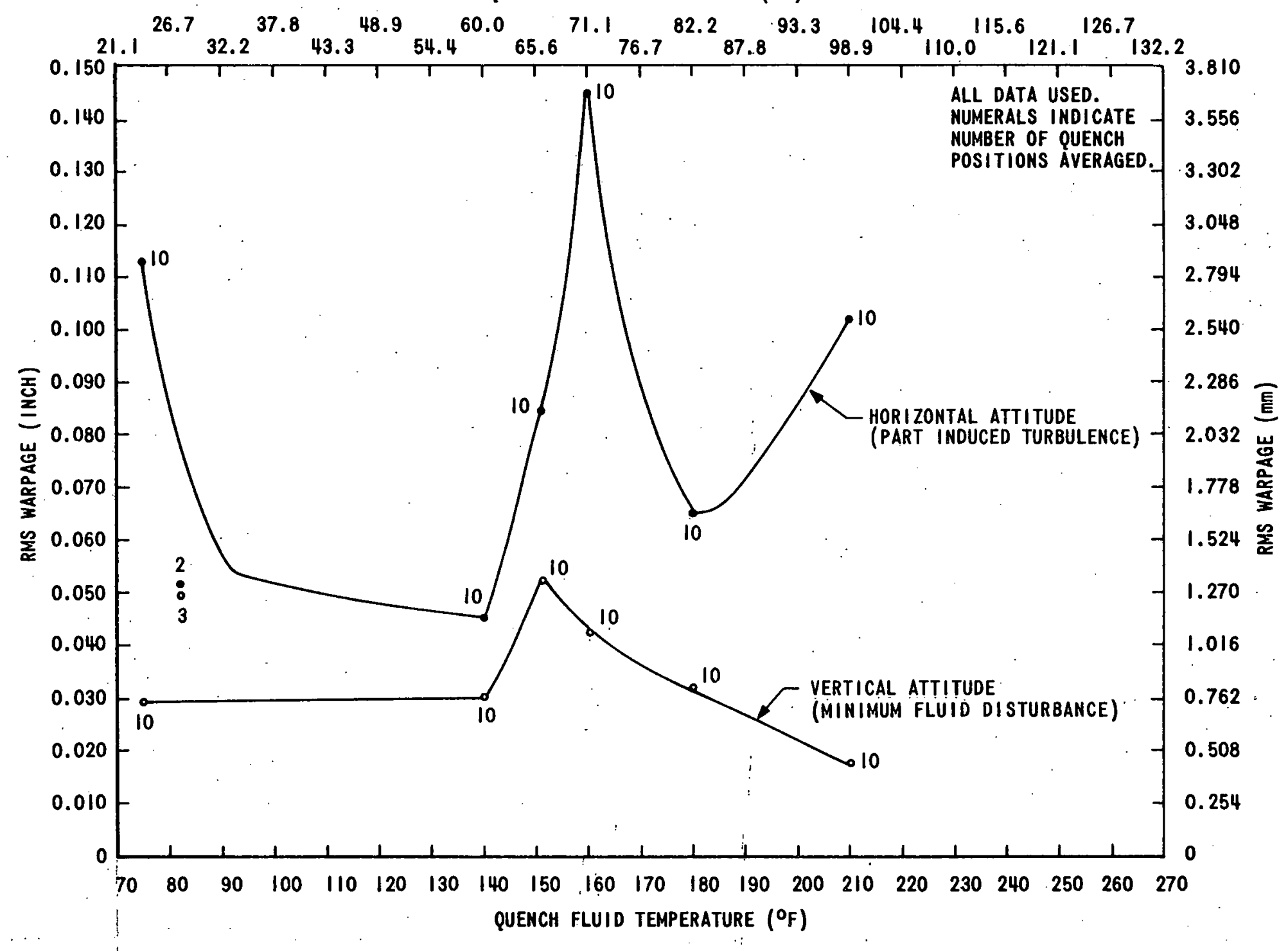

Figure 16. Effect of Water Quench on End-Point Deflection 
QUENCH FLUID TEMPERATURE $\left({ }^{\circ} \mathrm{C}\right)$

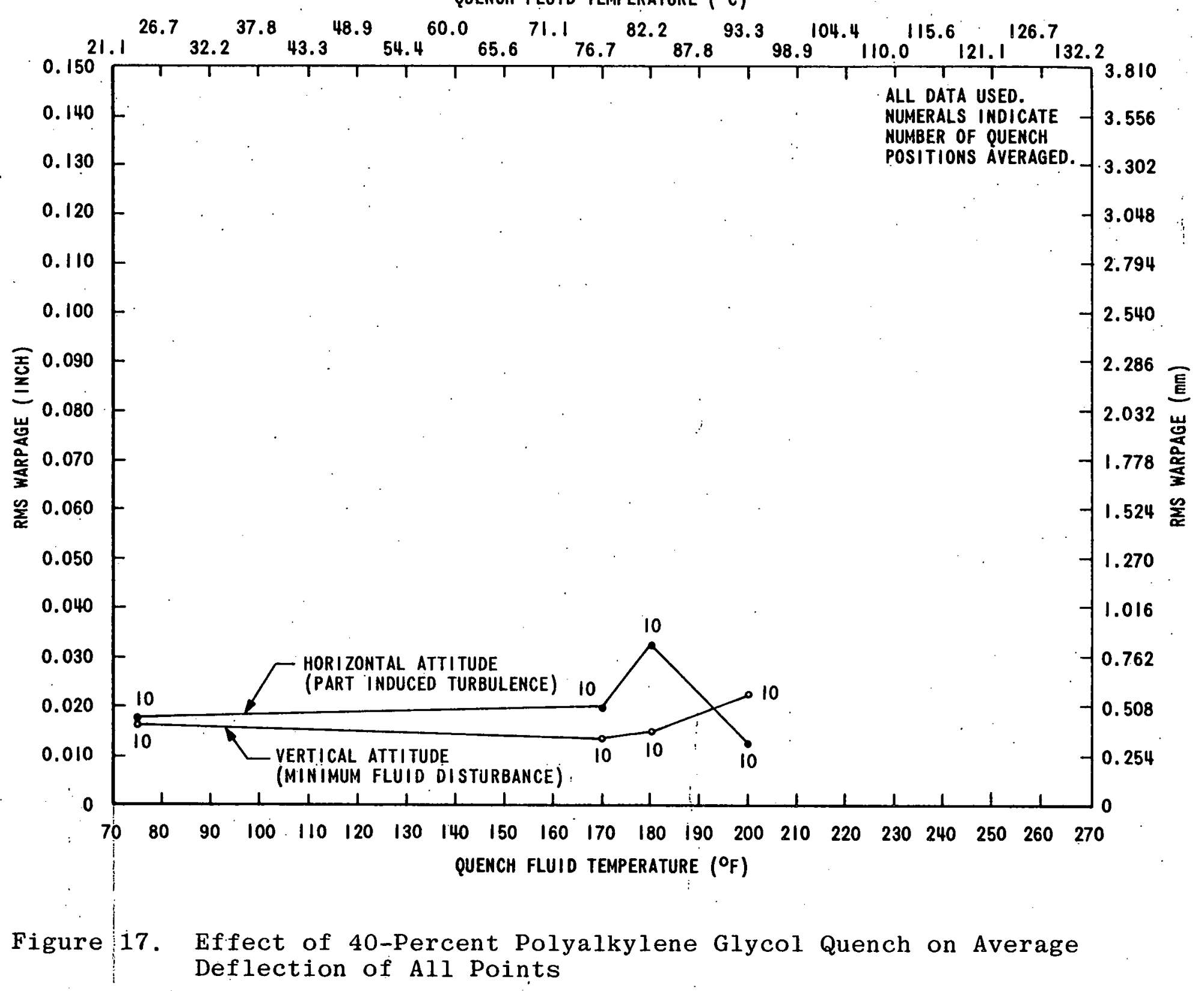


QUENCH FLUID TEMPERATURE $\left({ }^{\circ} \mathrm{C}\right)$

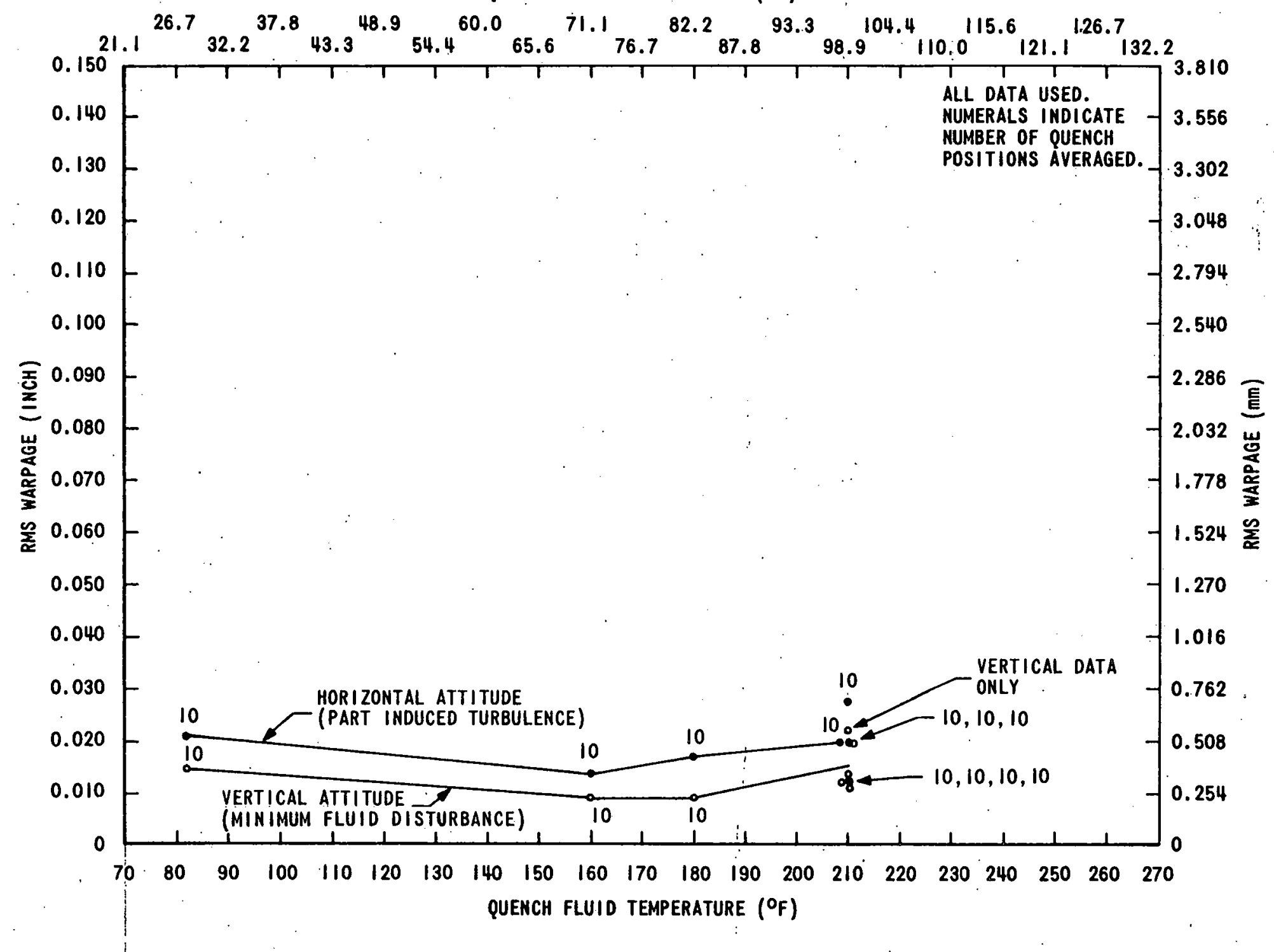

Figure 18. Effect of 20-Percent Polyalkylene Glycol Quench on Average Deflection of All Points 
QUENCH FLUID TEMPERATURE $\left({ }^{\circ} \mathrm{C}\right)$

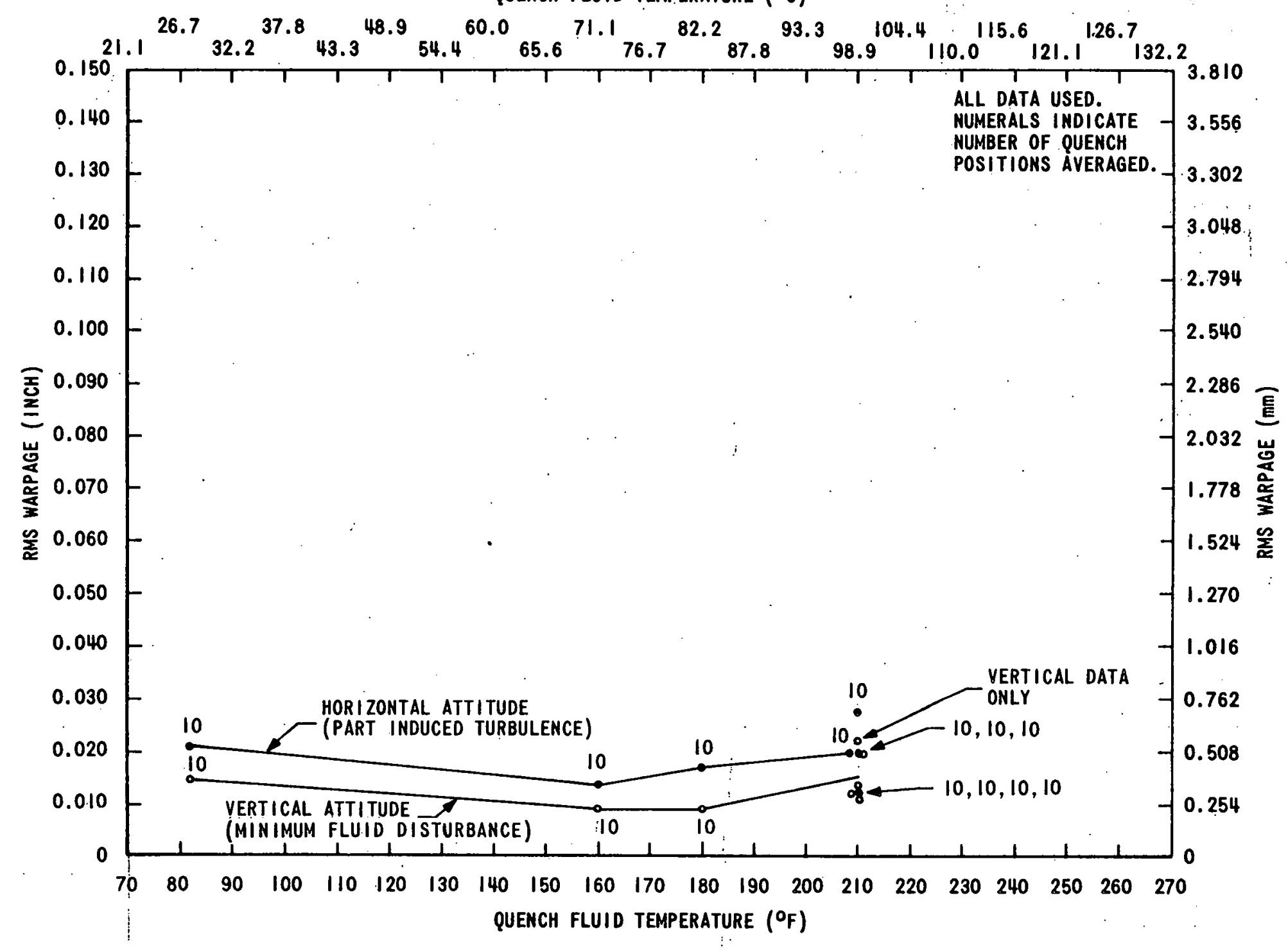

Figure 18. Effect of 20-Percent Polyalkylene Glycol Quench on Average 
QUENCH FLUID TEMPERATURE $\left({ }^{\circ} \mathrm{C}\right)$

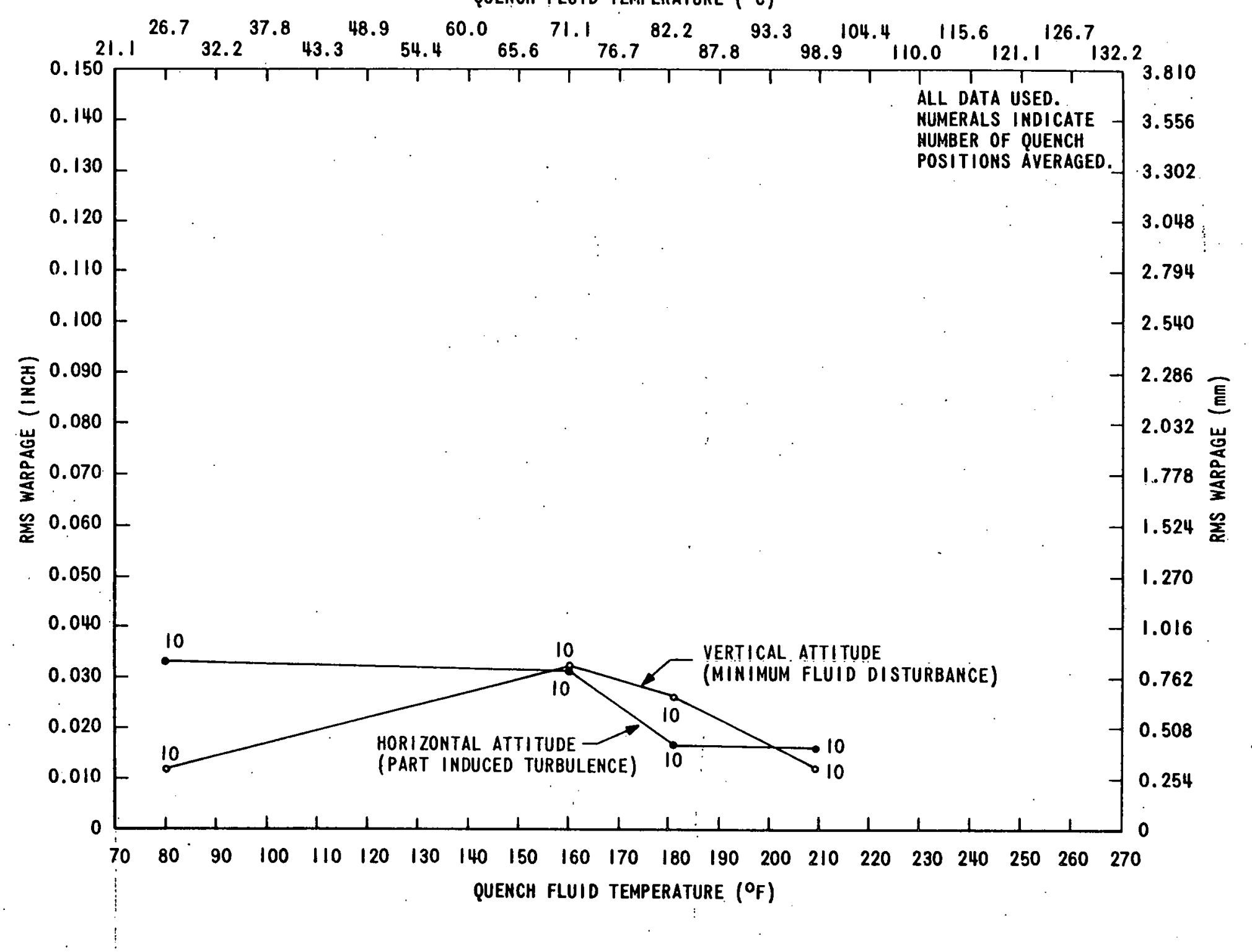

Figure 19. Effect of 10-Percent Polyalkylene Glycol Quench on Average Deflection of All Points 
QUENCH FLUID TEMPERATURE $\left({ }^{\circ} \mathrm{C}\right)$

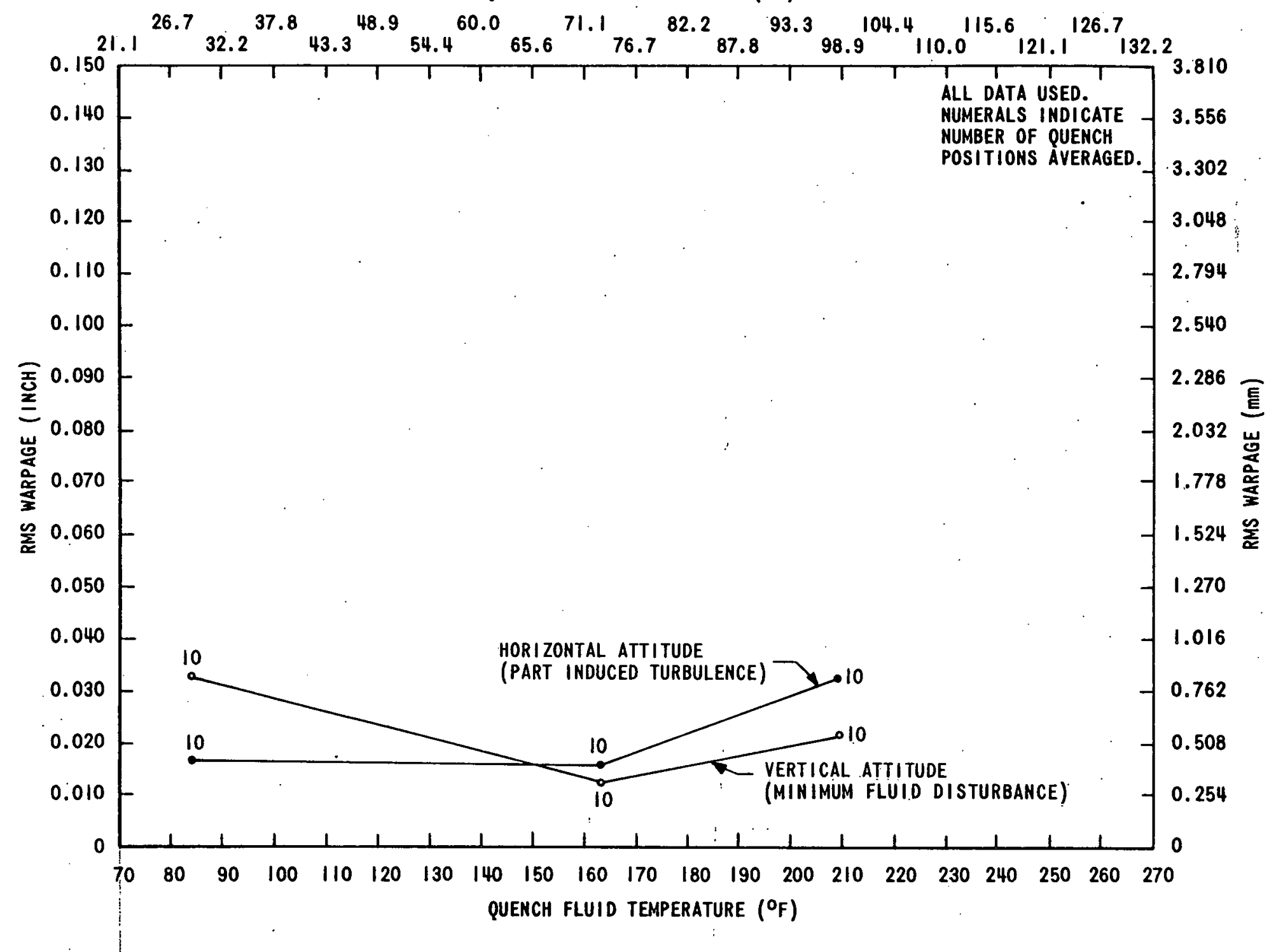

Figure 20. Effect of 5-Percent Polyalkylene Glycol Quench on Average Deflection of All Points 
QUENCH FLUID TEMPERATURE $\left({ }^{\circ} \mathrm{C}\right)$

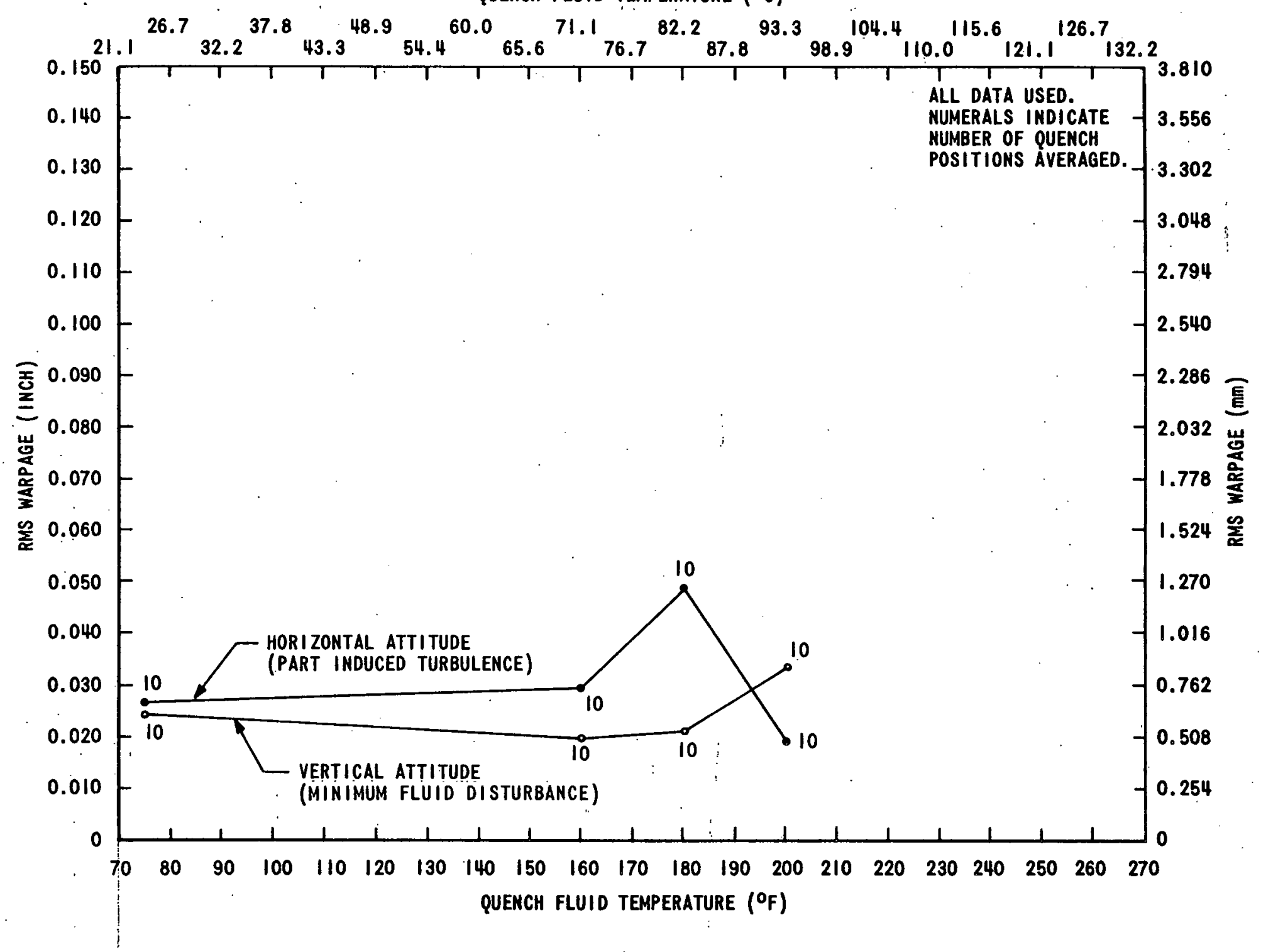

Figure 21. Effect of 40-Percent Polyalkylene Glycol Quench on End-Point Deflection 
QUENCH FLUID TEMPERATURE $\left({ }^{\circ} \mathrm{C}\right)$

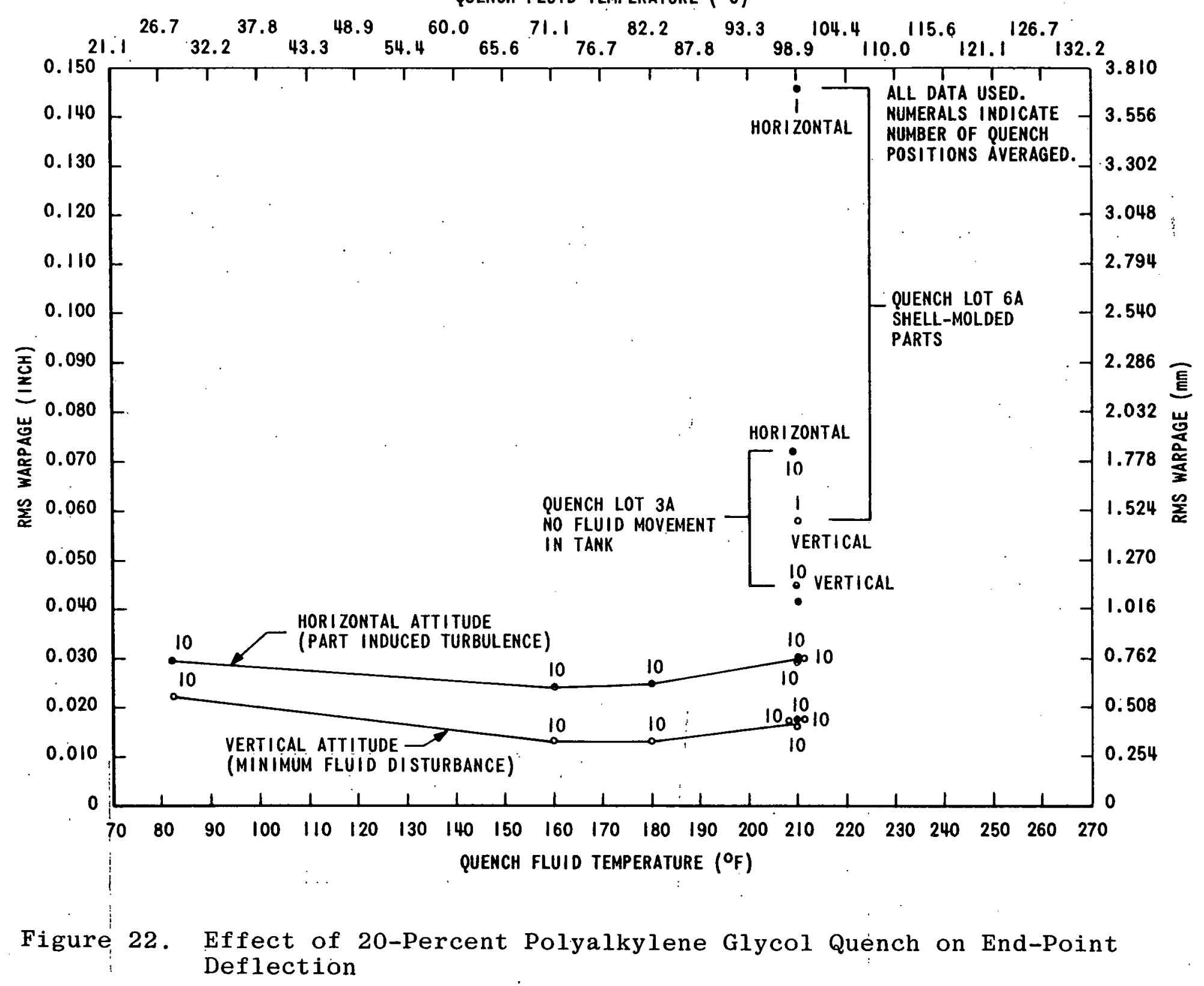


QUENCH FLUID TEMPERATURE $\left({ }^{\circ} \mathrm{C}\right)$

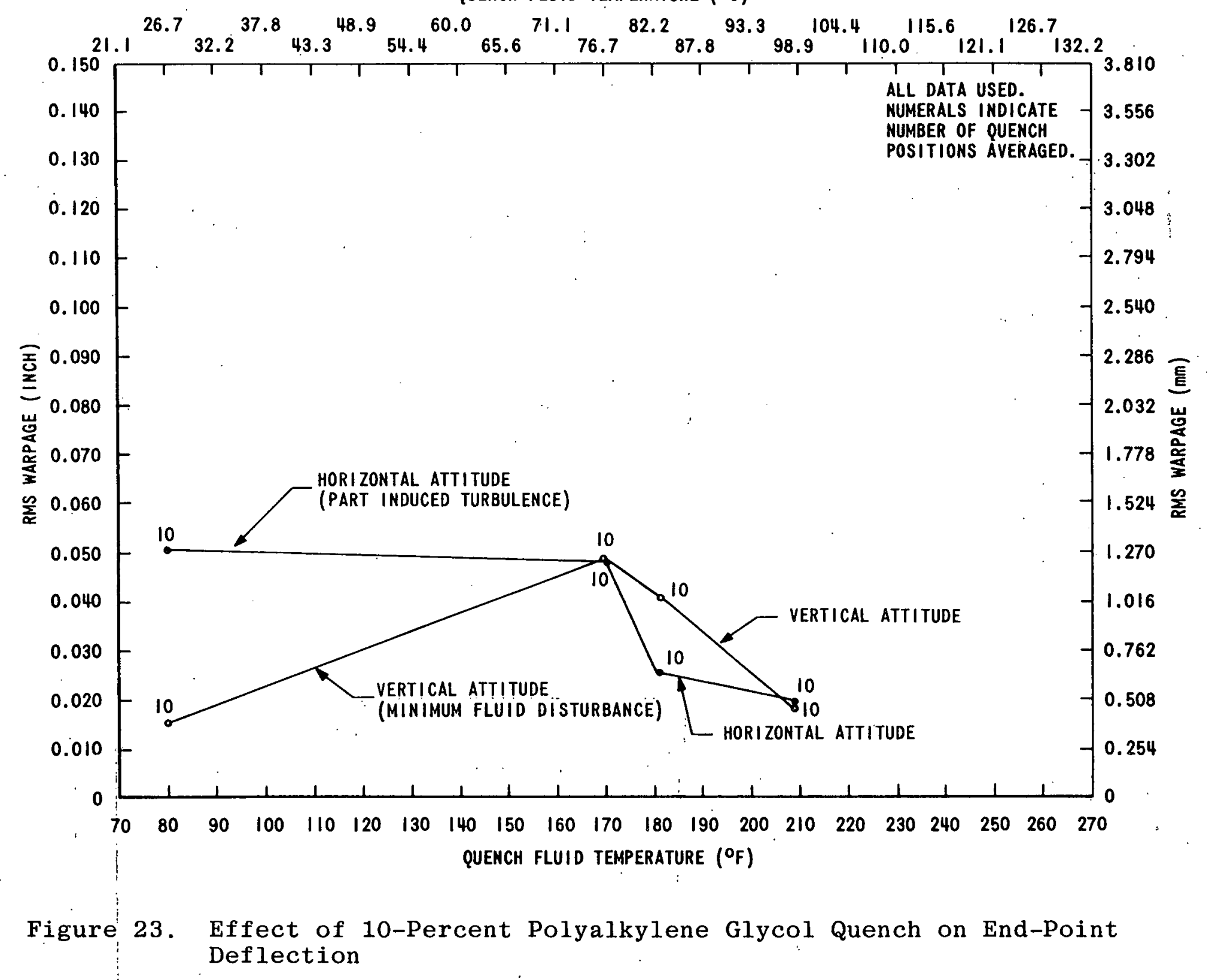


QUENCH FLUID TEMPERATURE $\left({ }^{\circ} \mathrm{C}\right)$

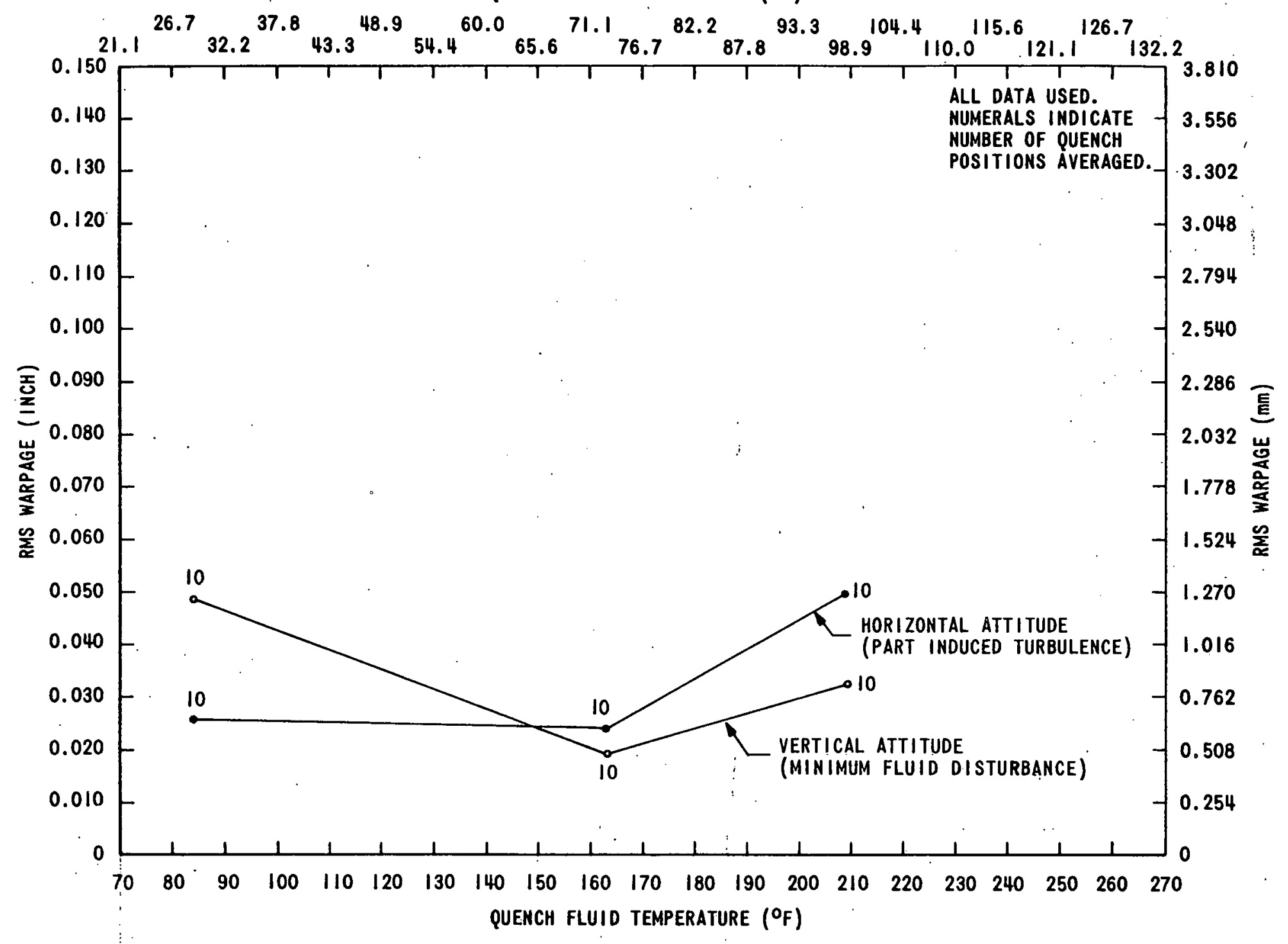

Figure 24. Effect of 5-Percent Polyalkylene Glycol Quench on End-Point Deflection 
effective in reducing warpage, and higher concentrations appear to significantly reduce the mechanical properties of the parts without a corresponding reduction in distortion. Solution concentrations between 20 and 40 percent were not studied.

The reduction of warpage with increased quenching temperatures appears to be much more predictable for polyethylene glycol solutions than for polyalkylene glycol solutions, although additional benefits from increased temperatures do not appear to occur at temperatures above that of the normal boiling point of pure water. This was observed through the higher boiling points of the solutions used. Higher boiling points should reduce warpage resulting from nonuniform gassing and gas-pocket formations when quenching solutions are maintained at the normal boiling temperature of water.

At the time of these experiments, the cost of polyethylene glycol was approximately only one-third that of polyalkylene glycol. The cost advantages, in addition to a more predictable behavior, indicate that polyethylene glycol solutions should be used in preference to polyalkylene glycol solutions at temperatures above $160^{\circ} \mathrm{F}\left(71.1^{\circ} \mathrm{C}\right)$, and they should be considered on a cost-basis alone for use at lower temperatures. Figures 25 through 32 show the relationships between composition, part attitude, and temperature for the various polyethylene glycol solutions investigated.

Methyl-Alcohol and Liquid-Nitrogen Quenches. Compositions of 40-, 20-, 10-, and 5-percent (by weight) methyl. alcohol in water also were studied for use as a quench. Warpage results were somewhat improved over those for water, but they were not particularly promising. The warpage data which were obtained are plotted in Figures. 33 and 34 . The data from the 5-percent methyl alcohol solution, which was to have been Computer Lot 35 , were lost in transit between the Hemet Casting Company and the Bendix Corporation and were never recovered. The data from this lot therefore are missing from Table 1 .

One lot of parts was quenched in liquid nitrogen. The data may be found in this report under Computer Lot 40 (quench) and Lot 7 (heat-treat quench) of Table 1 .

Turbulence, Quench Position, and Part Attitude. In general, warpage was reduced by minimizing the turbulence during quenching. This was done by minimizing the cross section that approached the quenching fluid, by eliminating asymmetric current patterns in the fluid, and by. considering the effect of the part design upon the fluid flow.

Warpage was found to vary by a factor of. 3 , depending upon the plan-view location of the casting in the quenching basket, with

Text continued on page 52 . 
QUENCH FLUID TEMPERATURE $\left({ }^{\circ} \mathrm{C}\right)$

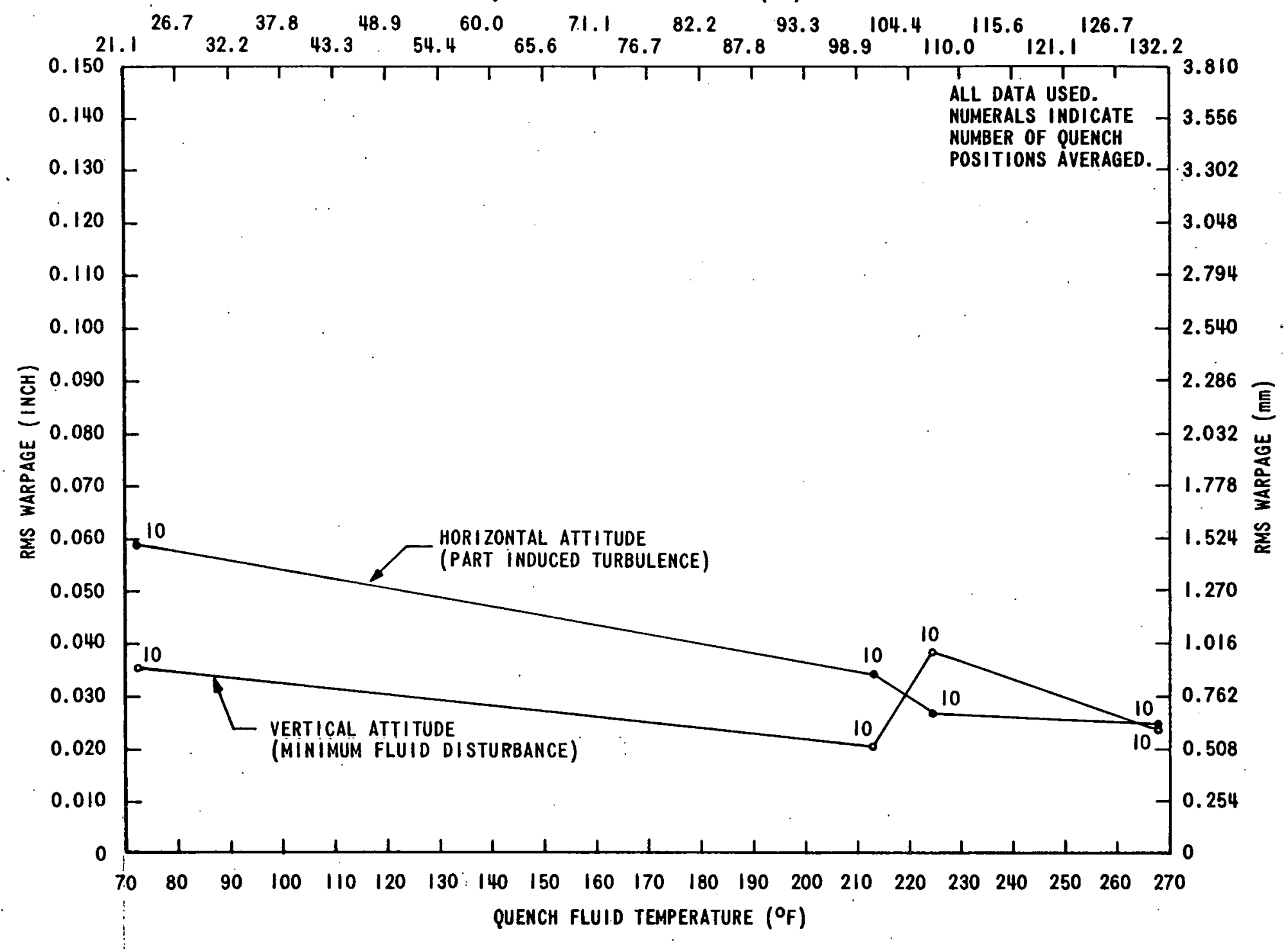

Figure 25. Effect of 90-Percent Polyethylene Glycol Quench on Average Deflection of All Points 
QUENCH FLUID TEMPERATURE $\left({ }^{\circ} \mathrm{C}\right)$

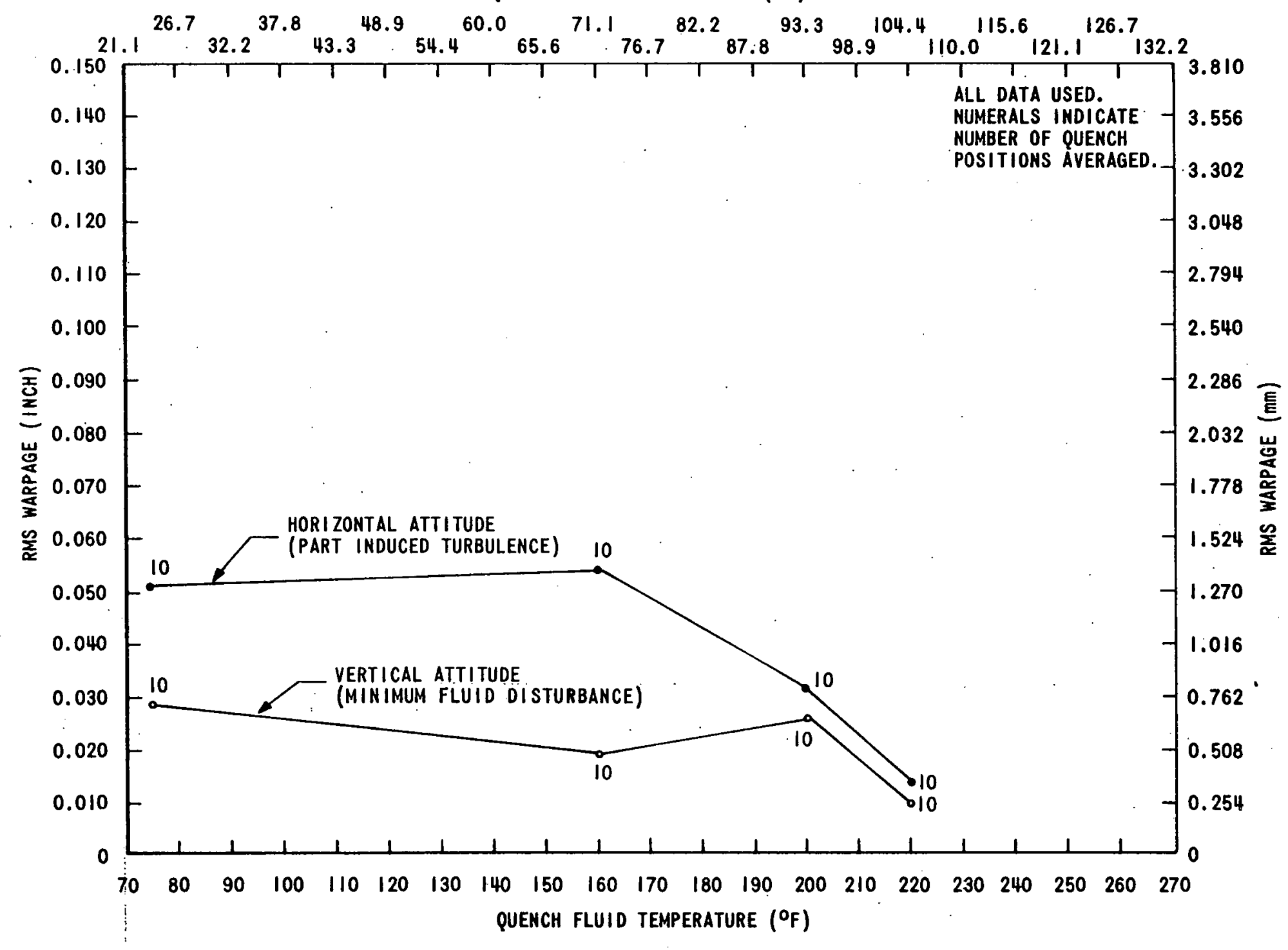

Figure 26. Effect of 60-Percent Polyethylene Glycol Quench on Average Deflection of All Points 
QUENCH FLUID TEMPERATURE $\left({ }^{\circ} \mathrm{C}\right)$

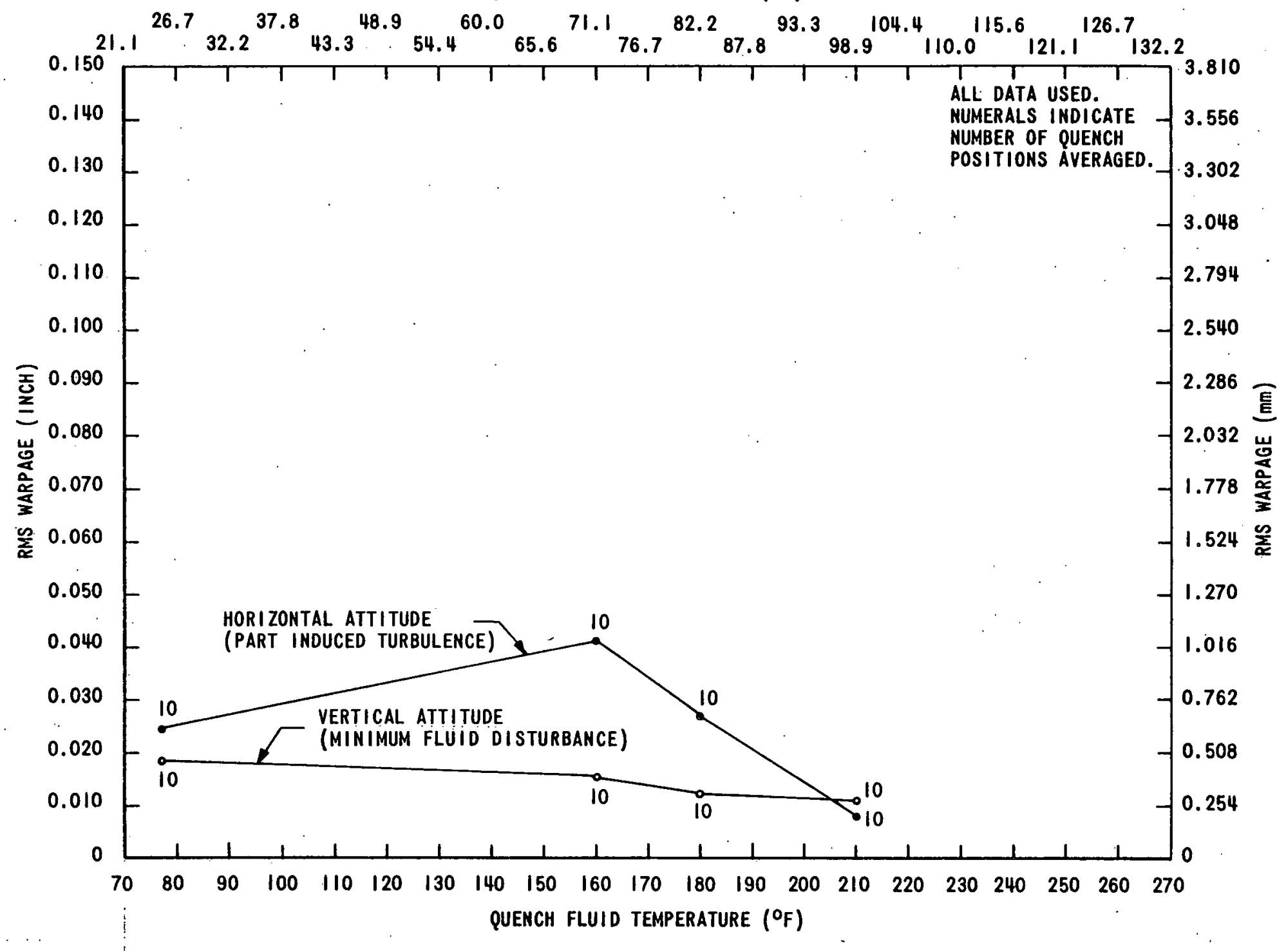

Figure 27. Effect of 40-Percent Polyethylene Glycol Quench on Average Deflection of All Points 
QUENCH FLUID TEMPERATURE $\left({ }^{\circ} \mathrm{C}\right)$

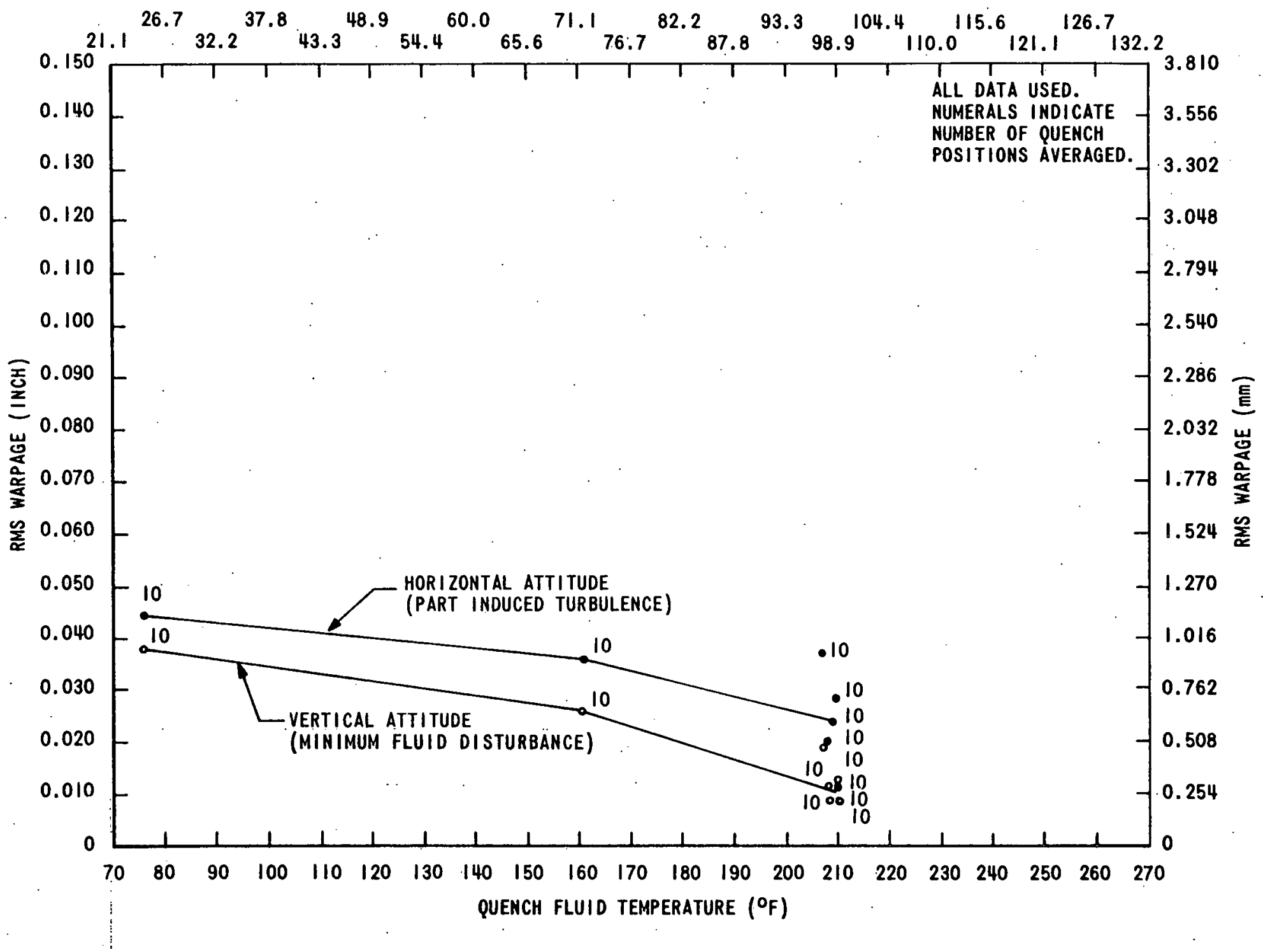

Figure 28: Effect of 20-Percent Polyethylene Glycol Quench on Average Deflection of All Points 
QUENCH FLUID TEMPERATURE $\left({ }^{\circ} \mathrm{C}\right)$

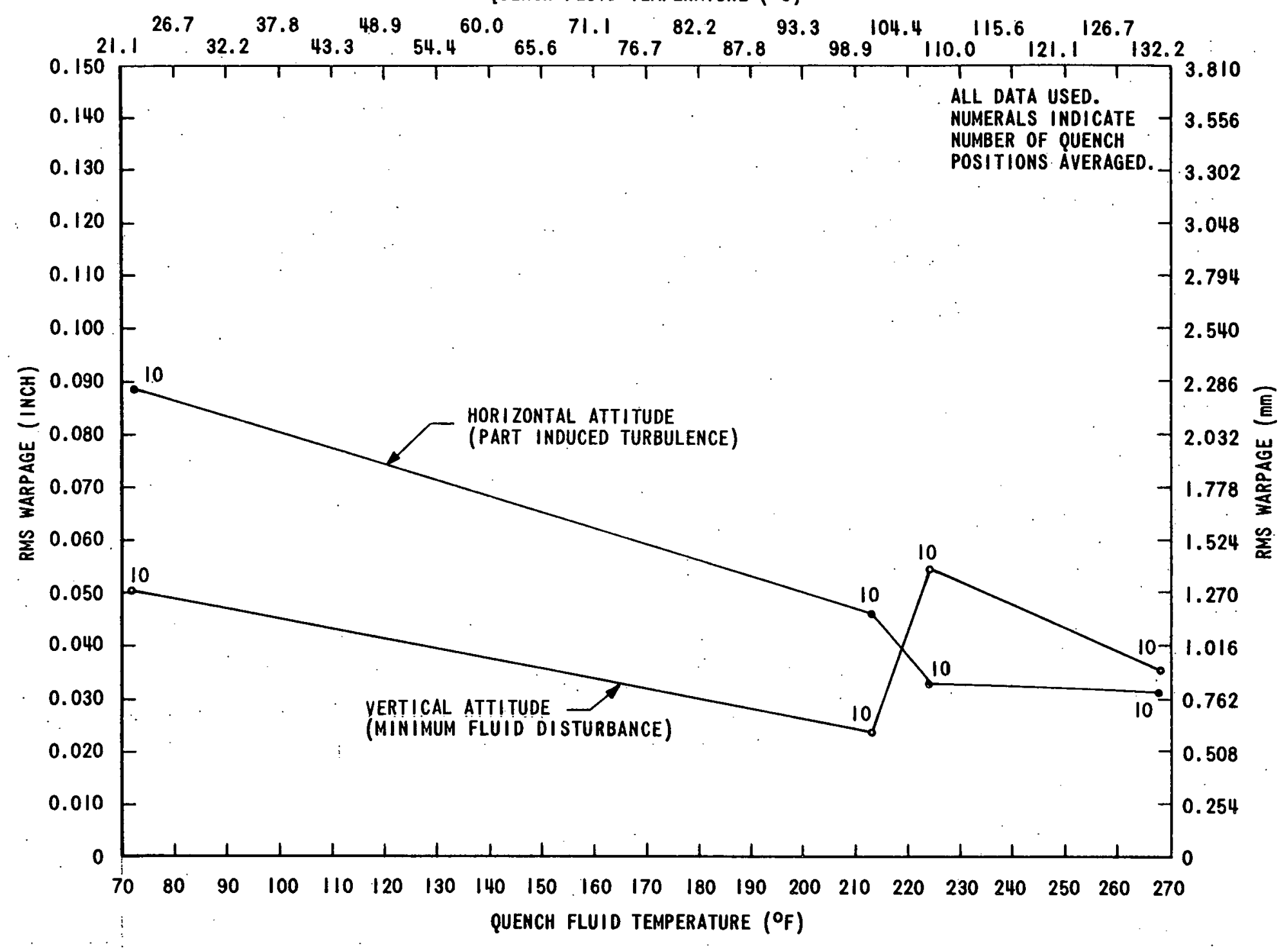

Figure 29. Effect of 90-Percent Polyethylene Glycol Quench on End-Point Deflection 
QUENCH FLUID TEMPERATURE $\left({ }^{\circ} \mathrm{C}\right)$

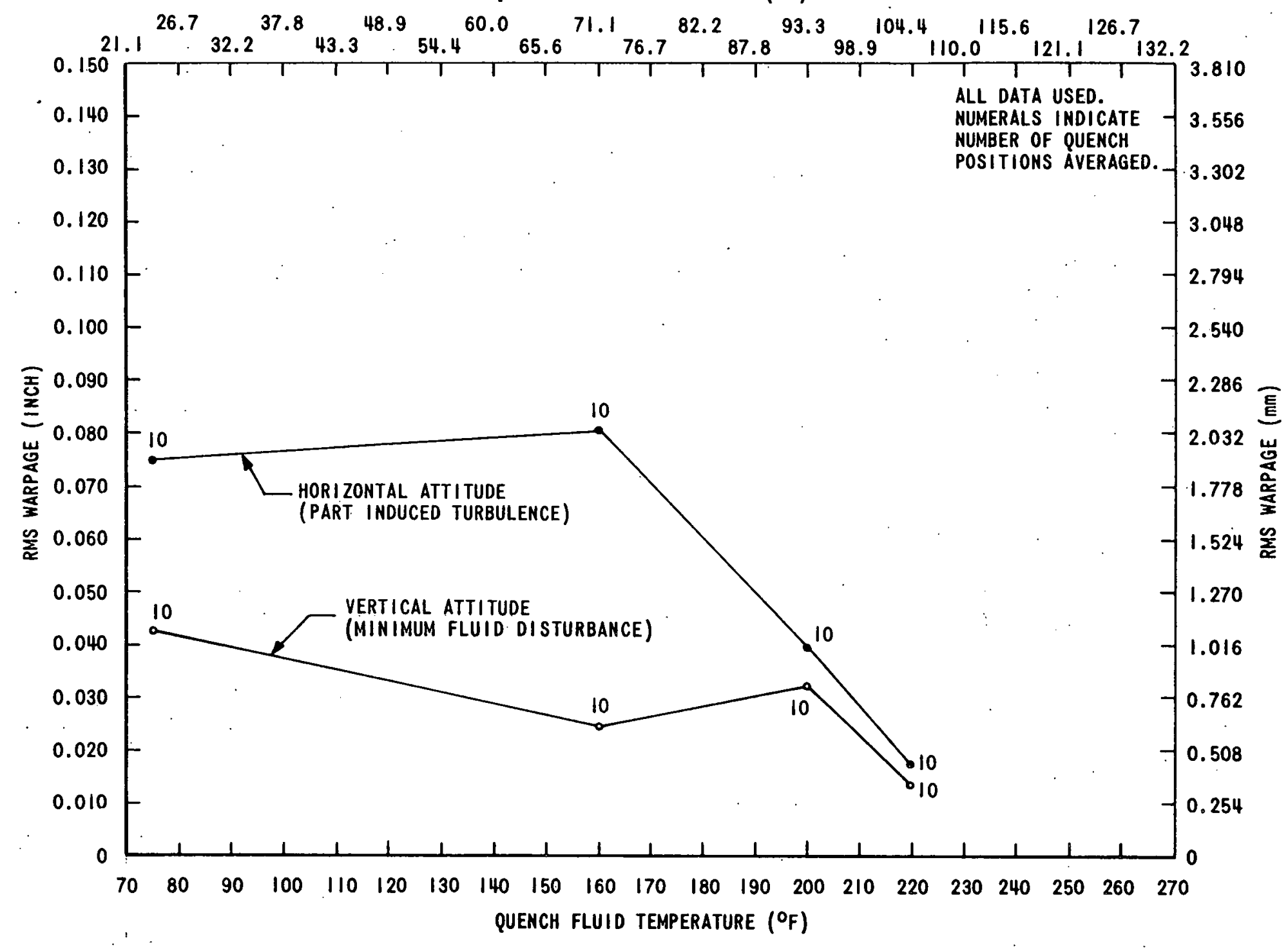

Figure 30. Effect of 60-Percent Polyethylene Glycol Quench on End-Point Deflection 
QUENCH FLUID TEMPERATURE $\left({ }^{\circ} \mathrm{C}\right)$

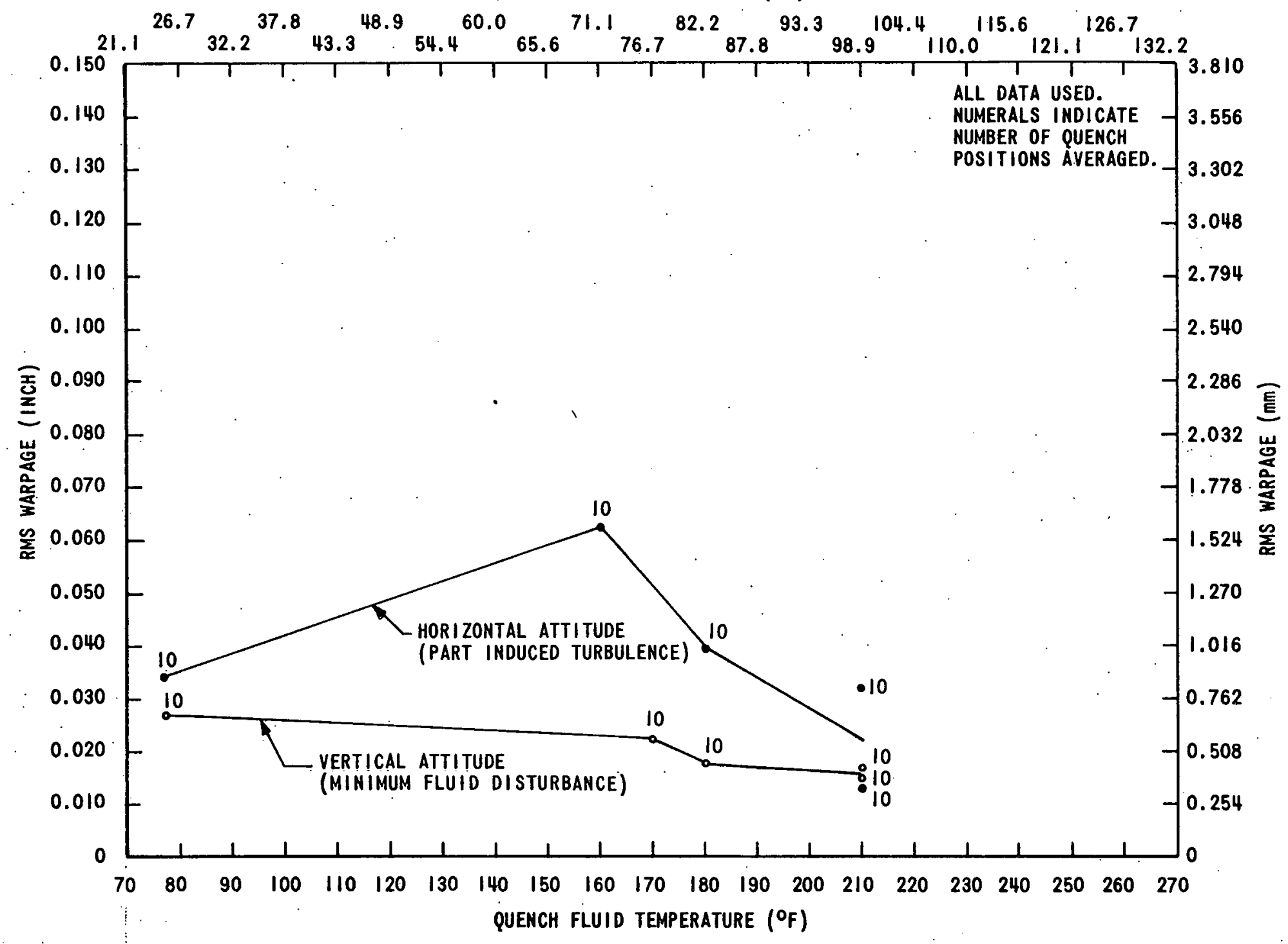

Figure 31. Effect of 40-Percent Polyethylene Glycol Quench on End-Point Deflection 
QUENCH FLUID TEMPERATURE $\left({ }^{\circ} \mathrm{C}\right)$

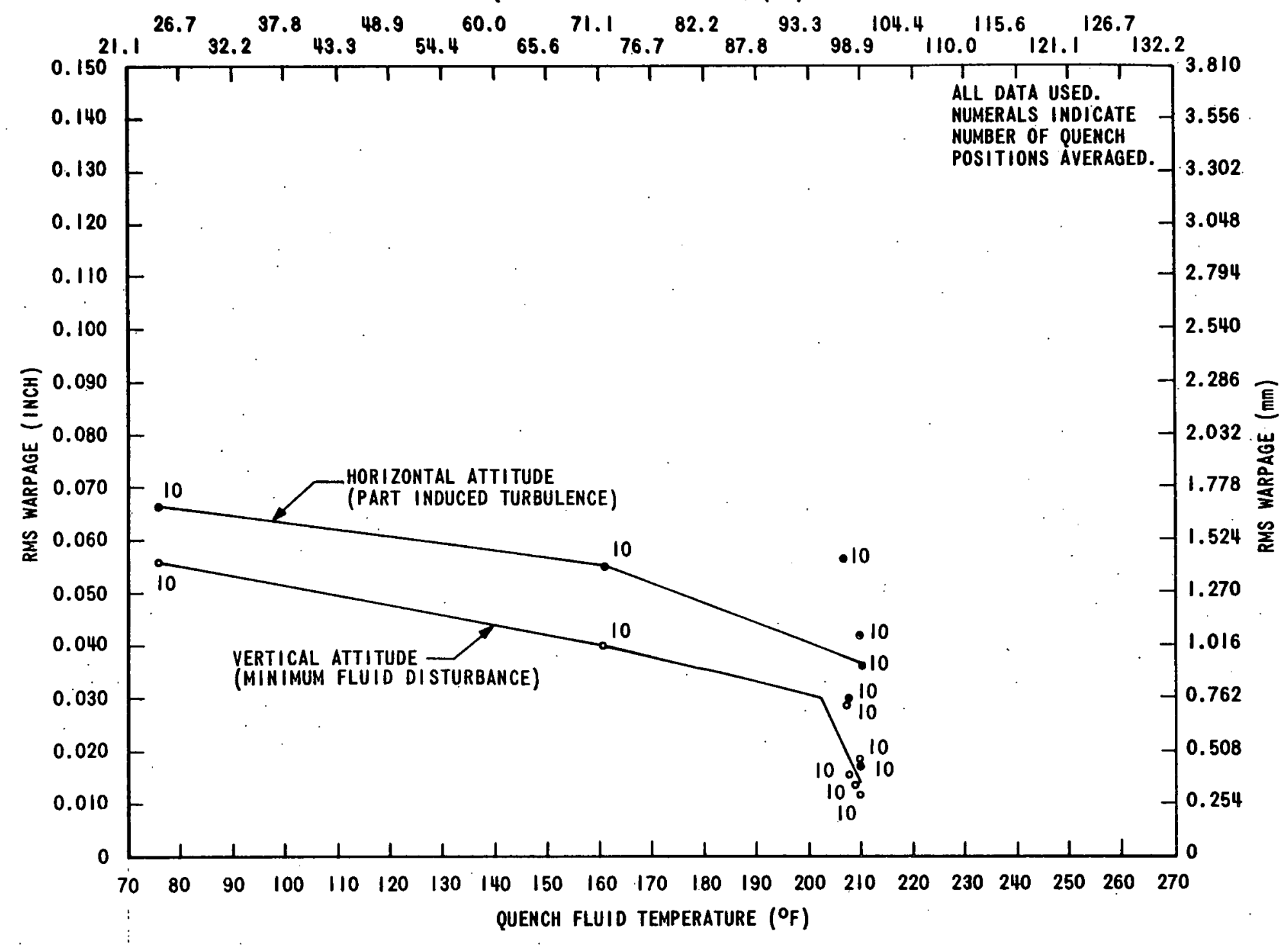

Figure 32. Effect: of 20-Percent Polyethylene Glycol Quench on End-Point 


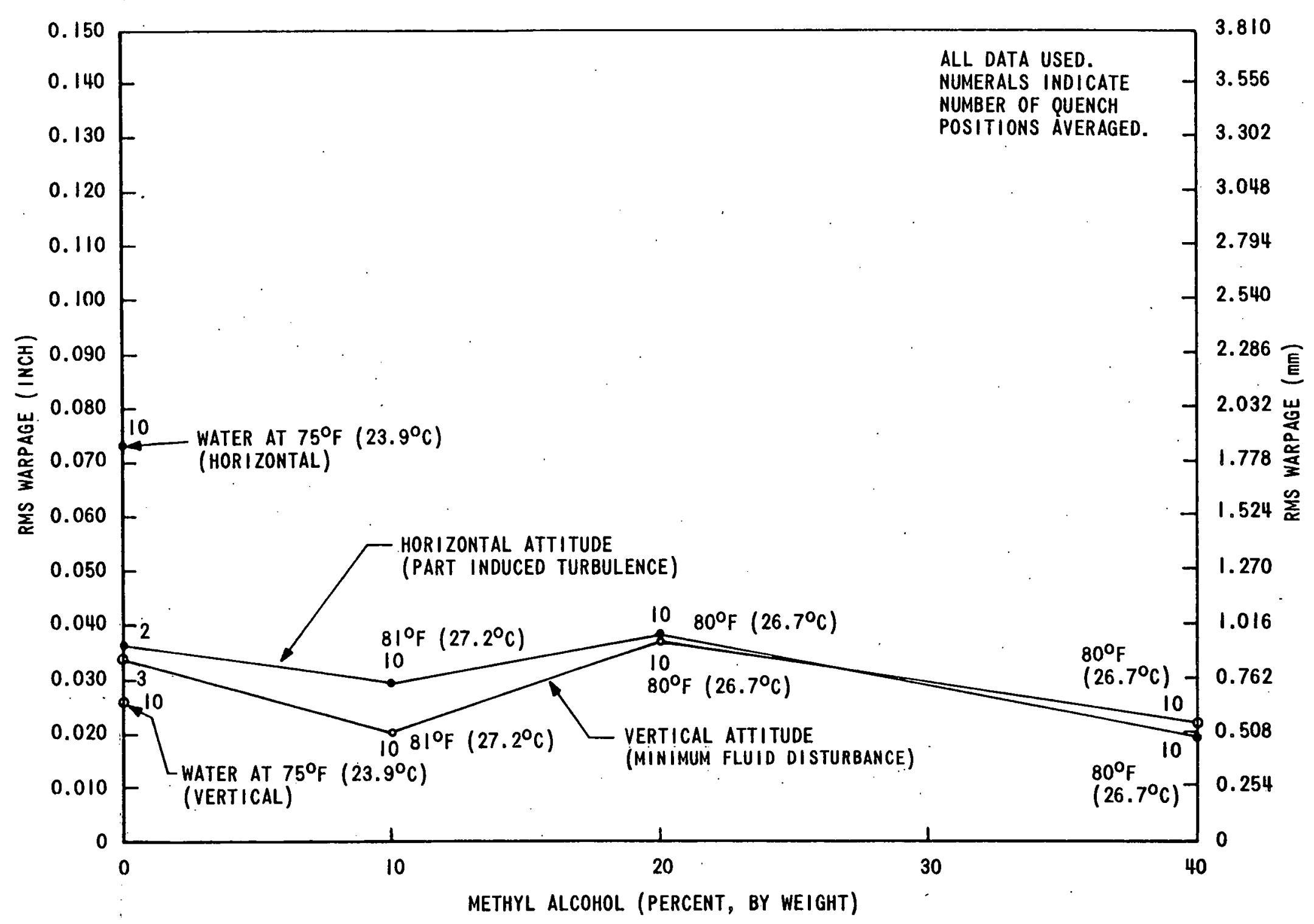

Figure 33. Effect of Methyl Alcohol Quench on Average Deflection of All Points 


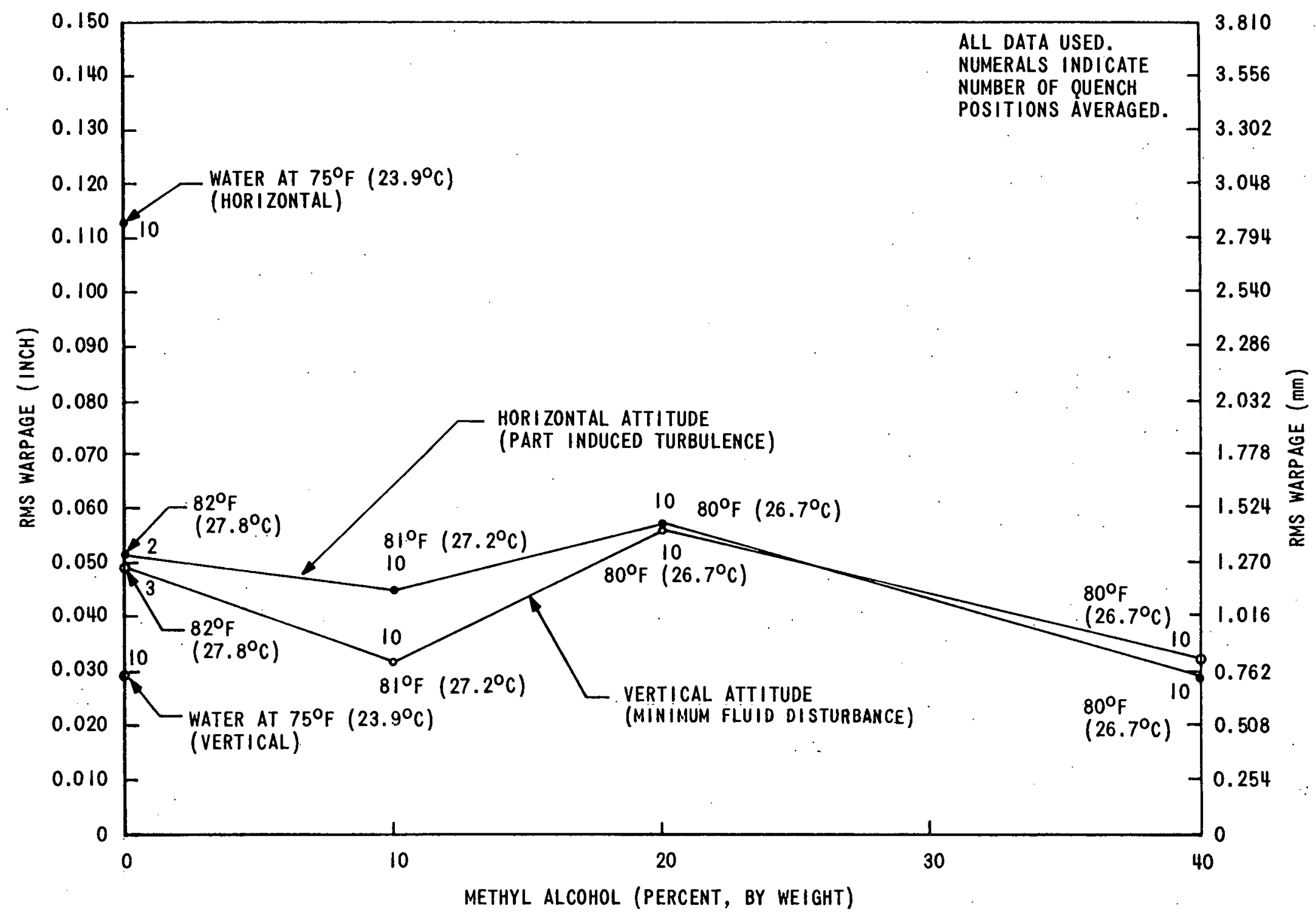

Figure 34. Effect of Methyl Alcohol Quench on End-Point Deflection 
the approach attitude of the part to the quenching media remaining constant. The location of the part in the quenching basket, or the quench position, is directly related to the turbulence produced by nonuniform current patterns in the quenching tank. The parts that were quenched in the horizontal attitude created more turbulence than did those quenched in the vertical attitude because of the greater areas presented to the quenching fluid upon contact.

Figures 35 through 38 show the relationship between quench position, part attitude, and warpage. The plots represent the rms average of approximately 106 end-point and 318 all-point values for the "all-data" plots. For the "central 60-percent data" plots, each plot represents 64 end-point and 190 allpoint values.

In Figure 39, the plot of the average end-point deflection for parts quenched in horizontal and vertical attitudes in Quench Positions 1 through 20 shows the advantage of the lowered turbulence produced at the vertical-attitude Positions 11 through 20 .

Variables Affecting Dimensional Stability. The following variables, listed in their apparent order of importance, were found to affect the dimensional stability of the parts after quenching.

Quenching-fluid temperature,

Quenching-fluid composition,

Differences in internal stress levels of flask- and shellmolded parts prior to heat-treatment,

- Attitude of the parts entering the quenching fluid (thus the fluid flow pattern produced by the parts), and

Fluid flow pattern created by the hydraulic agitation system of the tank.

The Effect of Annealing. Final warpage also can be reduced by furnace-annealing the parts after deflasking or deshelling, prior to removal of the gate and the solution heat-treatment. However, except for cases in which dimensional stability requirements outweigh cost considerations, the economics of furnace-annealing versus those of part-straightening should be considered. A greater reduction in warpage can be achieved by annealing shell-molded parts than by annealing flask-molded parts. Figure 40, consisting of three graphs, offers a comparison of the warpage after annealing with the additional warpage after quenching.

Text continued on page 61 . 


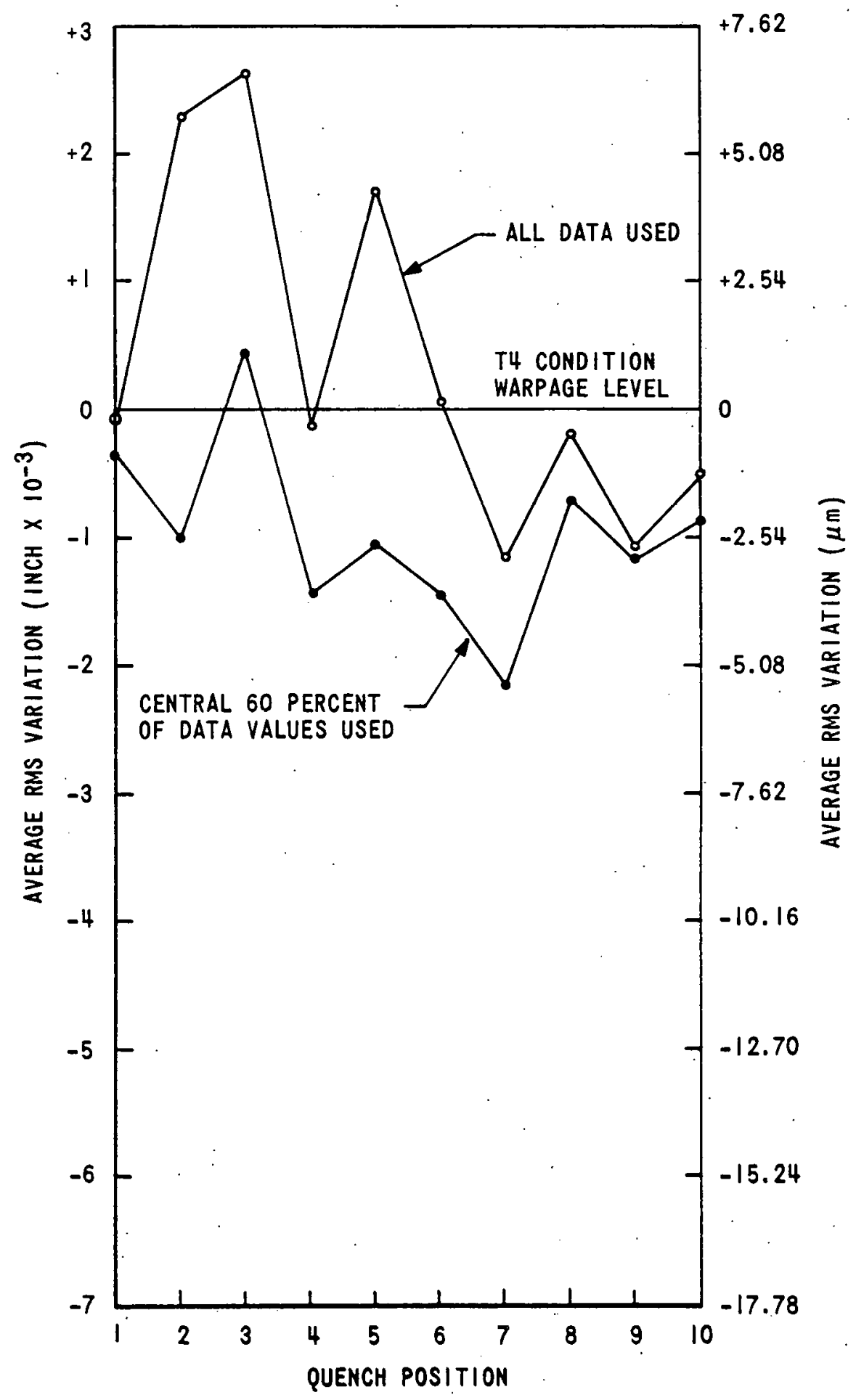

Figure 35. Effect of Precipitation Hardening (T6) on General. Warpage of A.1 Points of Parts Quenched in the Horizontal Attitude 


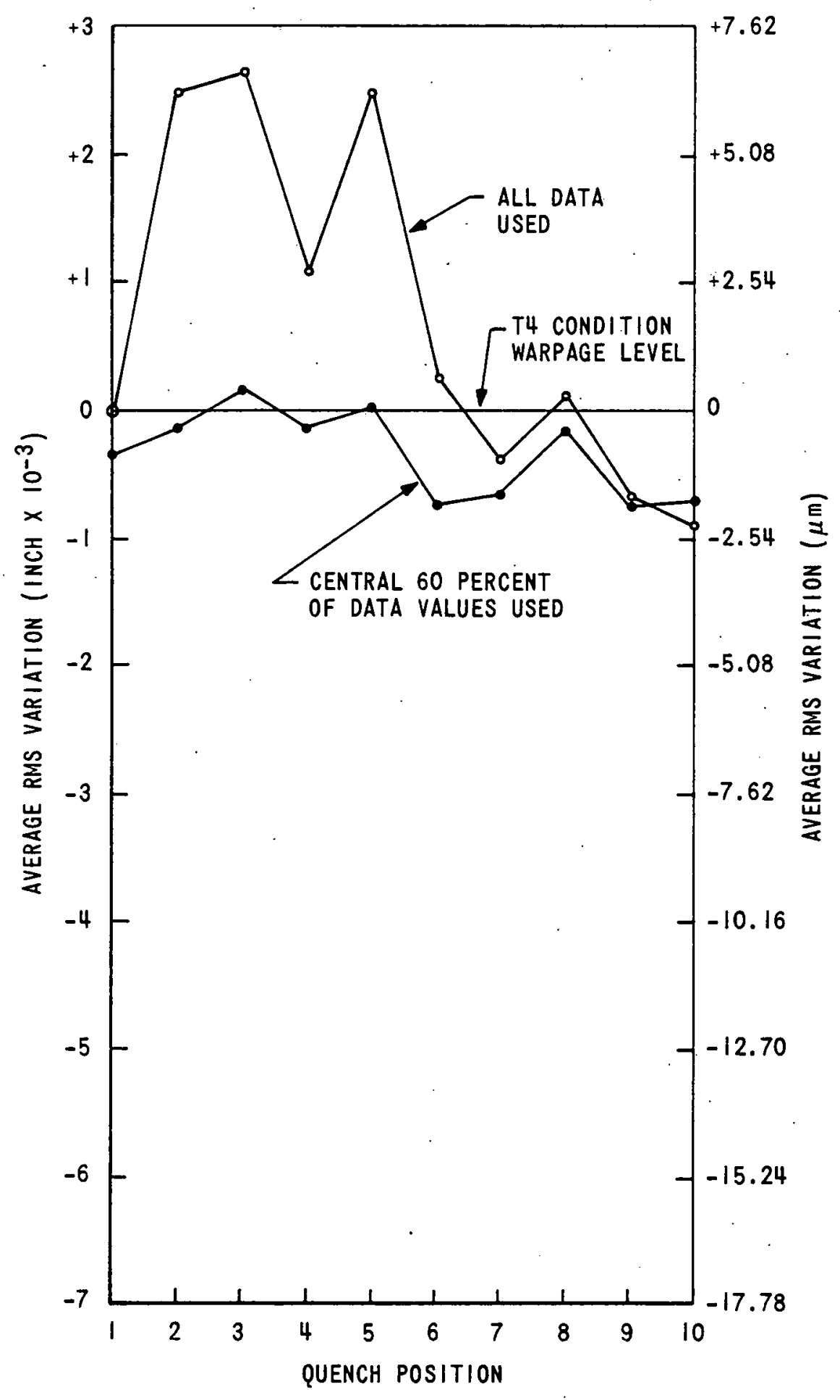

Figure 36. Effect of Precipitation Hardening (T. $\overline{6}$ ) on End-Point Deflection of Parts. Quenched in the Horizontal Attitude 


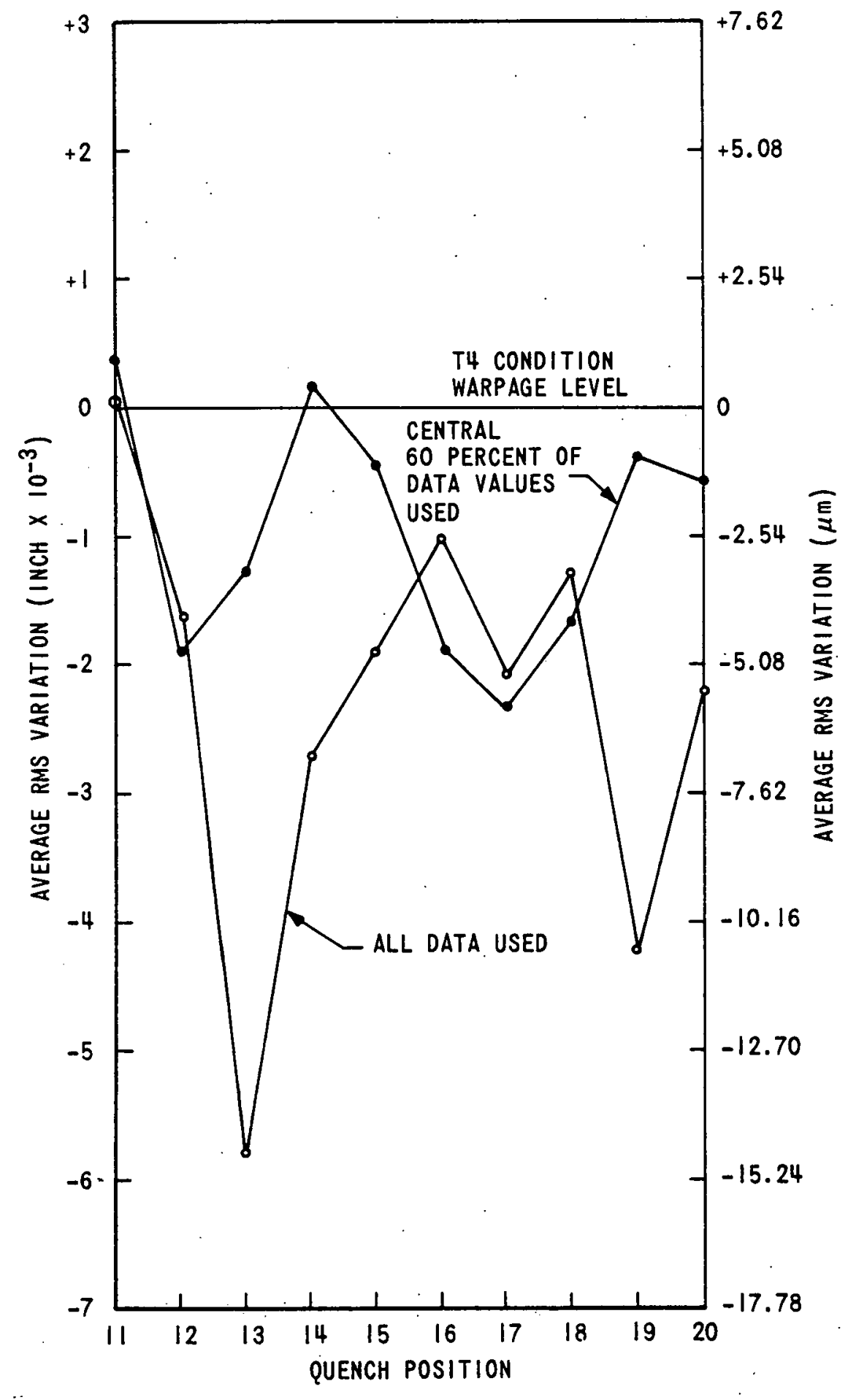

Figure 37. Effect of Precipitation Hardening (T6) on General Warpage of All Points of Parts Quenched in the Vertical Attitude 


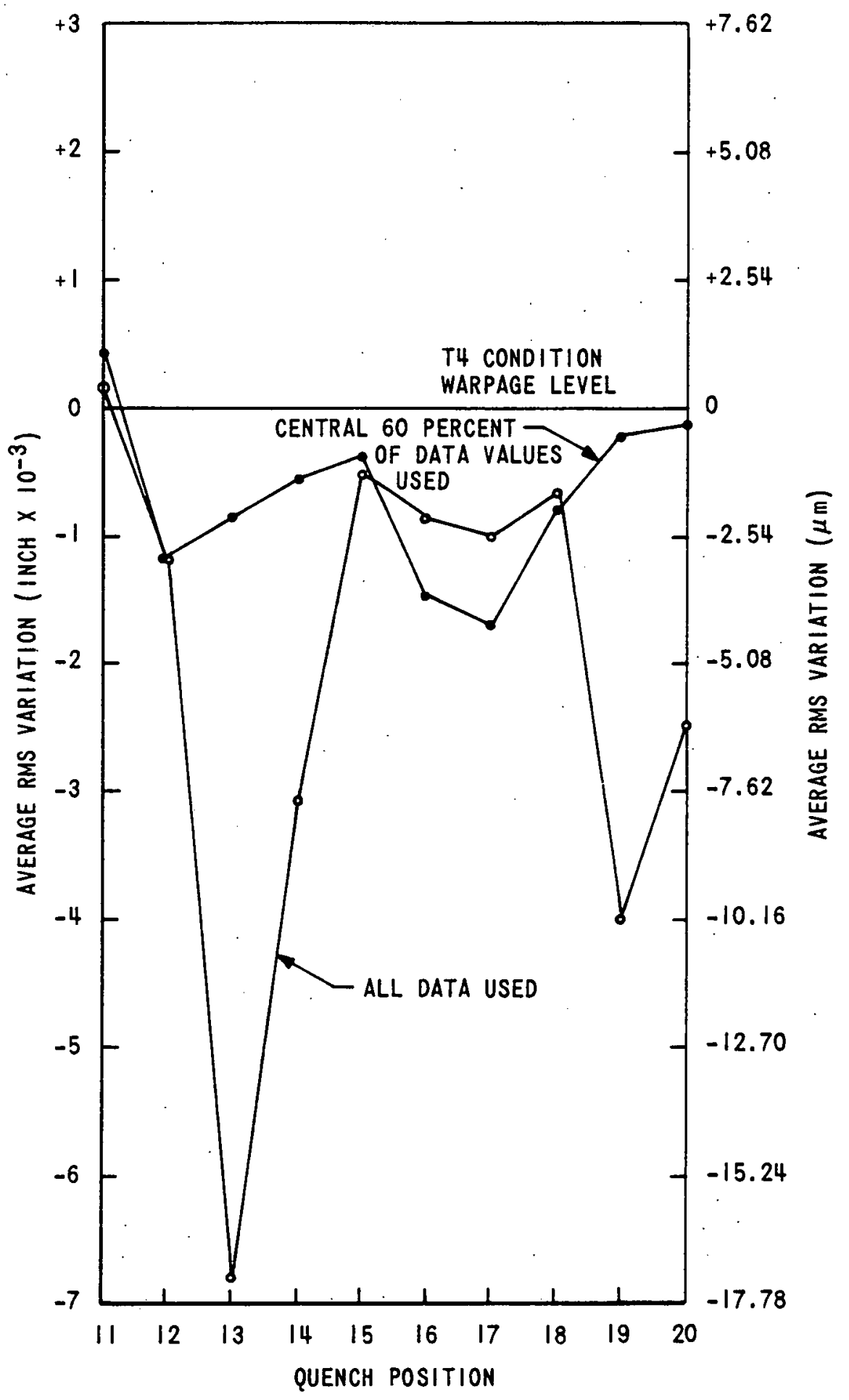

Figure 38. Effect of Precipitation Hardening (T6) on End-Point Deflection of Parts Quenched in the Vertical Attitude 


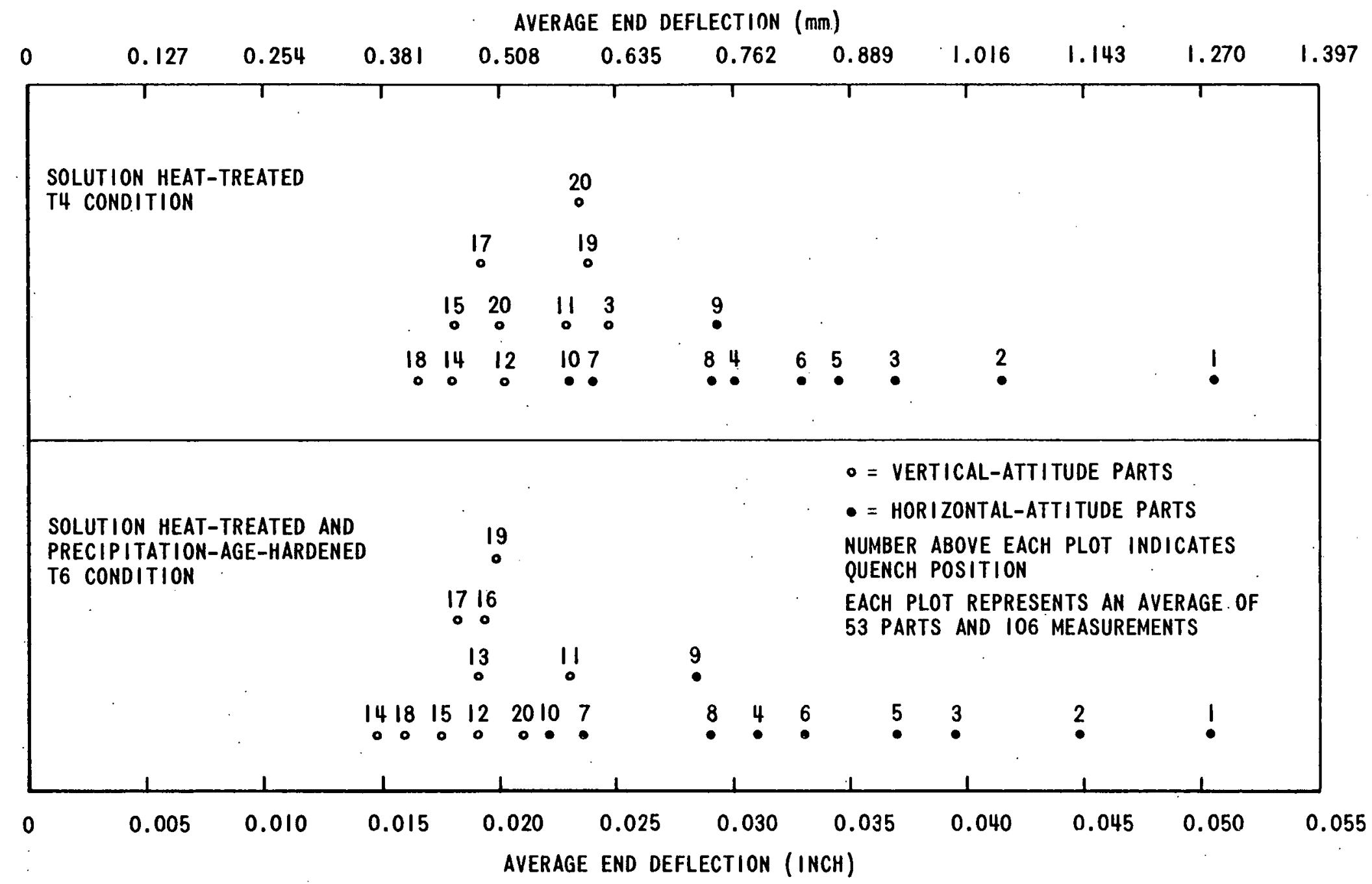

Figure 39. Variations in End-Point Deflection for Parts Quenched in Horizontal and Vertical Attitudes at Various Quench Positions 


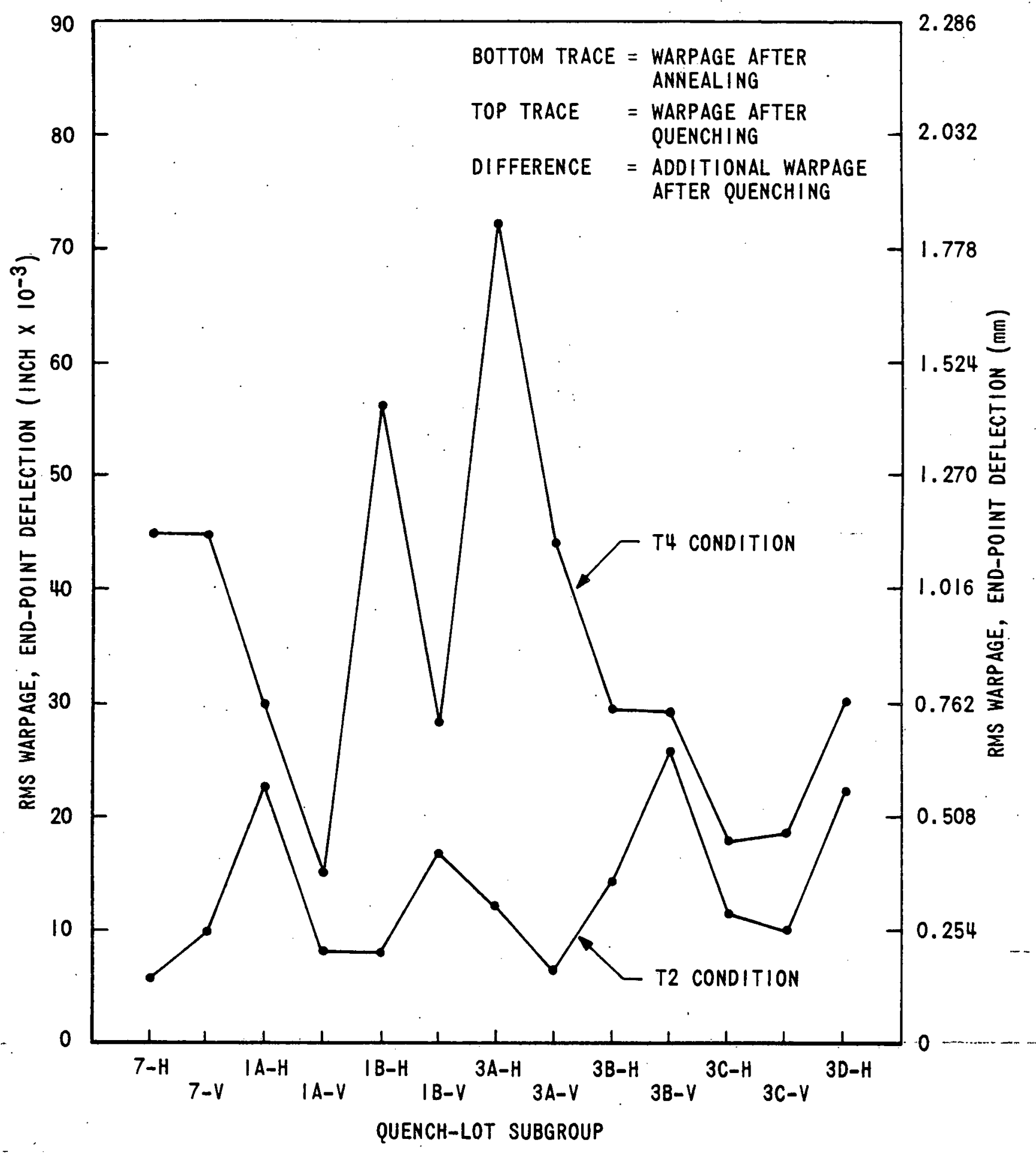

Figure 40. Warpage After Annealing (Bottom. Trace) Compared to Additional Warpage After Quenching (Difference Between Top and Bottom Trace) 


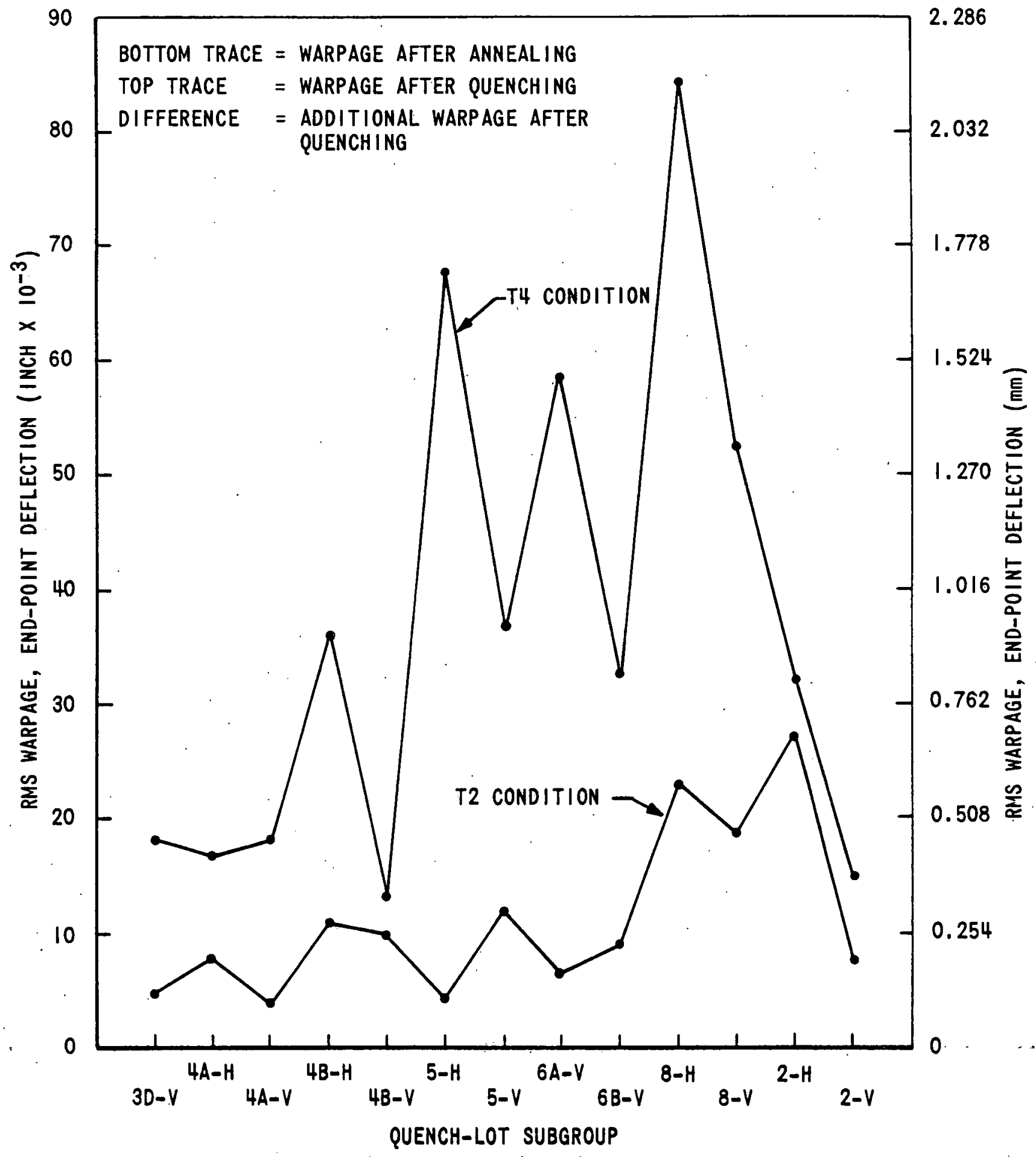

Figure 40 Continued. Warpage After Annealing (Bottom Trace) Compared to Additional Warpage After Quenching (Difference Between Top and Bottom Trace) 


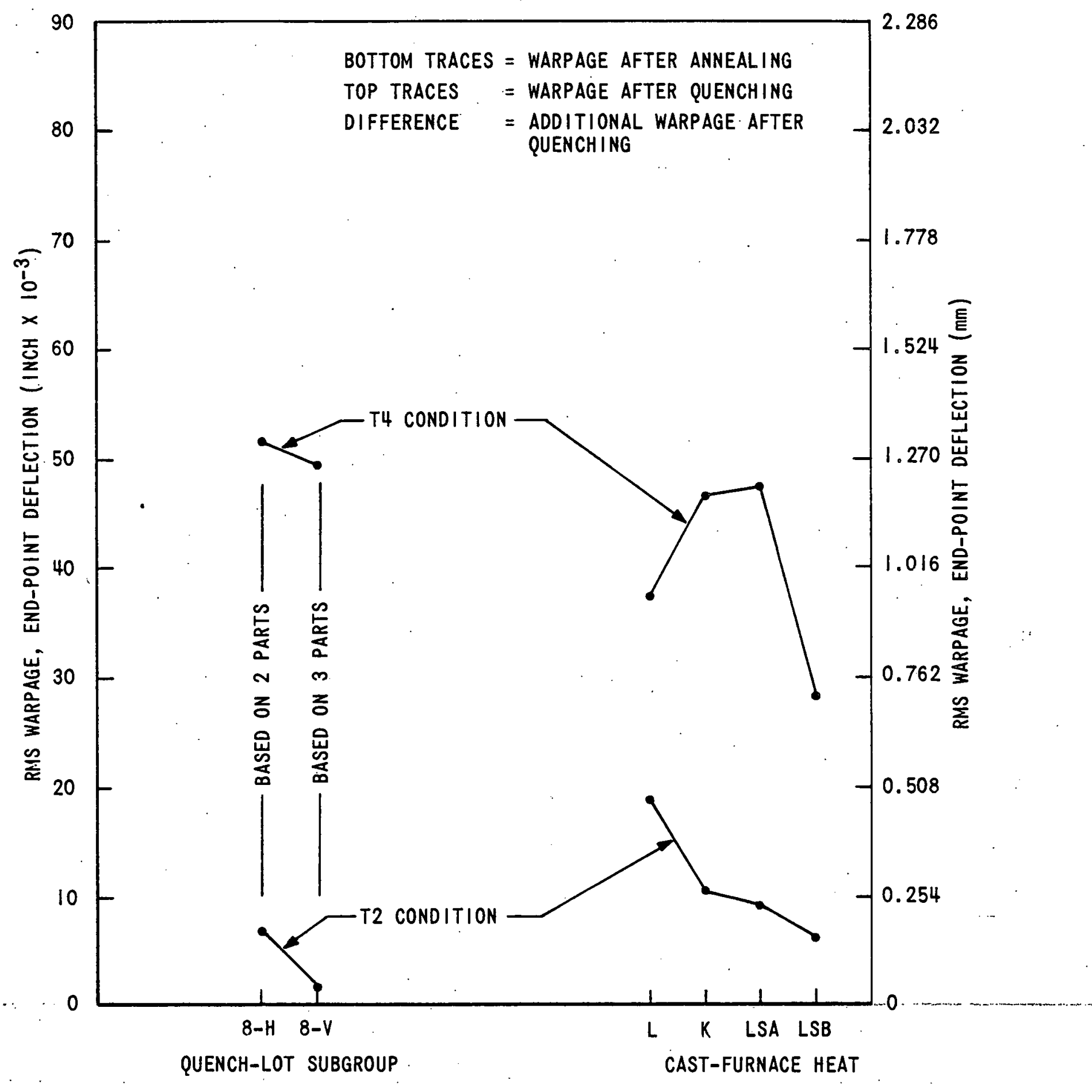

Figure 40 .Continued. Warpage After Annealing. (Bot.tom Trace) Compared to Additional Warpage After Quenching (Difference Between Top and Bottom Trace). 
The internal stresses which existed in the cast test parts and in the gating-part-runner. system were found to be significant. Solidification stresses accounted for a significant amount of warpage. Stresses were found in the gating-part-feeding system after the blade-to-base relationship of the parts was changed by removal of the gate runners and risers from the castings. Additional stresses in the parts themselves were relieved by annealing.

Warpage of parts from only Cast Heats $K$, L, LSA, and LSB were measured in the annealed condition since this source of stress was thought previously not to exist because of slow solidification and the 24-hour-equilibrium time employed prior to removal of the parts from the flasks. Based on calculations, shellmolded parts appeared to have lower internal stresses than did flask-molded parts.

A slight recovery in part-distortion appeared to occur after precipitation-age-hardening, but the amount was not of sufficient magnitude to be of practical benefit. This tendency was observed in approximately two-thirds of the calculated results.

\section{Strength Characteristics}

Maximum Tensile Strength. When the highest mechanical properties are desired from an A356-alloy part, they may be obtained by quenching in a water, polyalkylene glycol, or polyethylene glycol solution at a temperature from 150 to $160^{\circ} \mathrm{F}$ ( 65.6 to $\left.71.1^{\circ} \mathrm{C}\right)$. These quenching temperatures were found to yield parts having maximum mechanical properties. Figures 41 through 51 illustrate the relationship of quenching conditions to the mechanical properties of the parts.

Mechanical Properties and Warpage. Some of the variables which caused significant variations in distortion or warpage did not have a similar effect on mechanical properties. For example, a part's position in the quenching basket and its attitude during quench did not produce any significant or noticeable difference in its ultimate tensile strength or yield strength. The temperature of the quenching solution appeared to have the greatest effect on the strength of the part. Varying the composition of the quenching solution, which had a major effect on warpage, had a relatively minor effect on mechanical properties.

Although maximum mechanical properties were obtained from solutions at temperatures from 150 to $160^{\circ} \mathrm{F}\left(65.6\right.$ to $\left.71.1^{\circ} \mathrm{C}\right)$, mechanical properties were sufficiently high from solutions having a temperature of $210^{\circ} \mathrm{F}$. $\left(98.9^{\circ} \mathrm{C}\right)$ to meet all common $1 \mathrm{y}$ used federal and commercial "specifications. 


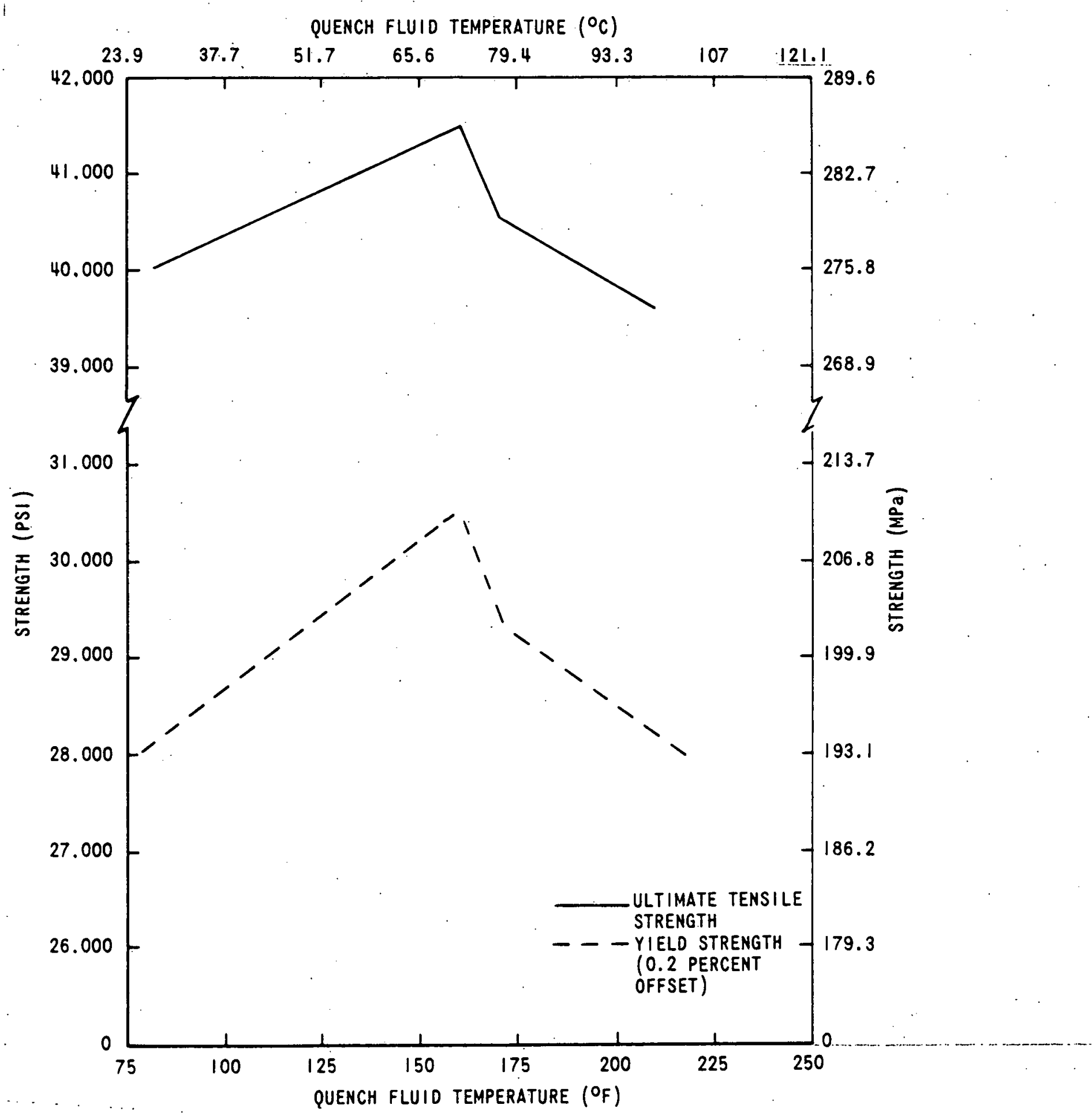

Figure 41. Mean Averages of Mechanical Properties Developed in 20-Percent Polyalkylene Glycol (Ucon A) Solution 


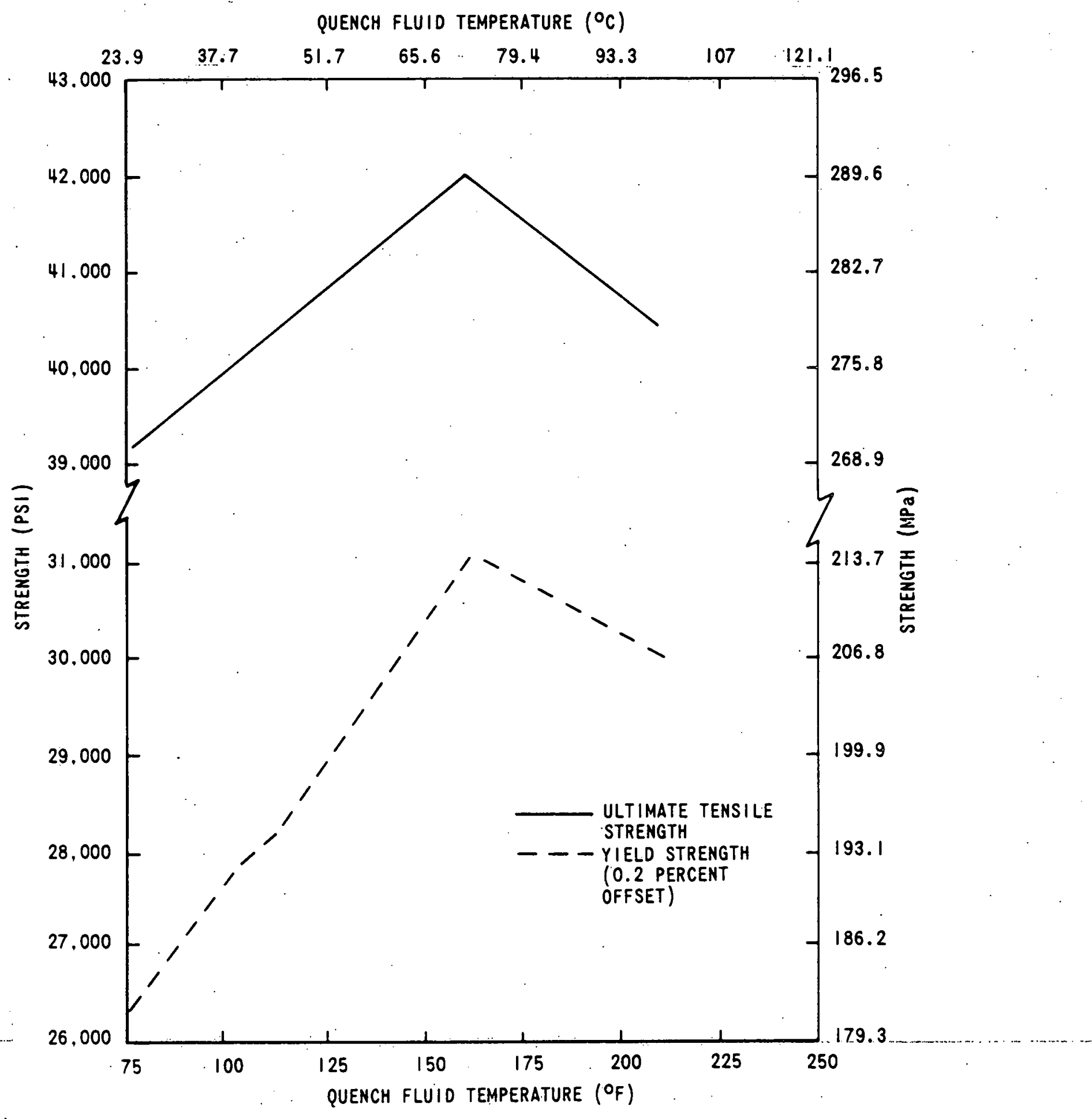

Figure 42. Mean Averages of Mechanical Properties Developed in 20-Percent Polyethylene Glycol Solution 


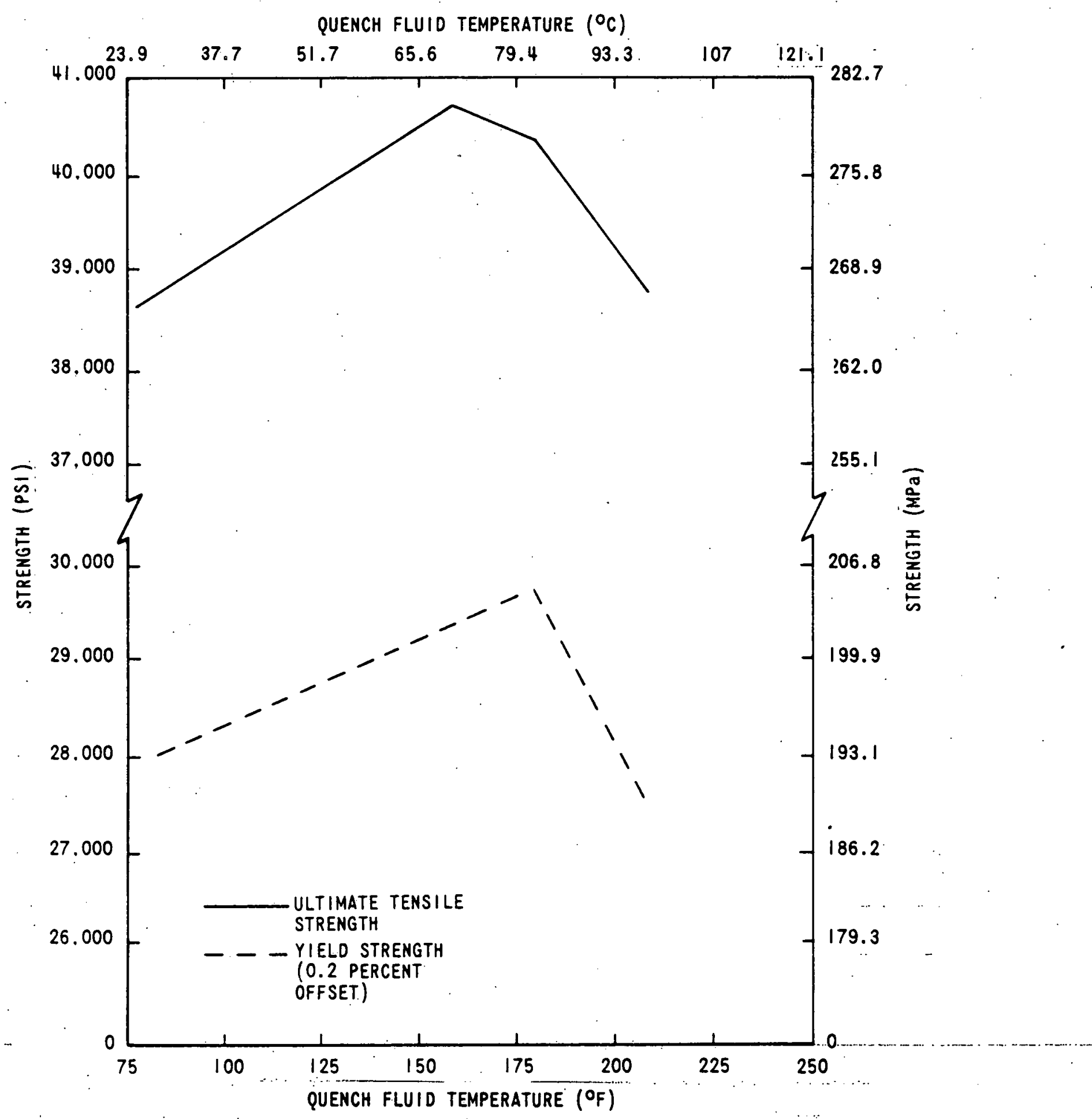

Figure 43. Mean Averages of Mechanical Properties Developed in 40-Percent Polyethylene Glycol Solution 


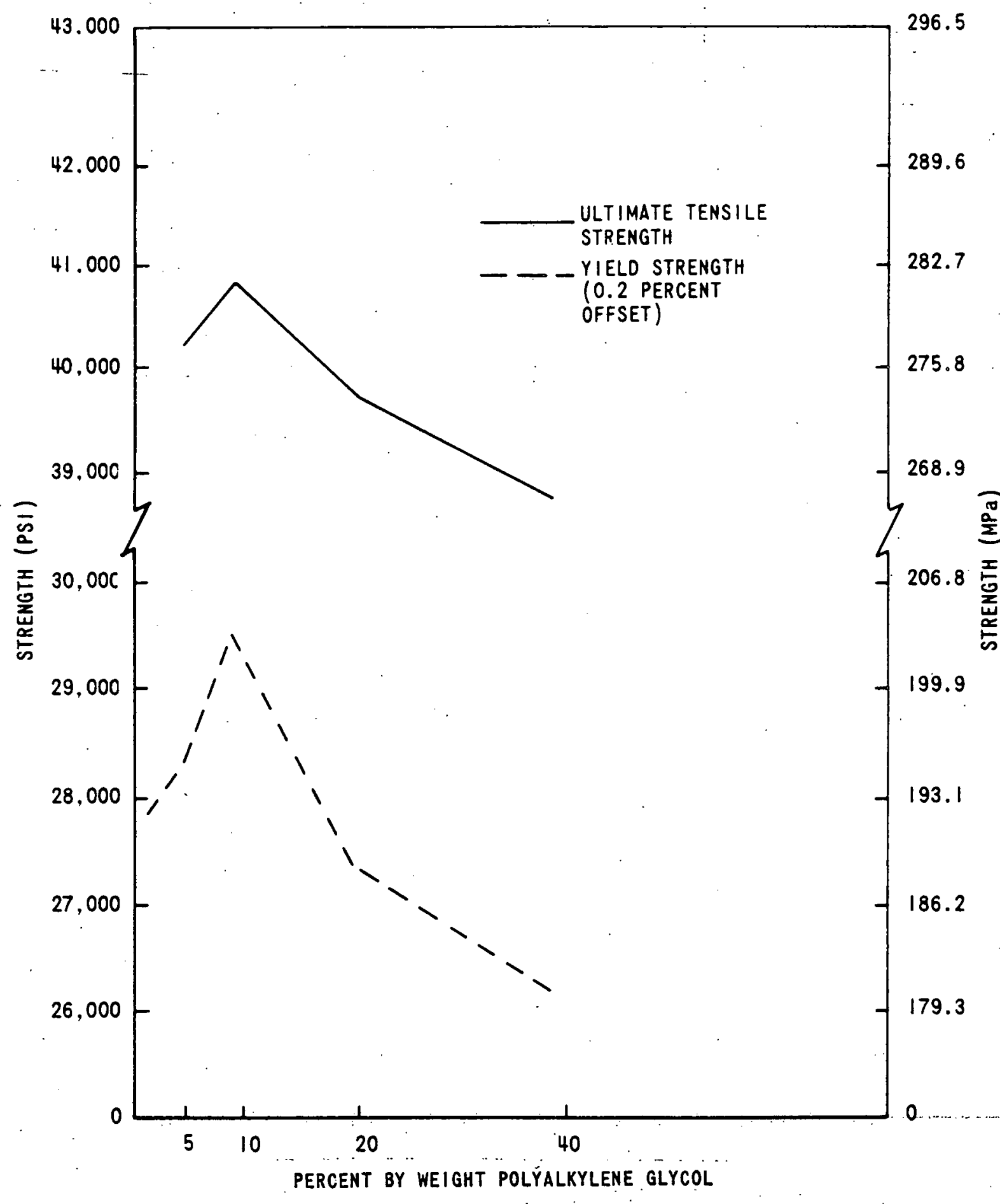

Figure 44. Mean Averages of Mechanical Properties Developed Versus Concentration of Polyalkylene Glycol (Ucon A) Solutions at 75 to $84^{\circ} \mathrm{F}\left(23.9\right.$ to $\left.28.8^{\circ} \mathrm{C}\right)$ 


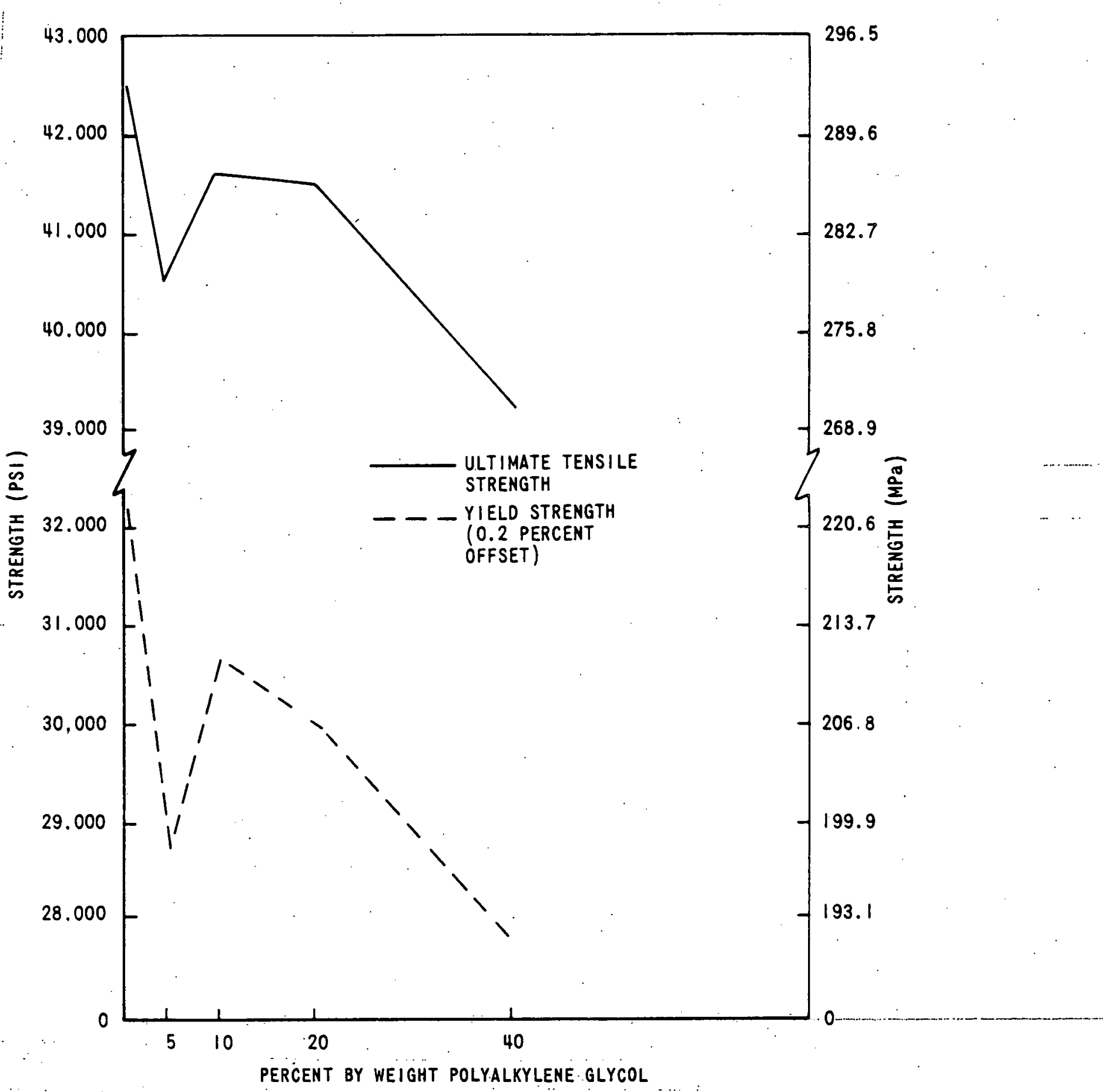

Figure 45. Mean Averages of Mechanical Properties Developed Versus Concentration of Polyalkylene Glycol (Ucon A) Solutions at 160 to $163^{\circ} \mathrm{F}\left(71.1\right.$ to $72.8^{\circ} \mathrm{C}$ ) 


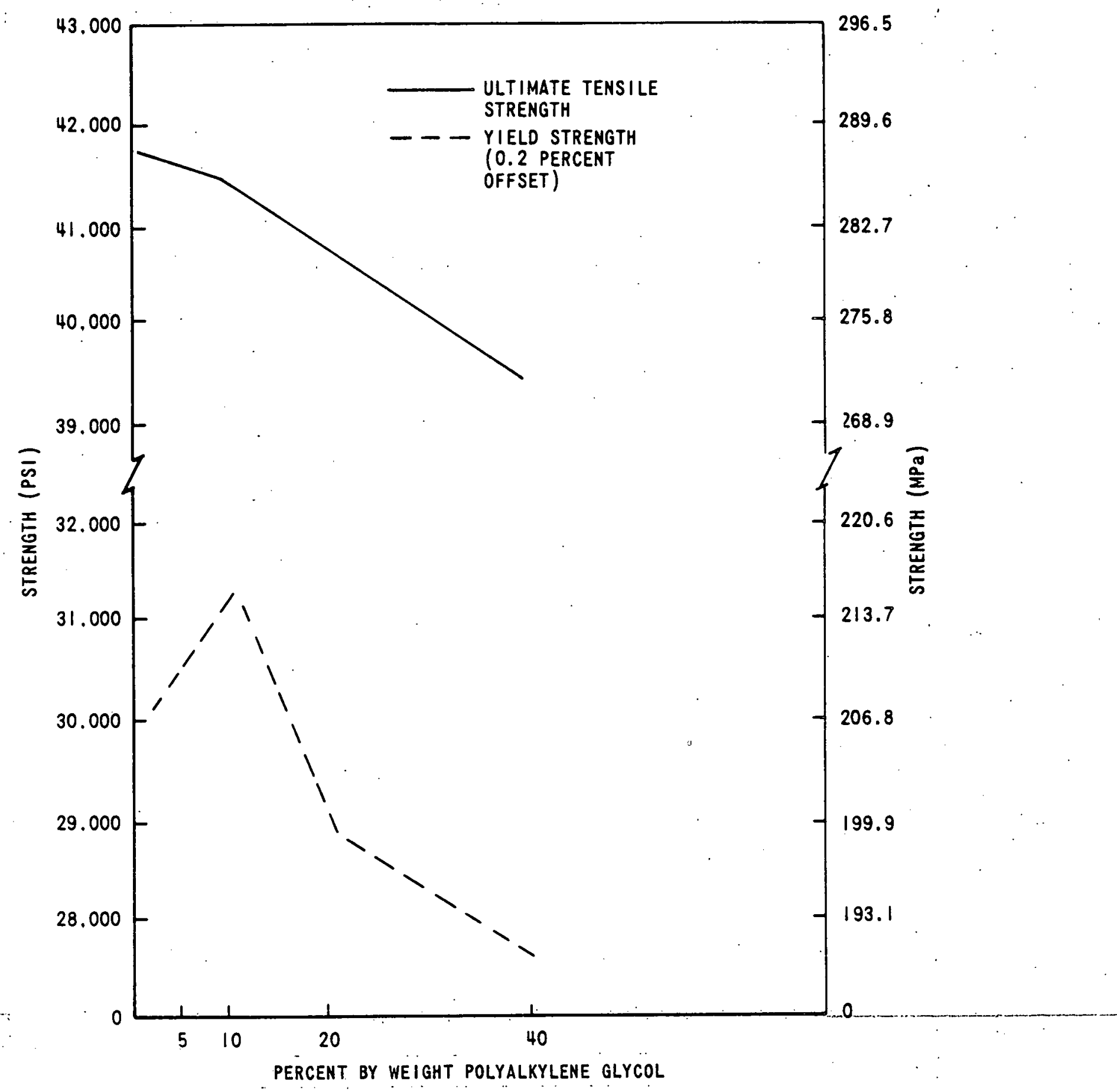

Figure 46. Mean Averages of Mechanical Properties Developed Versus Concentration of Polyalkylene Glycol (Ucon A) Solutions at 180 to $181^{\circ} \mathrm{F}\left(82.2\right.$ to $\left.82.8^{\circ} \mathrm{C}\right)$ 


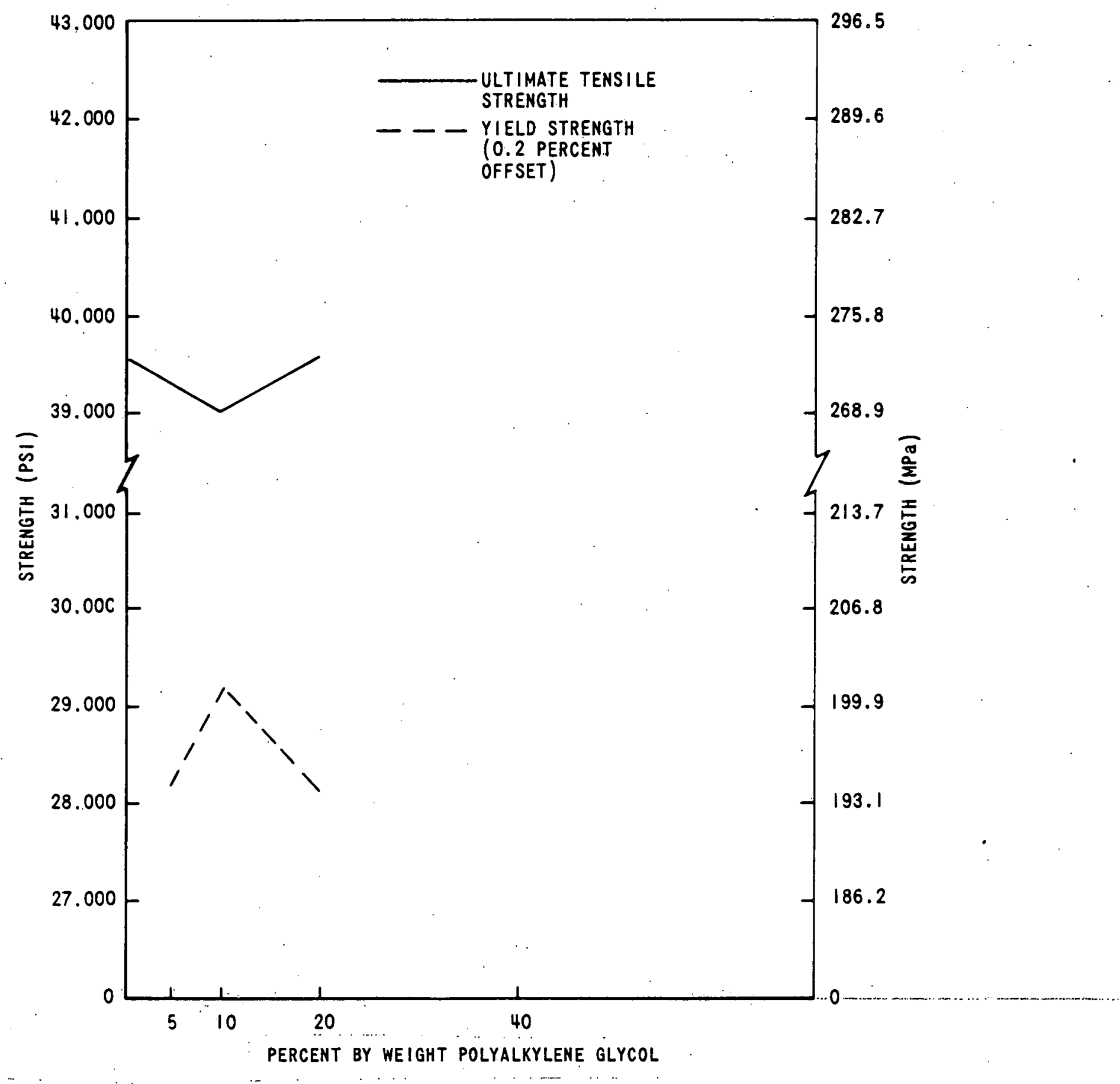

Figure 47. Mean Averages of Mechanical Properties Developed Versus Concentration of Polyalkylene Glycol (Ucon A). Solutions at 209 to $210^{\circ} \mathrm{F}\left(98.3\right.$ to $\left.98.9^{\circ} \mathrm{C}\right)$ 


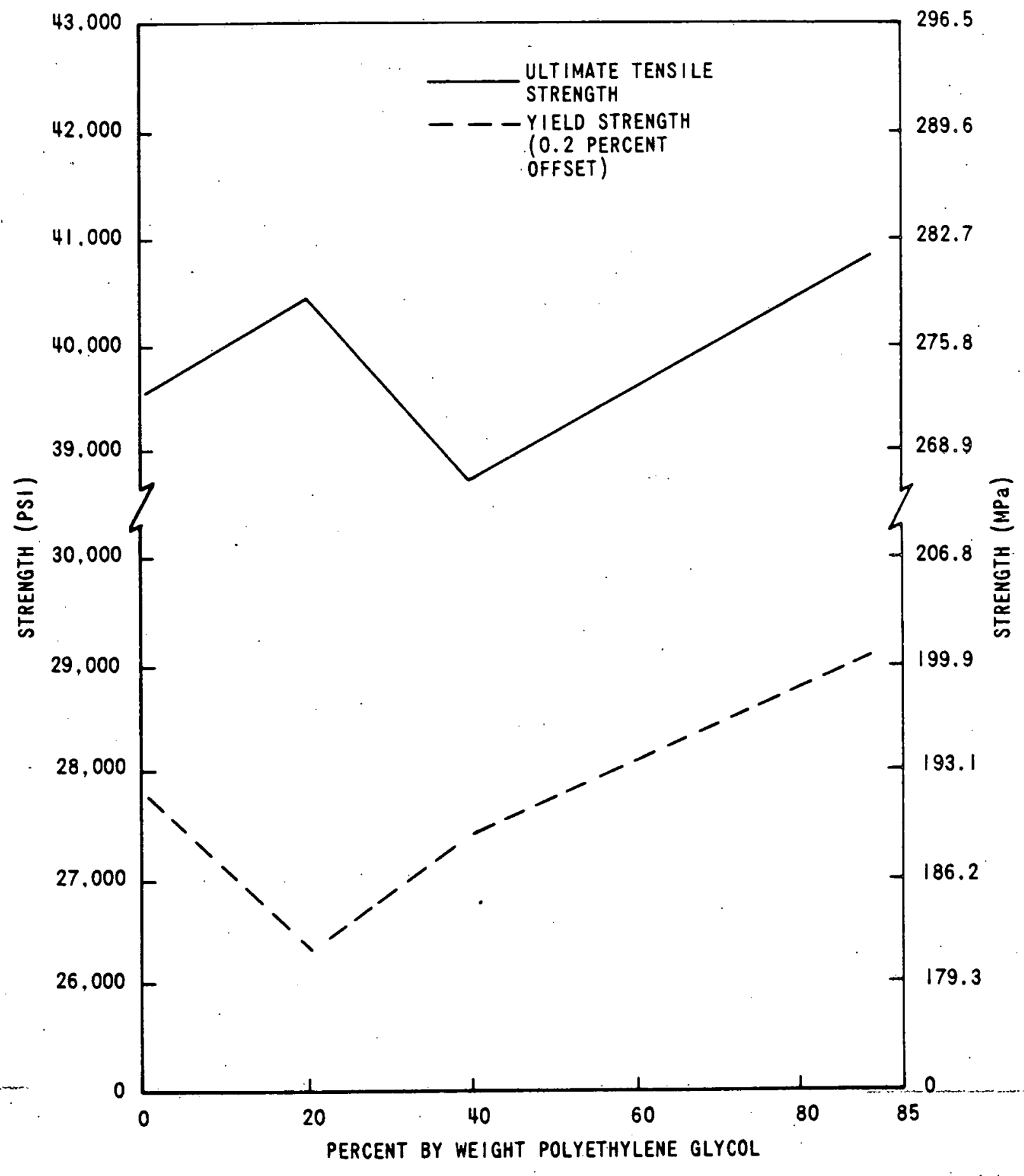

Figure 48. Mean Averages of Mechanical Properties Developed Versus Concentration of Polyethylene Glycol

Solutions at 72 to $77^{\circ} \mathrm{F}\left(22.2\right.$ to $\left.25.0^{\circ} \mathrm{C}\right)$ 


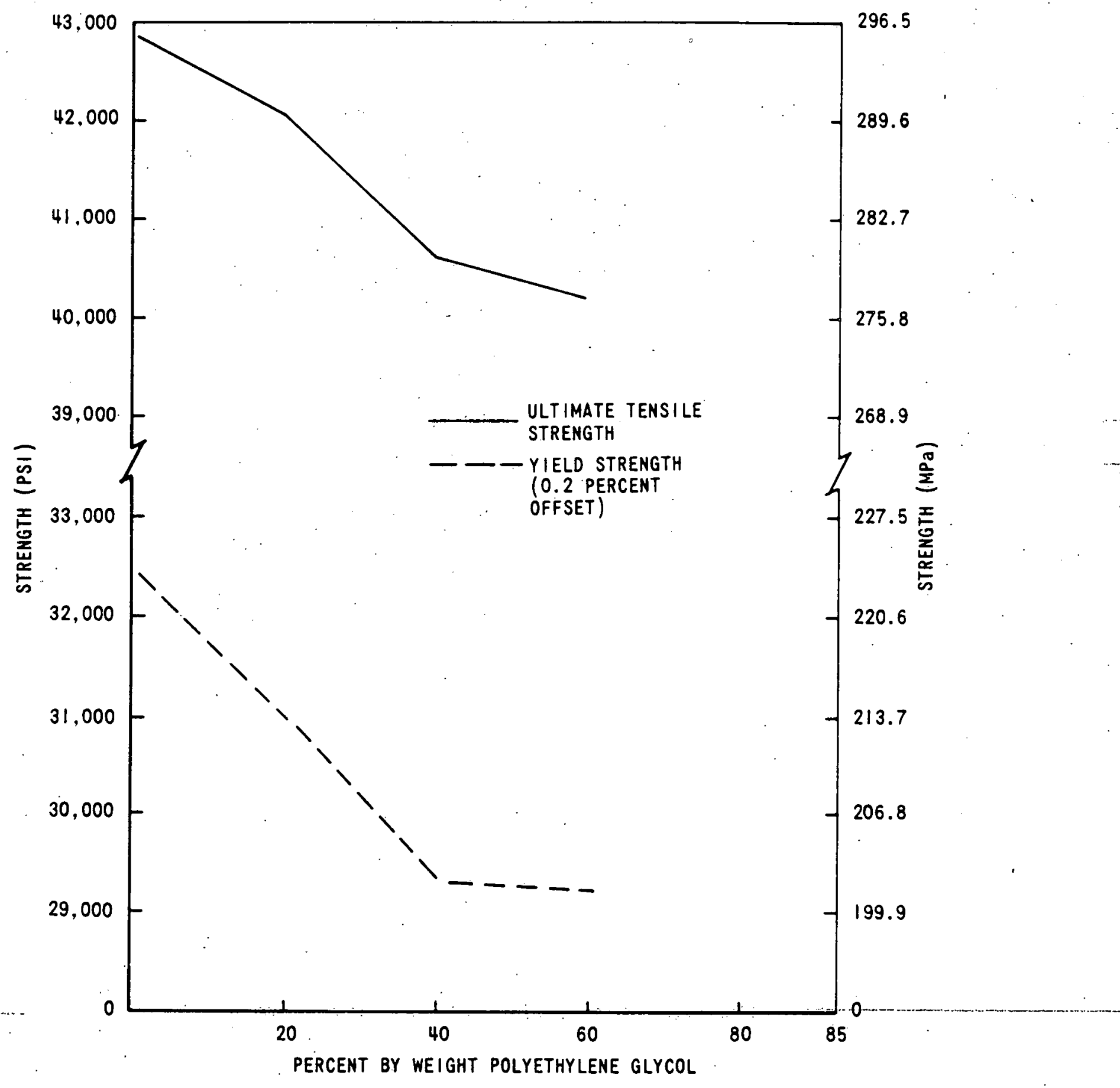

Figure 49. Mean Averages of Mechanical Properties Developed Versus Concentration of Polyethylene Glycol Solutions at 160 to $161^{\circ} \mathrm{F}$ (71.1 to $71.7^{\circ} \mathrm{C}$ ) 


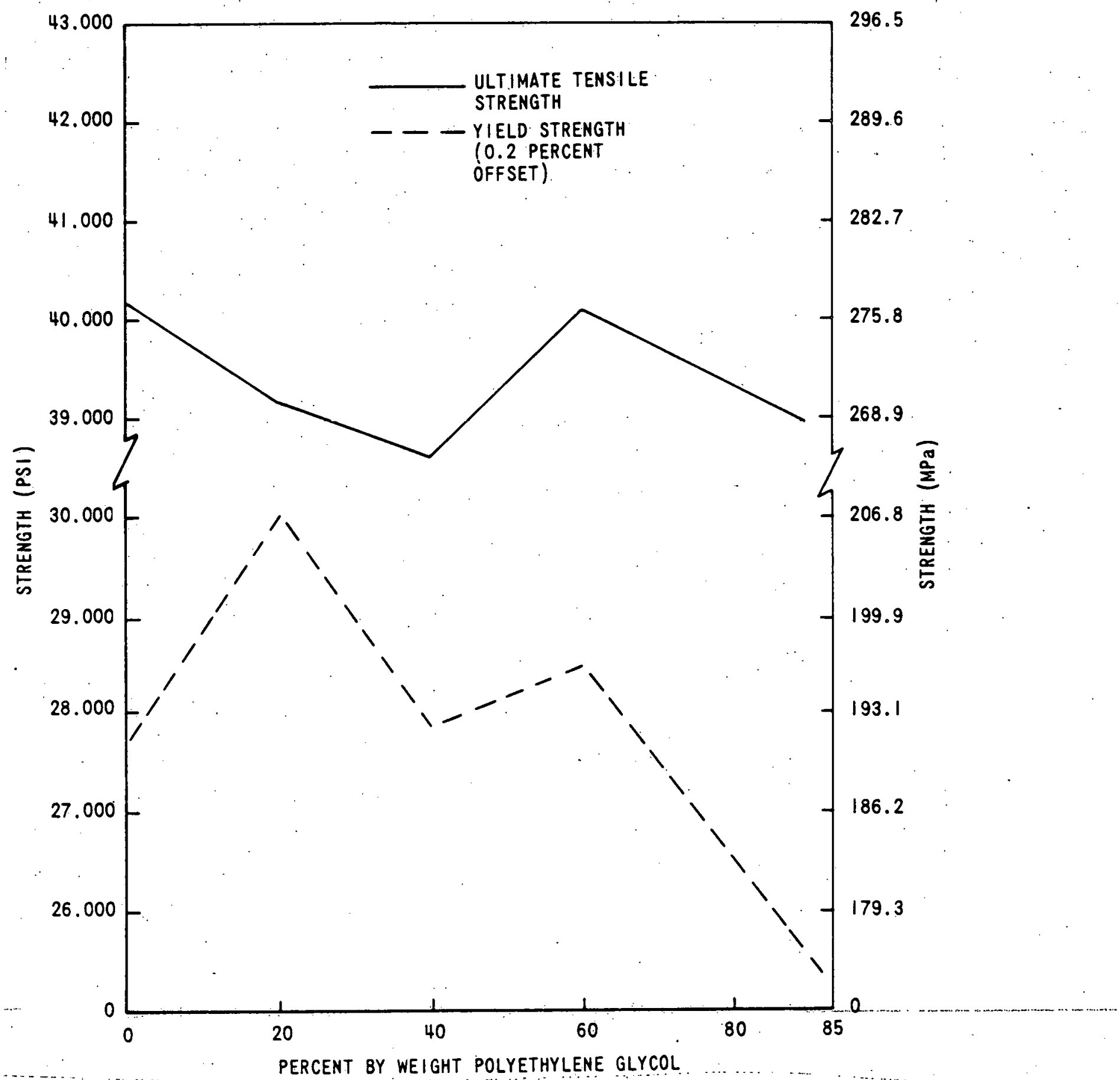

Figure 50. Mean Averages of Mechanical Properties Developed Versus Concentration of Polyethylene Glycol Solutions at $210^{\circ}$ to $213^{\circ} \mathrm{F}\left(98.9\right.$ to $\left.101.0^{\circ} \mathrm{C}\right)$ 


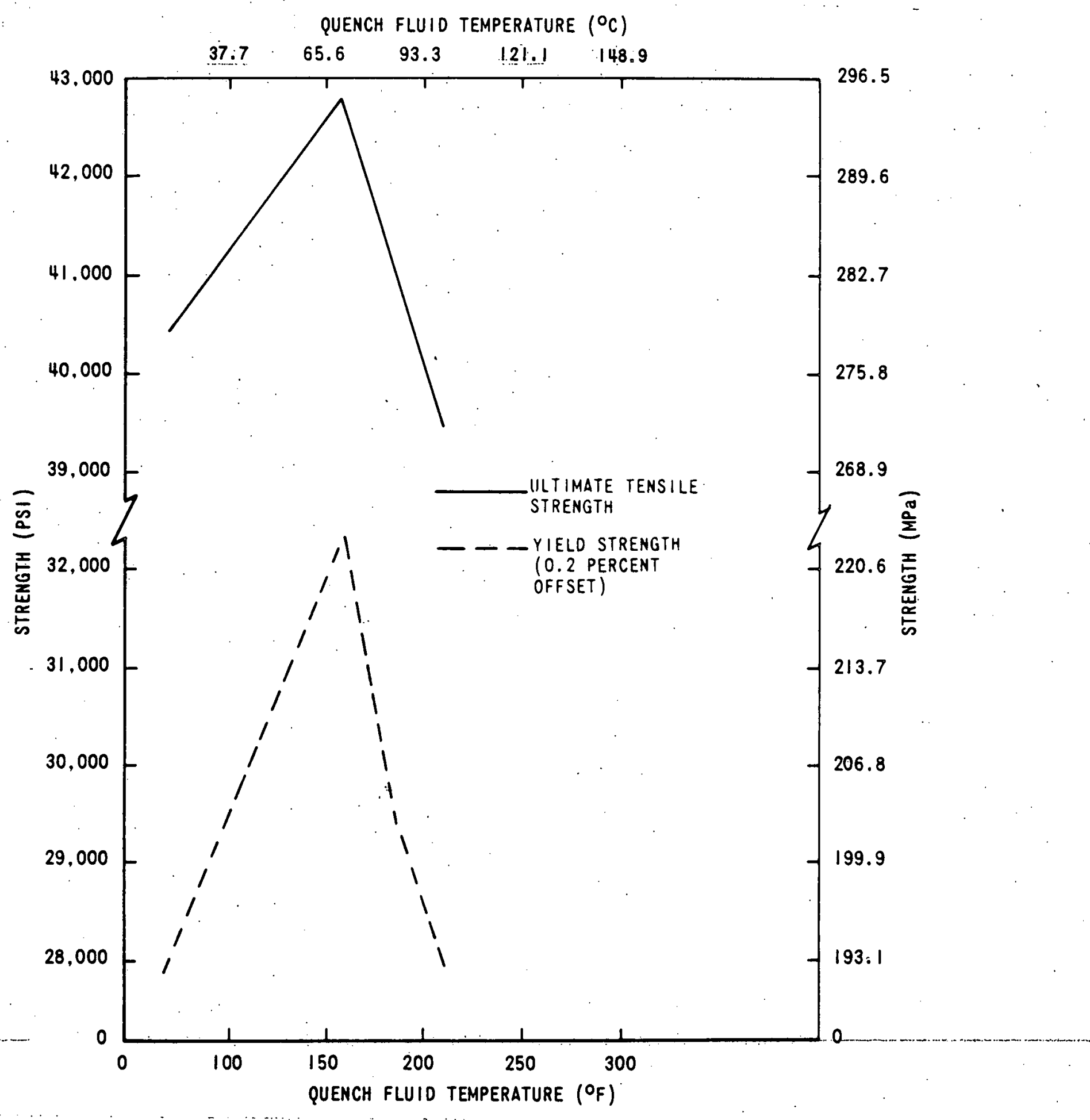

Figure 51. Mean Averages of Mechanical Properties Developed in Water Quench 
The peaking of the mechanical properties of parts from solutions in the temperature range from 150 to $160^{\circ} \mathrm{F}$ undoubtedly parallels the maximum quenching rate. This is probably a balance between the reduced heat-extractive power of the fluid at increased temperatures and the increased wettability (the thermal coupling of the part and the quenching solution) at higher temperatures. The wettability apparently is also increased with the addition of glycol to the quenching fluid. This would be expected because of the lower surface tension of glycol solutions as compared to the surface tension of water.

These observations, based on more than 2000 tensile tests of the A356 aluminum alloy, seem to refute the commonly held belief that increased mechanical properties always result when lower quenching-solution temperatures are used.

Mechanical Properties of Castings Versus Unmachined Specimens. From prepared radiographs, test bars machined from the heavy base of ten randomiy selected castings were found to be less sound than the as-cast test strips from the same castings. The bars from the heavy sections had slightly lower ultimate strengths and higher yield strengths than did the thinner, sounder, as-cast test bars. This probably was the result of slip impedance caused by the fine porosity acting as a barrier to dislocation movement.

Polyethylene Solution Concentrations. Based on available information, polyethylene-glycol solution concentrations between 20 and 90 percent and polyalkylene-glycol solution concentrations between 5 and 40 percent were selected for investigation. An analysis of the test results shows a close parallel between the response of polyalkylene glycol and that of polyethylene glycol in the 20- to 40-percent range. Further work should be done using polyethylene-glycol concentrations below 20 percent to determine whether the mechanical properties of the parts show improvement similar to that observed using low-concentration polyalkylene solutions.

A356 aluminum castings were used in this study; however, each alloy, fabrication form (casting or forging), and part configuration appear to require a modification of the quenching solution to yield optimum results. Such modifications can be accomplished by varying the quenching solution chemistry, concentration, and temperature. The method of placing the part into the quenching basket and the amount and type of fluid movement are also important factors which require additional study.

The Spin Ring, P/N 293159, illustrates these points. Early development units made of 6061-T651 aluminum failed in tests. The decision therefore was made to use X7050 forgings and to 
fund a short study between the vendor of the forgings and a commercial heat-treater to develop a quenching technique that would minimize distortion after heat-treatment without unduly sacrificing the mechanical properties of the part. The study, which utilized a series of room-temperature aqueous solutions of polyalkylene glycol, indicated that the part possessed excellent mechanical properties, but the distortion after machining was too great.

In a parallel effort, forgings were quenched at Bendix Kansas City in a 20-percent polyethylene-glycol solution at $210^{\circ} \mathrm{F}\left(98.9^{\circ} \mathrm{C}\right)$. Although the mechanical properties were not as high as those produced by the room-temperature quench, they were satisfactory for the desired application. The parts quenched under these conditions remained stable after machining.

Using these results as guidelines, work with this alloy and forging should be further pursued. Specifically, increased mechanical properties with acceptable stability should result from the use of higher polyethylene-glycol concentrations (up to 40 percent) at temperatures down to approximately $150^{\circ} \mathrm{F}$ $\left(64.6^{\circ} \mathrm{C}\right)$, and from the use of the 20-percent-polyethyleneglycol solution at an intermediate temperature of $195^{\circ} \mathrm{F}$ ( $\left.90.6^{\circ} \mathrm{C}\right)$.

Reduction of Solidification and Gating-System Stresses. Because the relief of stresses after annealing and removal of the closed-loop-gating-system represented a significant portion of the total warpage, a strong effort to reduce the occurrence of these stresses could be both technically and economically rewarding.

\section{ACCOMPLISHMENTS}

A warpage-sensitive part was designed and cast for use in the casting-warpage study.

The following variables, listed in their apparent order of importance, were found to affect the dimensional stability of the parts after quenching.

- Quenching-fluid temperature,

- Quenching-fluid composition,

- Differences in internal stress levels of flask- and she11molded parts prior to heat-treatment,

- Attitude of the parts entering the quenching fluid, and

- Fluid flow pattern created by the hydraulic agitation system of the tank. 
Polyalkylene glycol and polyethylene glycol solutions of 20 and 40 percent, by weight, appeared to be most effective in reducing warpage and did not significantly change the mechanical properties of the parts.

Minimum warpage resulted from a quenching solution temperature of $210^{\circ} \mathrm{F}\left(98.9^{\circ} \mathrm{C}\right)$. Quenching at a temperature of $160^{\circ} \mathrm{F}\left(71.1^{\circ} \mathrm{C}\right)$ produced maximum strength with less warpage than was obtained from room-temperature solutions. Warpage in the glycol quenching solutions was less than that which occurred in water at all temperatures studied.

Each alloy, fabrication form (casting or forging), and part configuration appear to require a modification of the quenching solution to yield optimum results. Modifications can be accomplished by varying the quenching solution chemistry, concentration, and temperature.

\section{FUTURE WORK}

Based upon the results of this casting-warpage study and associated requirements for specific products requiring minimized distortion, the following actions should be taken when needs dictate the application of. process refinements.

Further work should be done using polyethylene-glycol concentrations below 20 percent to determine whether the mechanical properties of the parts show improvement similar to that observed using low-concentration polyalkylene solutions.

- Quenching solution modifications as to chemistry, concentration, and temperature should be developed to yield optimum results for each alloy, fabrication form, and part configuration to be used.

Methods of placing the parts into the quenching basket and the amount and type of fluid movement should be further studied.

A quench study should be made using 7049 and 7050 aluminum alloy forgings with polyethylene glycol and polyalkylene glycol quench solutions to improve the forging heat-treat properties and to reduce the warpage of parts machined from the forgings.

A study should be made to reduce or eliminate closed-loopgating-system stresses and to evaluate the quantitative reduction of such stresses in specific products. 


\section{BIBLIOGRAPHY}

Adenis, D., and others. "Interrupted Quenching of Aluminum Alloys," Review AZuminum, "Number. 347, November, 1966, pp 1262-1272.

Brenner, P. "Effects and Technology of the Quenching of. Hardenable Light-Metal Semiproducts," Part 1, Metallkunde, Volume. 21, Number. 3; March, 1967, pp 202-206.

Bryant, A. J. "The Use of the Jominy.Test for Studying the Quench Sensitivity of Aluminum;" Institute of Metals Journal, Volume 90, June, 1962, pp 406-407.

"Cryogenic Quenching.," Mesta Machine Steel World, Volume 58, Number 4, April, 1967, pp 40-41.

"Fire Safe Metal Quenching," Engineering, Volume 203, Number 5258. London: January 27, 1967.

Fisher, John F. "A New Technique for Determining Quenching Rates," Metal Progress, Volume 81, May, 1962, pp 111-112.

Gregory, E., and E. N. Simons. "Quenching Media," Edgar AZZen News, Volume 41, May, 1962, pp 108-109.

"Heat Treatment," Federated Aluminum Casting AlZoys Handbook, American Smelting and Refining Company. New York: 1960, pp 8-11.

"Heat Treatment Problems Solved by New Quenching Media," Metalworking Products, Volume 8, Number 4, January 25, 1967.

Hill, H. N., and others. "Stress Relieving Aluminum," Metai-Treatment and Drop Forging, Volume 27, March, 1960, pp 101-102.

Hugony, E. "Heat Treatment of Ductile Light Metals," Part 2 , Trattamenti-Termici, Volume 3, September and October, 1960, pp 3-12.

Kawochi, Rihei. "Softening Characteristics of Al-Mg-Zn Alloys," Light Metals, Number. 31, July, 1958, pp. 22-34.

Laktionova,' N. A., and others. "Heat Treatment of AK6 Aluminum Alloy Articles in Hot Media," Alyumin Splavy; MetalZurgiya, Number 4. Moscow: 1966, pp 341-349. 
R. Bulcock, ERDA-KCAO, $1 D 49$

V. C. Vespe, ERDA-ALO

J. A. Freed, LASL

S. J. Buginas, LLL

H. M. Brinkmeier, Monsanto

C. H. Maak, SLA

M. Mote, SLL

J. D. Corey, D/554, BD50

L. Stratton, D/554, 2C44

R. F. Pippert, D/700, $1 \mathrm{~A} 42$

R. P. Frohmberg, D/800, 2 A39

J. A. Morrison, D/800, $2 A 40$

F. J. Boyle, D/821, $2 A 36$

J. L. Couchman, D/821, 2 A36

W. E. Cromwel1, D/821, 2A36

E. P. Patterson, D/821, $2 A 36$

R. E. Kessler, D/865, 2C40 